\title{
Concurrent and Predictive Links between Children's Classroom Experiences, Academic Engagement, and Anxious Solitude in Elementary School
}

\author{
by \\ Kathleen Hughes \\ MA, Carleton University, 2008
}

\begin{abstract}
A thesis submitted to
the Faculty of Graduate and Postdoctoral Affairs

in partial fulfillment of the requirements for the degree of

Doctor of Philosophy

In

Psychology

Carleton University

Ottawa, Canada
\end{abstract}


Academic Engagement and Anxious Solitude

\begin{abstract}
The primary goal of this dissertation was to examine the predictors and outcomes associated with behavioural academic engagement in childhood. Behavioural academic engagement can be described as attention, participation, and on-task behaviour in the classroom (Fredricks, Blumenfeld, \& Paris, 2004). Many factors have been found to predict behavioural engagement, such as classroom factors (e.g., teacher-child relationships, peer relationships, class climate), socio-demographic factors, and child factors (e.g., gender, anxious solitude). Although many educational outcomes are strongly inter-associated, the current dissertation examined the mediating role of academic engagement on the relation between classroom experiences and academic achievement. In addition, the moderating role of child factors was examined on the relations between classroom experiences and academic engagement. For the current study, data on $N=779$ children were drawn from the National Institute of Child and Human Development (NICHD) Study of Early Child Care and Youth Development (SECCYD) data set. A series of moderated-mediation models were examined at both grade 1 and grade 3 . Finally, predictors of change in engagement over time were examined. Among the results, support for the differential susceptibility hypothesis (Belsky, 1997) was found, indicating that anxious solitary children may be more reactive (both positively and negatively) to elements of the classroom environment. In addition, some gender effects were found, suggesting that anxious solitary boys may be at a particularly elevated risk for academic problems. Results are discussed in terms of their implications for future research and educational policies concerning the structure of the classroom environment.
\end{abstract}




\section{Acknowledgements}

First and foremost, I am greatly indebted to my advisor, Dr. Robert J. Coplan. Thank you for being so supportive, reliable, and enthusiastic when I needed encouragement, and for being critical and cautionary when I was off track. I am most appreciative of the autonomy you gave me over my topic and my approach. You are an excellent role model and mentor in life.

I am very thankful for my prospectus committee members, Drs. Anne Bowker and Stefania Maggi for their advice and guidance at my prospectus meeting as well as throughout my program. As well, I would like to acknowledge Dr. Amina Mire from the Department of Sociology at Carleton University, and Dr. Eric S. Buhs, from the Department of Educational Psychology at the University of Nebraska-Lincoln as members on my doctoral examination committee. I am honored to have you on my committee.

The project would not have been possible without the ICPSR program at the University of Michigan in Ann Arbor, or the wonderful staff who facilitated the training program on the NICHD SECCYD. This study was conducted by the NICHD Early Child Care Research Network supported by NICHD through a cooperative agreement that calls for scientific collaboration between the grantees and the NICHD staff. Thanks go to Dr. Heidi Gazelle at the University of Melbourne for informing me about this opportunity to work with secondary data.

This final product would not have been nearly as strong or as polished without the assistance of Dr. Douglas Vipond at St. Thomas University. Thank you for generously offering your editorial skills and for providing such a thorough review of my work. 
Thanks also to the numerous members of the Department of Psychology at Carleton University who helped me to complete this research. Thank you to Mila Kingsbury, for helping me through the struggles of data analysis and over the biggest hurdles in this project. I am very lucky to have you and the rest of the "Coplan Kids" as my academic siblings. Also, thanks goes to Belinda Boekhoven and Lisa Menard who helped me with my project in the early days of designing, and to Etelle Bourassa for her care and support throughout this process.

As well, I am very thankful to Dr. J. Doug Willms and Beth Fairbairn for allowing me to complete the final stages of my writing during my first months at the Canadian Research Institute for Social Policy at the University of New Brunswick.

On a more personal level, I would like to thank my friends and family, for the emotional support and for your patience during this (very long) process. I am very fortunate that my parents Mike and Debbie taught me how to be hard working, determined, and a little stubborn.

Finally, I am deeply grateful to my husband, Jonathan Kalman. You have been with me through every stage of this project, and you have spent more hours listening to my thoughts, concerns, worries, and rejoices about this dissertation than anyone else. You have been my reliable rock to lean on, my analytical appraiser, and my infinite inspiration. I am eternally thankful to you. 


\section{Table of Contents}

Abstract.......................................................................

Acknowledgements.......................................................

Table of Contents...............................................................

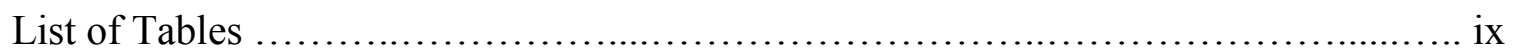

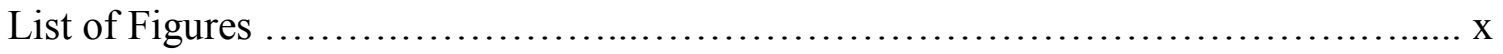

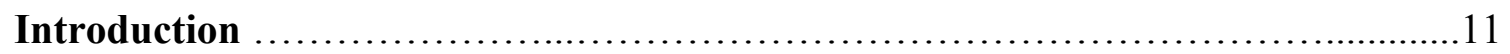

Conceptualizations of Academic Engagement ...............................12

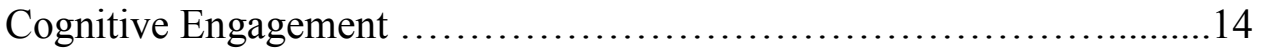

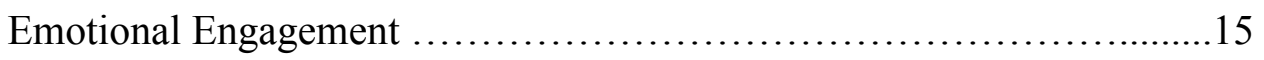

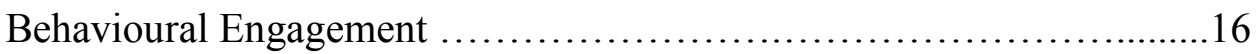

Stability and Change of Academic Engagement..........................20

Implications of Academic Engagement....................................21

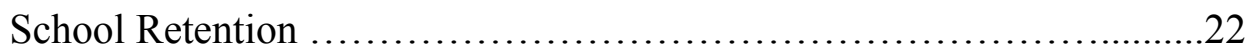

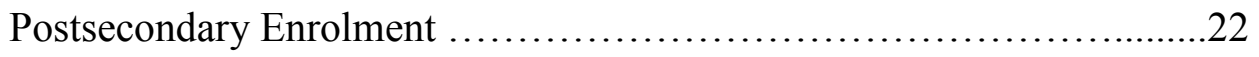

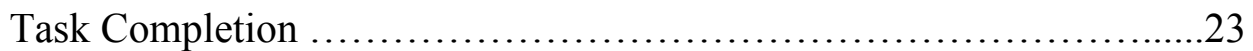

Academic Ability ...............................................23

Academic Performance and Report Card Grades ......................24

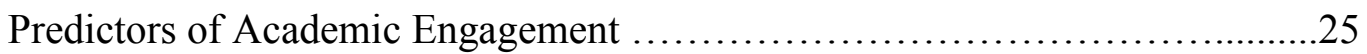

Classroom Experiences...........................................25

Teacher-Child Relationships ..............................25

Peer Relationships .....................................27

Classroom Climate .........................................29 
Socio-Demographic Factors .......................................... 30

Socioeconomic Status ......................................... 30

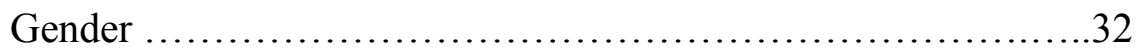

Anxious Solitude in Childhood ............................................... 34

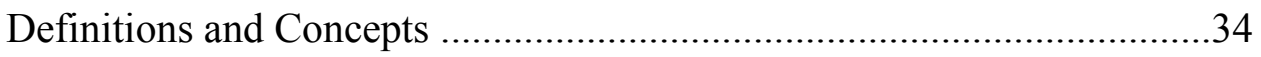

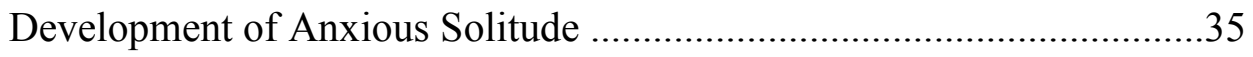

Anxious Solitude and Socioemotional Functioning ............................. 37

Anxious Solitary Children at School .......................................................39

Anxious Solitude and Academic Engagement ..........................43

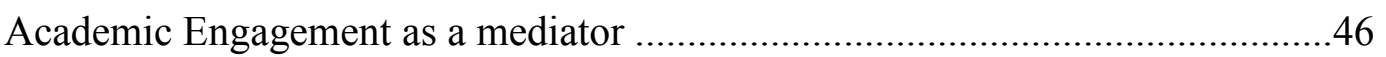

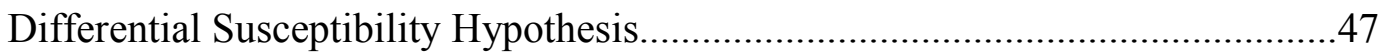

The Current Study ...................................................... 49

Theoretical Model ..........................................................49

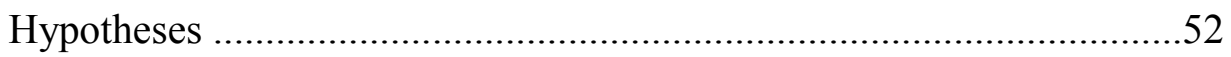

Concurrent Associations ..........................................52

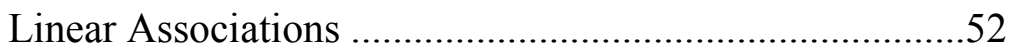

Mediation Effects ..............................................................53

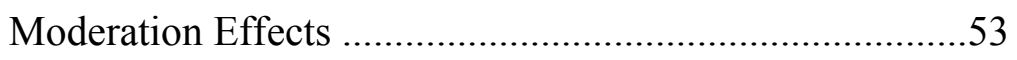

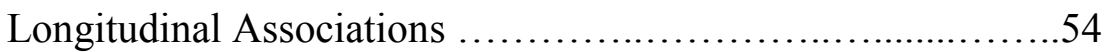

Stability of Constructs ........................................................54

Longitudinal Predictors of Academic Adjustment ...........54

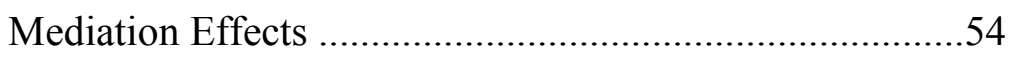

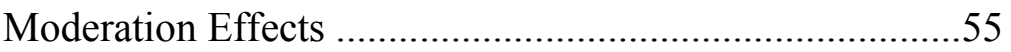




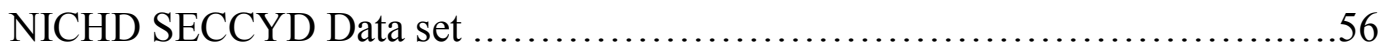

NICHD Participants ............................................5

Current Study Participants........................................58

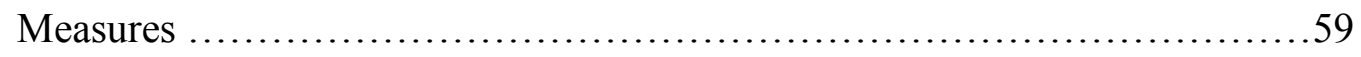

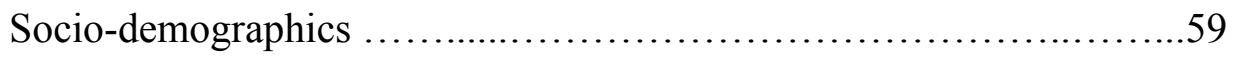

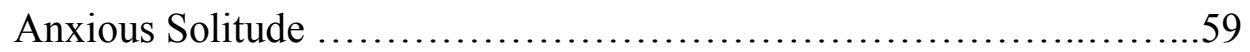

Behavioural Engagement .........................................60

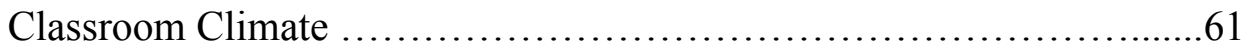

Teacher-Child Relationships .....................................64

Peer Relations .....................................................64

Academic Skills .....................................................65

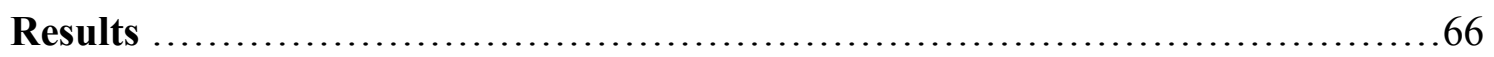

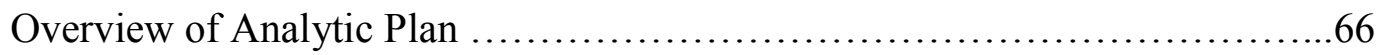

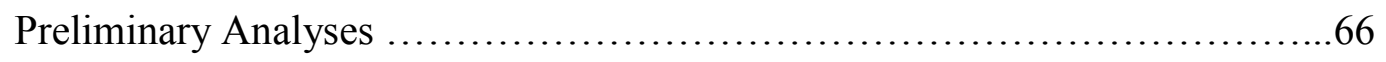

Analyses of Grade 1 (Time 1) Variables ..................................... 74

Correlations .................................................. 74

Moderated-Mediated Models.......................................79

Classroom Climate.............................................. 81

Classroom Relationships.......................................81

Summary of Analyses of Grade 1 (Time 1) Variables ..................87

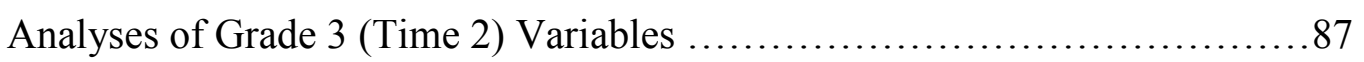

Correlations .......................................................... 87 
Moderated-Mediated Models. .89

Classroom Climate .90

Classroom Relationships. .90

Summary of Analyses of Grade 3 (Time 2) Variables .97

Longitudinal Analyses of Grade 1 \& Grade 3 Variables. .97

Correlations 97

Moderated-Mediation Models

Classroom Climate 100

Classroom Relationships 100

Moderated Regression of Change in Engagement. 100

Summary of Longitudinal Analyses. 106

Discussion 108

Importance of Academic Engagement in Children's School Adjustment 109

Gender and School Adjustment 115

Implications of Anxious Solitude for School Adjustment...... 118

Gender and Anxious Solitude .125

Limitations and Future Directions

Conclusions

References 136 


\section{List of Tables}

Table 1: Descriptive Statistics for Study Variables at Grade 1 .......................68

Table 2: Descriptive Statistics for Study Variables at Grade 3 ......................69

Table 3: Gender and Grade Effects of Teacher-Child Relationships \& Peer Relations....71

Table 4: Gender and Grade Effects of Engagement \& Classroom Climate...............73

Table 5: Gender and Grade Effects of Anxious Solitude .......................... 75

Table 6: Gender and Grade Effects of Achievement ................................. 76

Table 7: Correlations between SES \& Study Variables at Grade 1 \& Grade 3...........77

Table 8: Partial Correlations among All Study Variables in Grade 1 ...........................78

Table 9: MM Regression of Class Climate \& Academic Adjustment in Grade 1.........82

Table 10: MM Regression of Class Relations \& Academic Adjustment in Grade 1......85

Table 11. Partial Correlations among All Study Variables in Grade 3..........................88

Table 12: MM Regression of Class Climate \& Academic Adjustment in Grade 3.......91

Table 13: MM Regression of Class Relations \& Academic Adjustment in Grade 3.......95

Table 14: Partial Correlations of Study Variables in Longitudinal Analyses...................98

Table 15: Longitudinal MM Regression of Class Climate \& Academic Adjustment....101

Table 16: Longitudinal MM Regression of Class Relations \& Academic Adjustment...102

Table 17: Predictors of Change in Engagement from Grade 1 to Grade 3................104 


\section{List of Figures}

Figure 1: Conceptual Model of the Moderated-mediation Analyses.....................50

Figure 2: Interaction of Gender $\times$ Grade Effects on Classroom Climate................72

Figure 3: MM Regression of Class Climate \& Academic Adjustment in Grade 1........83

Figure 4: Simple Slopes of Gender on (Grade 1) Class Climate and Engagement .......84

Figure 5: MM Regression of Class Relations \& Academic Adjustment in Grade 1.......86

Figure 6: MM Regression of Class Climate \& Academic Adjustment in Grade 3.......92

Figure 7: Simple Slopes of Gender on (Grade 3) Class Climate and Engagement........93

Figure 8: Simple Slopes of Anxious Solitude on (Grade 3) Climate and Engagement.....94

Figure 9: MM Regression of Class Relations \& Academic Adjustment in Grade 3........96

Figure 10: Simple Slopes of Gender on Anxious Solitude \& Change in Engagement... 105

Figure 11: Simple Slopes of Gender on Peer Relations and Change in Engagement.....107 


\section{Concurrent and Predictive Links between Children's Classroom Experiences,} Academic Engagement, and Anxious Solitude in Elementary School

This dissertation is an investigation of the development and implications of academic engagement in childhood. Academic engagement can be described as how students interact with the school environment, through their emotions, behaviours, and cognitions (Fredricks, Blumenfeld, \& Paris, 2004). Behavioural engagement is a subcomponent of academic engagement that refers to effortful, on-task behaviour and participation in classroom activities (J. N. Hughes, Luo, Kwok, \& Loyd, 2008; Ladd \& Dinella, 2009; Li \& Lerner, 2011). Behavioural engagement is strongly linked to academic success and positive socioemotional adjustment (Skinner \& Belmont, 1993; Vile Junod, DuPaul, Jitendra, Volpe, \& Cleary, 2006).

Many factors have been found to predict behavioural engagement in school. Contextual factors such as classroom climate, teacher-child relationship quality, and peer relationships have been previously shown to be positively associated with academic engagement (Ladd \& Dinella, 2009; Rudasill \& Rimm-Kaufmann, 2009). Although classroom experiences are also linked to achievement outcomes in school (i.e., test scores, teacher ratings), this relation between classroom experiences and achievement may be mediated by academic engagement.

In addition to contextual factors, socio-demographic and individual factors have been identified as predictors of academic engagement. For example, girls have been found to be more engaged in classroom activities as compared to boys (Ryan, 2012). As well, internalizing difficulties such as anxious withdrawal have been found to predict academic engagement (Buhs, Ladd, \& Herald, 2006). In particular, children who display 
anxious and solitary behaviours have been found to be less likely to participate and to engage in classroom settings (K. Hughes \& Coplan, 2010).

The primary goal of this dissertation was to examine the predictors and outcomes associated with behavioural engagement in childhood. Several conceptual models of these complex inter-associations were investigated. For example, the moderating role of individual factors on the relation between contextual (classroom) factors and academic engagement was explored. That is, the moderating role of gender and anxious solitude on the relations between classroom experiences (teacher-child relationship, classroom climate, peer relations) and academic engagement was investigated. In addition, the mediating role of academic engagement on the relation between classroom experience and academic achievement was examined. These various associations were examined concurrently in grade 1 and grade 3, as well as longitudinally across grade levels. Finally, predictors of the change in academic engagement across grade levels were explored.

To accomplish these goals, archival data from the NICHD's Study of Early Child Care and Youth Development were used. This archival data set contains information on 1,364 participants from birth to age 15 and includes social development and school environment measures that are relevant to the current dissertation. This data set contains observation measures of academic engagement and classroom climate in addition to teacher ratings of child anxious solitude, peer relationships, achievement, and teacherchild relationship quality.

\section{Conceptualizations of Academic Engagement}

Student engagement, school engagement, and academic engagement have been used interchangeably to describe a multifaceted measure of the emotional quality and 
dedication that students display towards their learning environment (Dotterer \& Lowe, 2011; Wang \& Holcombe, 2010). For the purposes of this dissertation, the labels academic engagement, engagement, and occasionally behavioural engagement will be employed to represent this construct.

Academic engagement can be considered as the amalgamation of several earlier conceptually related constructs. Contemporary research on engagement grew out of earlier work on student conduct and on-task behaviour (Peterson, Swing, Stark, \& Wass, 1984; Pierson \& Connell, 1992), student attitudes, interests and values (Dolan, 1983; Epstein \& McPartland, 1976; Yamamoto, Thomas, \& Karns, 1969) and motivational goals and self-regulated learning (Zimmerman, 1992). Leach and Dolan (1985) may have been the first to use the term academic engagement to describe motivation and on-task behaviour in the classroom. However, it was several years later before other components such as school commitment and attitudes towards learning were also considered part of academic engagement (Long, Stinson, \& Braeges, 1991).

As an aggregate of several constructs, academic engagement is a complex variable. This complexity has led to discrepancies in the definition and operationalization of this term. Theoretical conceptualizations of academic engagement have been varied in the literature. For example, some researchers have considered school retention to be an outcome of academic engagement (Archambault, Janosz, Morizot, \& Pagani, 2009), whereas others regard school retention to be a component of engagement (Li \& Lerner, 2011). Similarly, some studies have described motivation as a component of engagement (Greene, Miller, Crowson, Duke, \& Akey, 2004), whereas other studies define motivation as a predictor of engagement (Wang \& Holcombe, 2010). 
In an attempt to bring definitional and conceptual clarity to this literature, Fredricks, Blumfeld, and Paris (2004) presented a comprehensive theory of academic engagement. Fredricks and colleagues conceptualized engagement as a multifaceted construct that describes the interactions between a student and the school environment. These interactions can be viewed in a holistic way through understanding the three domains of engagement: cognitive, emotional, and behavioural. Although the current dissertation examines only the domain of behavioural engagement, brief overviews of both cognitive and emotional engagement are presented for the reader's understanding of the multifaceted nature of the academic engagement.

Cognitive engagement. Cognitive engagement refers to self-efficacy, motivation, attentional focus, and psychological effort (Church, Elliot, \& Gable, 2001; Duchesne \& Ratelle, 2010). Self-efficacy is described as self-confidence, belief in one's ability to achieve, and attribution style towards learning (Greene et al., 2004; Jimerson, Campos, \& Greif, 2003). Students who have higher levels of self-efficacy are more likely to believe they can succeed and more likely to have a positive attribution style (Dotterer \& Lowe, 2011). Students who have lower levels of self-efficacy are at risk for experiencing learned helplessness in the classroom and may develop a self-defeating attribution style (Greene et al., 2004).

Attentional focus and psychological effort both refer to self-regulation and the ability to concentrate on tasks (Wang \& Holcombe, 2010). Students who are able to pay attention and focus on learning activities are considered to be more cognitively engaged (Wang, Willet, \& Eccles, 2011). In comparison, students who are highly distractible, 
unable to focus, or unable to make a committed effort to their learning are considered to be less cognitively engaged (Wang et al., 2011).

Finally, motivation can refer to the reason for learning and achieving (Jimerson et al., 2003). Students can be motivated by mastery goals (such as mastering skills) or by performance goals (such as how they present themselves to others; Duchesne \& Ratelle, 2010; Greene et al., 2004). Students who are mastery goal oriented are more likely to be intrinsically motivated to improve their abilities. Students who are performance goal oriented are more likely to be extrinsically motivated to appear competent, receive awards, and impress others (Church et al., 2001).

Emotional engagement. Whereas cognitive engagement refers to mindful effort towards school, emotional engagement is the affective attachment to a school environment. Emotional engagement has been defined as a sense of belonging, support in the classroom, identification with school, and feelings towards school and learning (Buhs et al., 2006; Furrer \& Skinner, 2003). Sense of belonging or relatedness can refer to perceptions of acceptance and social support in the classroom (Finn, 1989; Furrer \& Skinner, 2003; Wang et al., 2011).

Sense of belonging can also refer to a style of attachment to other members of the classroom (Johnson, Crosnoe, \& Elder, 2001; Roorda et al., 2011). For instance, students may form very close and positive attachments with teachers who are warm, approachable, and supportive (Dotterer \& Lowe, 2011; J. N. Hughes, Luo, Kwok, \& Loyd, 2008), but may have greater difficulty bonding with teachers who are disorganized and unfocused, or strict and discipline oriented (J. N. Hughes et al., 2008; Roorda et al., 2011). Students who have positive relationships in school, and who are an appreciated member of the 
class are more likely to have a stronger sense of belonging (Wentzel, 1997). In comparison, students who are victimized, ostracized, and neglected in the classroom will have a lower sense of belonging (Buhs \& Ladd, 2001; Furrer \& Skinner, 2003).

Identification with school refers to a sense of pride, solidarity, and commitment to a classroom, school, or learning environment (Finn, 1989; Voelk1, 1997; Wang et al., 2011). Students who identify with their learning community tend to have more school spirit and pride. In addition, these students tend to be more invested in the well-being of the school community, and may be more inclined to work towards bettering that community (Voelkl, 1997; Wang \& Holcombe, 2010).

The final aspect of emotional engagement is attitudes and beliefs towards school and learning. This aspect of emotional engagement refers to students' feelings towards their teachers, their school, and learning in general. General attitudes towards learning can be assessed through measuring students' values and beliefs regarding education and the importance of education in their lives (Wang et al., 2011). Specific attitudes towards individual learning experiences can be assessed through students' feelings towards teachers and their school. In particular, students' self-reports of school liking and school avoidance have been identified as key components of emotional engagement (Buhs et al., 2006; Connell \& Wellborn, 1991; Fredricks et al., 2004; Ladd \& Dinella, 2009; Skinner \& Belmont, 1993).

Behavioural engagement. The third domain of academic engagement is behavioural engagement. Behavioural engagement is perhaps the most studied form of academic engagement. Behavioural engagement refers to observed actions such as attendance, activity participation, work habits, and cooperation in the classroom (J. N. 
Hughes et al., 2008; Ladd \& Dinella, 2009; Li \& Lerner, 2011). Attendance refers not only to classroom and daily attendance at school, but also to extracurricular involvement, school retention, and school completion (Connell, Halpern-Felsher, Clifford, \& Crichlow, 1995; Jordan, 2000). For example, Archambault and colleagues (2009) examined how engaged students were in the school community, through involvement in sports, clubs, and societies. In comparison, Li and Lerner (2011) defined engagement as class attendance and bringing books to class.

Another aspect of behavioural engagement is social conduct in the classroom. This refers to social behaviours such as cooperation, sharing, and being prosocial towards peers (Finn, Pannozzo, \& Voelk1, 1995; Finn \& Rock, 1997; J. N. Hughes et al., 2008). Typically, this is defined as adhering to classroom rules - acting in a socially acceptable way (Archambault et al., 2009). This has also been referred to as cooperative engagement (Birch \& Ladd, 1997; Buhs \& Ladd, 2001). Aside from cooperation, aggression has been examined as a measure of disengagement in the classroom (Finn et al., 1995; J. N. Hughes et al., 2008). Aggression has been typically defined as being disruptive and acting hostile towards others (Birch \& Ladd, 1997; Ladd, 1999).

Finally, participation and effortful on-task behaviour are considered to be aspects of behavioural engagement (Birch \& Ladd, 1997; Finn et al., 1995; Skinner \& Belmont, 1993). These aspects are sometimes referred to as autonomous engagement, which is defined as taking initiative, working independently, and seeking challenges (Birch \& Ladd, 1997; Buhs \& Ladd, 2001). Other works have characterized this form of engagement as goal-directed or constructive behaviour in the classroom environment (Furrer \& Skinner, 2003). Autonomous engagement is typically measured as a composite 
of specific classroom behaviours, such as writing, reading, asking questions, and participating in tasks (Vile Junod et al., 2006). Some research has attempted to distinguish between subcategories of autonomous behavioural engagement. For example, the distinction between active (e.g., writing, reading, talking to a teacher, volunteering answers) and passive (e.g., listening to teacher, watching a demonstration by a peer) engagement has been made (Vile Funod et al., 2006).

Aspects of behavioural engagement have been found to be inter-associated (Wang \& Eccles, 2012). For example, students who attend class regularly and arrive at school with their books and materials tend to participate more in class (Li \& Lerner, 2011). In addition, students who contribute more to class activities tend to behave more positively to towards their peers and are more likely to complete high school (Archambault et al., 2009; Rumberger \& Larson, 1998). Also, students who do not attend class regularly tend to participate less when they are in class (Janosz, Archambault, Morizot, \& Pagani, 2008). Finally, students who are more disruptive and hostile towards classmates may be less likely to complete high school (Archambault et al., 2009).

Although cognitive, emotional, and behavioural engagement each assesses a different dimension of academic engagement, all three of these constructs are highly interrelated (Fredricks et al., 2004). For example, students who can commit greater cognitive focus to their learning activities are more likely to remain on task in school (Ladd \& Dinella, 2009). In addition, children who receive more emotional support from teachers and peers may have higher levels of self-efficacy and be more motivated to succeed in school (Akey, 2006; Wentzel, Battle, Russell, \& Looney, 2010). Finally, students who participate in the classroom and become involved with extracurricular 
activities are more likely to enjoy school and to identify with their learning community (Archambault et al., 2009; Connell, 1990; Wentzel, 1997).

It is important to acknowledge that although Fredricks and colleagues (2004) attempted to create a cohesive model of engagement, some inconsistencies in the literature still persist. For example, "effort on tasks" has been defined as a component of both behavioural (Finn et al., 1995) and cognitive (Connell \& Wellborn, 1991) engagement. This reflects the high degree of inter-associations among the components of engagement.

More recent definitions of engagement have followed the multidimensional definition made by Fredricks and colleagues (2004). For example, several recent studies have attempted to measure cognitive, emotional, and behavioural engagement concurrently (Appleton, Christenson, Kim, \& Reschly, 2006; Archambault et al., 2009; Dotterer \& Lowe, 2011; Janosz et al., 2008; Wang \& Holcombe, 2010; Wang et al., 2011). This was largely done to assess a "holistic" measure of student engagement (Appleton et al., 2006; Wang et al., 2011). Wang and colleagues (2011) found that components of cognitive engagement (self-regulation and learning strategies), emotional engagement (sense of belonging and valuing education), and behavioural engagement (paying attention and participation) were all highly interrelated. Moreover, all three domains of engagement were found to statistically load onto one factor, which indicates that they are different facets of one overarching construct.

In this dissertation, the exclusive focus is the domain of behavioural engagement. As behavioural engagement is the most examined component of academic engagement, there is a stronger theoretical base to draw upon. This is particularly true with respect to 
the association between internalizing problems and academic engagement (K. Hughes \& Coplan, 2010).

In addition to theoretical rationales, there were a variety of practical reasons for this particular limitation. An observation measure of engagement included behavioural engagement only, as it was not possible to observe emotions or cognitions. Although the NICHD SECCYD database contains student self-reports of emotional and cognitive engagement, these measures are available only in later elementary grades (5 and 6). No measures or proxies for emotional or cognitive engagement were available at the grade levels of interest for the current study.

Stability and change of academic engagement. Academic engagement has been found to be moderately stable throughout middle childhood (i.e., elementary school; Fredricks et al., 2004) with a general trend to decline in adolescence (Janosz et al., 2008; Li \& Lerner, 2011). More specifically, self-regulated learning, sense of belonging, and classroom participation have all been shown to decline from grade 7 to grade 11 (Wang \& Eccles, 2012). However, this decline is not always consistent. Li and Lerner (2011) identified various trajectories for both behavioural and emotional engagement from grade 5 to grade 8 . Although $20 \%$ of students followed a decreasing trajectory of behavioural engagement, $60 \%$ maintained a moderate level of behavioural engagement, and $20 \%$ maintained a high level of behavioural engagement (Li \& Lerner, 2011). Similarly, only $6 \%$ of students were found to have and moderate-to-low level of emotional engagement, which decreased sharply over time. Approximately $40 \%$ of students were found to have moderate levels of emotional engagement which decreased only slightly, and 54\% were 
found to have a high level of emotional engagement, which decreased slightly over time (Li \& Lerner, 2011).

Child characteristics were found to impact changes in engagement over time. For example, girls had higher initial levels of behavioural and emotional engagement, and maintained higher levels of engagement over time (Li \& Lerner, 2011). In addition, students from higher-income families were found to maintain higher levels of behavioural and emotional engagement over time (Li \& Lerner, 2011). Therefore, boys from lower-income families were found to be at the greatest risk for substantial declines in student engagement over time (Li \& Lerner, 2011).

\section{Implications of Academic Engagement}

Conceptually, academic engagement has become a central component of understanding student achievement and holistic well-being (Fredricks et al., 2004; Li \& Lerner, 2011). Students who are more motivated and have higher self-efficacy in the classroom may have higher skills of academic ability due to their dedication towards studying (Janosz et al., 2008). In addition, students who participate, pay attention, and spend more time on task in school may have more opportunities to increase their knowledge and academic skills (DiPerna, Volpe, \& Elliot, 2002). Finally, students who feel more positively towards school may be more inclined to stay in school and to attend postsecondary education (Akey, 2006; Wentzel et al., 2010).

These purported theoretical links have been largely empirically substantiated (Connell, Spencer, \& Aber, 1994; Connell \& Wellborn, 1991; Furrer \& Skinner, 2003; Marks, 2000; Skinner, Wellborn, \& Connell, 1990). For example, academic engagement is a strong predictor of many aspects of school adjustment (Janosz et al., 2008; Li \& 
Lerner, 2011). These associations have been found when considering short-term (Buhs \& Ladd, 2001; Furrer \& Skinner, 2003) and long-term outcomes (J. N. Hughes et al., 2008; Li \& Lerner, 2011). Academic engagement has been found to be predictive of homework completion, report card grades, standardized test scores, school retention, and postsecondary school enrolment (Furrer \& Skinner, 2003; Janosz et al., 2008; Li \& Lerner, 2011; Manlove, 1998; Pierson \& Connell, 1992).

School retention. At a most basic level, academic engagement is connected with school retention (Archambault et al., 2009; Connell et al., 1994; Finn \& Rock, 1997; Janosz et al., 2008). For example, students who identify more strongly with their school are more likely to attend school and less likely to drop out (Finn, 1989). In addition, students who participate in class are more likely to graduate from high school (Rumberger \& Larson, 1998). More recently, Archambault and colleagues (2009) found that a lack of overall engagement (cognitive, emotional, and behavioural combined) predicted high school dropout. However, when the three domains of engagement were examined individually, only low behavioural engagement predicted high school dropout (Archambault et al., 2009). This link between behavioural engagement and school retention has been demonstrated in longitudinal studies. For example, teacher ratings of behavioural engagement in grade 1 have been found to predict high school retention (Alexander, Entwisle, \& Dauber, 1993).

Postsecondary enrolment. Not only is academic engagement linked with high school completion, but engagement has also been shown to be predictive of postsecondary school enrolment and level of education obtained (Boxer et al., 2010; Dubow, Boxer, \& Huesmann, 2009). For instance, students who have a greater sense of 
belonging, and who are less likely to be disruptive in class are more likely to receive a higher level of education (Akey, 2006; Wentzel et al., 2010). In addition, identification with school and valuing education were found to be connected with desired educational aspirations and obtained level of education (Boxer et al., 2010; Dubow et al., 2009). Therefore, academic engagement in the classroom can predict short-term, long-term, and lifelong academic outcomes.

Task completion. Aside from attendance and retention, academic engagement is linked with academic success and productivity. One form of measuring productivity has been through task completion. For example, students who pay attention in class and have materials organized at school were more likely finish academic tasks in a timely manner (Connell et al., 1994; Finn \& Rock, 1997). In addition, academic engagement was found to predict homework completion outside of school and arrival at school with appropriate materials (Finn \& Rock, 1997).

Academic ability. In addition to task completion, academic engagement has been found to predict academic abilities. For example, students who are more engaged in school tend to perform more strongly on measures of academic skills (Dotterer \& Lowe, 2011; Marks, 2000; Patrick et al., 2007; Wang \& Holcombe, 2010). In one study, students' self-reports of effort towards tasks and feelings towards school predicted tests scores of reading and math (Dotterer \& Lowe, 2011). Moreover, increased opportunities to respond and participate in school have been associated with performance on tests of achievement (Connell et al., 1994; K. Hughes \& Coplan, 2010; Leach \& Dolan, 1985). For instance, Connell and colleagues (1994) found that a combined measure of feelings 
towards school, paying attention, and completing tasks was linked to scores on standardized tests of achievement.

Academic performance and report card grades. Academic engagement not only influences academic ability but has also been connected to academic performance. For instance, academic engagement has been linked with report card grades (Dotterer \& Lowe, 2011; Jordan, 2000; Manlove, 1998; Wang \& Eccles, 2012). In particular, one study found that students' interest, concentration, and enjoyment predicted their selfreported grades (Shernoff \& Schmidt, 2008). A second study found that adolescents' selfregulated learning and classroom participation predicted GPA (Wang \& Eccles, 2012). Finally, class attendance and sense of connectedness was found to be predictive of student GPA over time (Li \& Lerner, 2011).

Engagement not only predicts self-rated and objective measures of academic performance. Academic engagement has also been linked with teachers' perceptions of student ability (K. Hughes \& Coplan, 2010; Ladd \& Burgess, 2001). Students who participate more in classroom activities, come prepared to school, and volunteer answers in class are rated by teachers as more proficient in reading and math (K. Hughes \& Coplan, 2010). In addition, teacher ratings of students' behavioural engagement have been linked with academic achievement (Fredricks et al., 2004; Furrer \& Skinner, 2003; K. Hughes, Coplan, \& Rubin, 2011). Indeed, teacher-rated behavioural engagement appears to be a good predictor of long-term academic achievement (Skinner et al., 1998). For instance, teacher ratings of behavioural engagement in grade 1 were found to predict report card grades over the next four years (Alexander et al., 1993). 
The current dissertation examines the links between behavioural academic engagement and teacher-rated academic performance in both math and language. Teacher ratings were used because they are among the strongest and most frequently used indicators of academic achievement (Roorda et al., 2011).

\section{Predictors of Academic Engagement}

Although academic engagement is predictive of academic and socioemotional outcomes, it is important to note that academic engagement is also responsive to many contextual factors. Academic engagement has been shown to be fluid, malleable, and indicative of various classroom and child factors. Predictors of academic engagement will now be discussed. This discussion is relevant to the current study, as all predictors presented in the section that follows were examined.

Classroom experiences. Academic engagement takes place largely within the classroom environment. Therefore, many classroom factors have been found to contribute to academic engagement. These factors include teacher-child relationships, peer relationships, and the general classroom climate. A discussion of these predictive factors will now be presented.

Teacher-child relationships. Teachers have been described as ambassadors of learning. Teachers' behaviours in the classroom can influence students' motivation and understanding of tasks, students' perceptions of the demands of the classroom, and students' feelings towards school and learning. Therefore, teachers' behaviours are predictive of academic engagement in the classroom (Connell, 1990; Roorda et al., 2011; Rudasill \& Rimm-Kaufmann, 2009). 
A teacher who is passionate and enthusiastic may influence students to be more motivated and cognitively engaged. Indeed Brophy (1986) found that teachers' guidance, enthusiasm, curiosity, interest, and praise predicted student motivation in the classroom. Moreover, middle school students reported higher cognitive engagement and greater use of learning and metacognitive strategies in classrooms when teachers encouraged students to attempt challenging work (Blumenfeld \& Meece, 1988).

In addition to enthusiasm, teachers who provide structure to the classroom may elicit higher levels of participation and more on-task behaviour from their students (Battistich, Solomon, Watson, \& Schaps, 1997; Skinner \& Belmont, 1993). Teachers who are fairer and more flexible in the administration of school rules and support student autonomy are more likely to have more behaviourally engaged students (Miller, Leinhardt, \& Zigmond, 1988; Turner et al., 1998). Moreover, teachers who provide students with more support and care tend to have less disruptive behaviours in their class and lower student dropout rates (Ryan \& Patrick, 2001; Skinner \& Belmont, 1993). Finally, teachers who are supportive may help students to feel more connected to the classroom and the school environment (Birch \& Ladd, 1997; Roorda et al., 2011). In addition to teachers' behaviours in the classroom, the quality of the teacherchild relationship has been found to be a predictor of academic engagement. Teacherchild relationships incorporate the perceptions and actions of both the teacher and child (Birch \& Ladd, 1997; Rudasill \& Rimm-Kaufmann, 2009), and are the primary relationship a child will have with their school environment. This relationship can influence how a child behaves, thinks, and feels in regards to school (Roorda et al., 2011). Close and positive teacher-child relationships in early elementary have been found 
to be predictive of cooperative participation and positive work habits in the classroom (Birch \& Ladd, 1997; Dotterer \& Lowe, 2011; J. N. Hughes et al., 2008; Ladd, Birch, \& Buhs, 1999; Valeski \& Stipek, 2001). In comparison, less close and more conflicted teacher-child relationships have been found to be associated with disengagement and disruptive behaviour in the classroom (Baker, 2006; Birch \& Ladd, 1997; Connell, 1990; Stipek \& Miles, 2008). For instance, having a poor teacher-child relationship has been associated with poorer work habits, less classroom participation, and more negative feelings towards school (Hamre \& Pianta, 2001; Ladd et al., 1999; Ladd \& Burgess, 2001). Finally, close teacher-child relationships have been shown to be particularly beneficial to at-risk students (J. N. Hughes et al., 2008; Rudasill \& Rimm-Kaufmann, 2009).

Peer relationships. Another classroom factor that can impact academic engagement is peer relationships (Buhs, 2005; Hoglund, 2007; Ladd \& Dinella, 2009). Previously, the connection between peer relationships and engagement was considered to be weak and nonsignificant once teacher-child relationships were taken into account (Ryan, Stiller, \& Lynch, 1994). However, more recent studies have found support for the unique link between peer relationships and academic engagement (Furrer \& Skinner, 2003).

Indeed, peer relationships at school can be influential in shaping a child's perception of school, learning, and desire to achieve (Furrer \& Skinner, 2003; Wentzel, Barry, \& Caldwell, 2004). Children who have positive relationships with peers in the classroom are more likely to feel satisfied in school and to display socially appropriate behaviours in class (Berndt \& Keefe, 1995; Ladd, 1990; Wentzel, 1994). 
Moreover, children who experience peer rejection are more likely to disengage in school (Buhs, 2005; Ladd et al., 1999; Ladd, Kochenderfer, \& Coleman, 1997; Sage \& Kindermann, 1999; Wentzel, 1999). For instance, elementary school children who are rejected from the peer group are more likely to display poor conduct and lower classroom participation. Children who are rejected from peers at school are also more likely to report lower interest in school (Buhs \& Ladd, 2001; DeRosier, Kupersmidt, \& Patterson, 1994).

Once children are rejected from the peer group, they may feel marginalized and not included in social interactions and learning-based activities (Buhs et al., 2006; Hoglund, 2007). Rejected children may disengage as a strategy to avoid further abuse or rejection. Alternatively, rejected children may be forced to disengage because they are excluded from academic activities (Hoglund, 2007).

Longitudinal results have indicated that peer rejection is linked with peer abuse and peer exclusion. Peer abuse is in turn linked with long-term increases in school avoidance, whereas peer exclusion is linked with long-term decreases in school participation (Buhs et al., 2006). This may indicate that rejected children are excluded, which in turn leads to decreased school participation. This may also indicate that rejected children are abused by their peers, which in turn leads to a desire to avoid school (Buhs et al., 2006).

Further research has shown that it is important not only to be accepted by peers but to have the right "type" of friends. In one study that examined friendship groups, it was found that levels of academic engagement were similar within each group. Groups of friends who valued education were more likely to achieve, and groups of friends who 
devalued education were less likely to achieve (Chen, Chang, He, \& Liu, 2005). In addition, peer groups who actively discuss ideas and critique each other's work helped to enhance each other's cognitive engagement over time (Meloth \& Deering, 1994). Finally, children in highly engaged peer groups tend to increase their behavioural engagement over time (Kindermann, 1993).

Classroom climate. The relationships a student forms in school can impact their engagement in the classroom. However, other classroom dynamics can also impact academic engagement. For example, the classroom climate has been found to be a strong predictor of academic engagement (Dotterer \& Lowe, 2011; Ecceles et al., 1998; Patrick et al., 2007; Ryan \& Patrick, 2001).

Classroom climate can be described as the general classroom environment, or factors that contribute to classroom environment. Measures of classroom climate have examined environmental factors such as emotional warmth, emotional support, hostility, structure, and closeness (Dotterer \& Lowe, 2011; Gazelle, 2006; Pianta et al., 2002). Classroom climate has been primarily examined in elementary classrooms (Connell \& Wellborn, 1991) but has also been studied with respect to older populations (Ryan et al., 1994).

Classroom climate has the potential to impact academic engagement because children's behaviours are responsive to the environment. A welcoming environment that makes a child feel comfortable is more likely to elicit engagement (Wang \& Holcombe, 2010). For instance, a classroom characterized by emotional support and closeness may provide students with a stronger sense of acceptance, belonging, and relatedness (Dotterer \& Lowe, 2011; Pianta et al., 2002). The sense of being welcomed and 
appreciated may in turn lead children to become more behaviourally engaged (Connell \& Wellborn, 1991; Patrick et al., 2007). Finally, when students receive support from both teachers and peers, they are more likely to engage in their learning activities and show more self-regulated learning (Marks, 2000; Patrick et al., 2007). One recent study examined the links between classroom climate and all major components of academic engagement (Wang \& Holcombe, 2010). Researchers found that teacher support, autonomy, and class discussions were linked to school identification, participation, and self-regulated strategies (Wang \& Holcombe, 2010).

In addition to support, classrooms characterized by greater structure, clarity of expectations, and reliable organization may be perceived as more predictable and thus more accommodating to students. Quality of instruction, clarity of teacher expectations, and consistent response patterns have been shown to predict student participation and ontask behaviour (Connell \& Wellborn, 1991; Dotterer \& Lowe, 2011; Pianta, et al., 2002; Skinner \& Belmont, 1993). Organized classrooms that support autonomy and a masteryfocused orientation (as opposed to performance-focused) are more likely to promote positive self-concepts and higher self-efficacy among students (Greene et al., 2004; Madonna, Bailey, \& Wesley, 1990; Pianta et al., 2002). Finally, McMahon and Wernsman (2009) found that high satisfaction and low friction among students predicted higher levels of self-efficacy in language.

Socio-demographic factors. Although contextual factors inside the classroom may influence academic engagement, it is also important to consider influential sociodemographic variables, such as socioeconomic status and gender. A review of these constructs will now be discussed. 
Socioeconomic status. Socioeconomic factors such as family income and parental education have been found to be important contributors to child academic engagement. Dubow and colleagues (2009) found that parental education predicted the level of education that children obtained. This finding can be interpreted to suggest that children who have more highly educated parents may be more likely to value education themselves and perhaps likely to pursue higher education. However, the link between parental and child education may actually indicate a privilege linked to socioeconomic status. Children from higher SES groups may have more resources available to them to obtain a higher level of education (Dubow et al., 2009). Parents who are more highly educated may have higher incomes and more resources to provide their children with access to higher education.

Socioeconomic status has also been associated with behavioural engagement (Johnson et al., 2001; Kalil \& Ziol-Guest, 2005; Ladd et al., 1999; McLoyd, 1998). Elias and Haynes (2008) argued that socioeconomic status can impact children's socioemotional competence and their experience of social support. These two factors may in turn influence student motivation in the classroom. For example, schools in lower SES neighbourhoods are more likely to have rigid curriculum, overcrowded classrooms, inadequate school facilities, and fewer teachers (Elias \& Haynes, 2008). These conditions may act as mediators in the association between socioeconomic status and achievement (Hoff \& Mitchell, 2006). For example, children who meet the criteria for free or reducedprice lunch programs tend to perform more poorly at school, but this is mediated by poor teacher-to-student ratios (Elias \& Haynes, 2008). The associations between SES, 
classroom support, socioemotional competence, and academic achievement indicate that SES may play a role in predicting academic engagement.

Gender. Another consistent predictor of academic engagement is gender.

Although some studies report no gender differences in terms of engagement (K. Hughes \& Coplan, 2010), the majority of studies have found a link. More specifically, most studies have found that female students tend to participate in class more than male students (Finn \& Rock, 1997; Johnson et al., 2001; Martin, 2004; Weis, Carolan, \& Baker-Smith, 2010; Zimmerman \& Martinez-Pons, 1990). In addition, boys tend to have lower levels of emotional engagement than girls (Whitlock, 2006). A recent study that examined behavioural, emotional, and cognitive engagement found that girls were more behaviourally and emotionally engaged than boys, but there were no gender differences in cognitive engagement (Wang et al., 2011). Moreover, girls have been found to maintain higher levels of behavioural and emotional engagement over time as compared to boys (Janosz et al., 2008; Li \& Lerner, 2011). Finally, boys are almost twice as likely to drop out of school (Janosz et al., 2008).

One possible interpretation of this gender difference in academic engagement is socialization theory (Maccoby, 1998). According to this theory, female and male children are socialized in unique ways and are encouraged to behave and respond to the demands of the environment in different ways (Maccoby, 1998). Therefore, girls and boys may be socialized to behave differently in school and to respond to the school environment in unique ways (Li \& Lerner, 2011; Maccoby, 1998).

Girls may be encouraged to be passive, cooperative, and quiet, while boys may be encouraged to be active, competitive, and dominant (Ewing \& Taylor, 2009; Maccoby, 
1998). Therefore, girls' stereotyped behaviours may be perceived as being more appropriate in the school context as compared to boys' (Baker, 2006; Curby, Rudasill, Edwards, \& Perez-Edgar, 2011). Furthermore, the girls may receive more encouragement towards reading, writing, and other academic behaviours (Randolph, Kangas, \& Ruokamo, 2010). Finally, girls may be more likely to perceive female teachers as potential role models, and may therefore be more inclined to value school and learning as compared to boys (Roorda et al., 2011).

Outside of school, boys may be discouraged from engaging in activities such as reading, writing, sitting quietly, and patiently cooperating with others (Maccoby, 1998). Therefore, the demands placed on boys inside and outside of school may differ. These mixed expectations may cause boys to have difficulty conforming to the expected behavioural patterns in school (Baker, 2006; Curby et al., 2011; Hamre \& Pianta, 2001; Maccoby, 1998). Due to a low percentage of male elementary school teachers, boys may also be socialized to believe that school is a female-dominant environment (Roorda et al., 2011). In addition, boys may be less likely to value school or learning as compared to girls (Li \& Lerner, 2011; Randolph et al., 2010). Therefore, compared to boys, girls may be more behaviourally and emotionally engaged in school.

Socio-demographic variables such as socioeconomic status and gender have been shown to influence how children thrive and engage in learning environments. In addition, child factors such as personality and temperament may influence how children meet the demands of school. The final construct which will be examined in the current study is anxious solitude. A central focus of this study is examining predictive links between anxious solitude and behavioural academic engagement. Therefore the following 
overview of this concept, including its links to socioemotional and academic outcomes and a focus on the theoretical and empirical links to academic engagement will now be presented.

\section{Anxious Solitude in Childhood}

Definitions and concepts. Anxious solitude is described as playing alone when among familiar playmates (Gazelle, 2006) and displaying internalizing symptoms (anxiety, tension, loneliness, fear). Anxious solitude is theoretically associated with similar terms such as behavioural inhibition, shyness, and social withdrawal. Behavioural inhibition describes toddlers who exhibit heightened physical arousal and nervousness towards novelty and new experiences (Garcia-Coll, Kagan \& Reznick, 1984). Shyness is a temperamental trait characterized by nervousness and hesitation in social situations (Rubin, Coplan, \& Bowker, 2009). Social withdrawal is a behavioural pattern referring to the avoidance of social situations and a lack of initiation towards peer interactions (Buhs et al., 2006).

Although these terms are not perfectly synonymous, and each describes a unique construct, there is much overlap between the four terms. For example, a behaviourally inhibited toddler is more likely to become a socially withdrawn preschooler (Kagan et al., 2007). A child who is socially withdrawn may withdraw due to feelings of shyness around peers (Coplan, Arbeau, \& Armer, 2008). Finally, anxious solitude can be considered a representation of shyness at school, as shy children tend to withdraw and display anxious symptoms (Gazelle, 2006).

Social development literature has historically linked the literature on these four concepts, with research reports on shyness often referring to studies that examined social 
withdrawal (Coplan \& Arbeau, 2008) and with anxious solitude assessments often building from assessments of shyness (Gazelle, 2006). For the purposes of this study, the term anxious solitude will be used synonymously with terms like shyness and behavioural inhibition to denote unease, fear, anxiety, and behavioural withdrawal in social settings.

Development of anxious solitude. Anxious solitude typically includes both wariness and fearfulness towards novel social evaluations as well as embarrassment and self-consciousness in situations of perceived social evaluation (Asendorpf, 1991; Cheek \& Buss, 1981; Crozier, 1995; Zimbardo, 1977). Children who are anxious solitary tend to be hesitant to initiate peer interactions, often withdraw from social situations, and may have difficulty maintaining friendships (Coplan et al., 1994; Schneider et al., 1998). As well, compared to their more sociable counterparts, anxious solitary children initiate fewer conversations, have a more difficult time continuing them, speak less, and use shorter phrases (Asendorpf, 1994; Asendorpf \& Meier, 1993; Crozier \& Perkins, 2002).

Anxious solitude has been posited to be theoretically underpinned by an approach-avoidance conflict of motivations (Asendorpf, 1990). According to this theory, anxious solitary children have the desire to interact with others, but greatly fear being judged or evaluated by them. Anxious solitary children are motivated to "approach" others: to socialize with, be with, and be accepted by them. However, anxious solitary children are also motivated to "avoid" others due to their fears of being socially evaluated, judged, and rejected by their peers. This conflict of wanting to be with others — but not wanting to be rejected by them—can impact how anxious solitary children socialize with others. For example, anxious solitary children are sometimes so 
preoccupied with saying the "wrong thing" (something that will be condemned by their peer group) that they choose to remain silent (Asendorpf \& Meier, 1993). In addition, anxious solitary children may want to play with others on the playground but hesitate to do so out of fear. This can lead to hovering or onlooking behaviours, wherein children stand close to other children but do not take part in group activities (Coplan, Prakash, O’Neil, \& Armer, 2004).

There is some evidence that anxious solitude is at least partially biologically based. Early in infancy, physical symptoms of behavioural inhibition can be detected (Garcia-Coll, Kagan, \& Reznick, 1984; Kagan, Reznick, \& Snidman, 1988). Infants and toddlers who are behaviourally inhibited tend to show more distress when separated from their mothers or presented with novel challenges (Garcia-Coll et al., 1984; Kagan et al., 1988). In addition, both anxious solitude and behavioural inhibition have been linked to such physiological traits as higher cortisol levels, lower threshold for arousal, and faster and more consistent heart rate (Fox, Henderson, Rubin, Calkins, \& Schmidt, 2001; Kagan et al., 1998; Spangler \& Schieche, 1998).

However, anxious solitude does not appear to be entirely biologically based. Anxious solitude has been linked with various environmental components, such as mothers' personality and parenting style (Rubin et al., 2009). For instance, anxious solitude in children has been associated with both anxiety and neuroticism in mothers (Coplan, Reichel, \& Rowan, 2008). Also, mothers who employ a more overprotective style of parenting and who regularly involve themselves in the concerns of their children are more likely to have anxious children (Rubin \& Mills, 1992). One possible interpretation of this finding is that parents who speak for their children may actually 
inhibit their children's development and may promote anxious and withdrawn behaviours in their children (Rubin et al., 2009). Another study reported that anxious children may be more likely to have mothers who speak negatively about the world and who may thereby teach their children that the world is a fearful place (Rubin, Burgess, \& Hastings, 2002). Other studies suggest that children may become anxious solitary because of environmental factors that impact their beliefs and feelings about the world.

Taken together, these studies suggest that anxious solitude has both biological and environmental influences. Although anxious solitude has been reported to be a fairly stable trait (Kagan et al., 1988), different life events may also impact it (Coplan et al., 2008). Notwithstanding the causes of anxious solitude, the trait has been linked to a variety of outcomes.

Anxious solitude and socioemotional functioning. Across the lifespan, anxious solitude is associated with a wide range of negative adjustment outcomes. Anxious solitary children's hesitance towards social interactions, fears about perceived social evaluations, and the motivational approach-avoidance conflict are thought to contribute towards poor adjustment outcomes. For instance, children who have difficulty approaching, talking to, and playing with others may be more likely to have difficulty forming and maintaining friendships (Rubin et al., 2006). In addition, children who avoid social situations and withdraw from others may not be considered "likeable" by their peers (Chen, DeSouza, Chen, \& Wang, 2006; Rubin \& Krasnor, 1986). In support of these hypotheses, research has indicated links between anxious solitude and negative peer relations, including higher rates of peer rejection (Coplan, Girardi, Findlay \& Frohlick, 
2007; Kalutskaya \& Buhs, 2013), lower friendship quality (Schneider, 1999), and lower social competence (Chen et al., 2006).

These negative social outcomes may impact emotional well-being among anxious solitary children. Children who experience peer rejection and lack close friendships may be more likely to experience loneliness and victimization (Coplan et al., 2004; Coplan, Closson, \& Arbeau, 2007; Gazelle \& Ladd, 2003). In addition, children who consistently worry about the judgments of others may be more likely to feel insecure and to develop a negative self-image. Indeed, researchers have reported links between anxious solitude and a range of emotional difficulties, including fear and emotional loneliness (Coplan et al., 2004), as well as low self-esteem and optimism (Crozier, 1995; Schmidt \& Buss, 2010). Although the term anxious solitude refers to a subclinical population, anxious solitary children may also be at an elevated risk for developing symptoms of depression (Gazelle \& Ladd, 2003), anxiety (Kagan, Snidman, Zentner, \& Peterson, 1999; Rapee, Kennedy, Ingram, Edwards, \& Sweeney, 2005), and more severe mental health problems such as social phobia (Rapee \& Spence, 2004). Therefore, anxious solitude has been shown to be linked with internalizing difficulties in childhood (Coplan \& Armer, 2005; Rubin \& Coplan, 2004; Kalutskaya \& Buhs, 2013).

Anxious solitude and internalizing problems in early childhood is also predictive of socioemotional outcomes in adolescence (Prior, Smart, Sanson, \& Oberklaid, 2000) and adulthood (Caspi, Elder, \& Bem, 1988). Even after controlling for short-term outcomes, anxious solitude remains a significant predictor of long-term anxiety and other internalizing difficulties (Gazelle \& Ladd, 2003). One possible interpretation of these 
findings is that internalizing problems associated with anxious solitude may increase over time.

However, it is important to emphasize that not all children who are characterized as anxious solitary will experience negative social, emotional, and academic outcomes (Degnan \& Fox 2007). Considering that $80 \%$ of people have claimed to be shy at one point in time (Zimbardo, 1977), it is importance to note that many (if not most) shy and anxious solitary children grow up without experiencing significant difficulties. Some researchers have argued that the "most extremely shy" (i.e., top 15\%; Kagan, 1997) children are most at risk for later problems. Other researchers have moved away from this categorical view and instead explore the associates of anxious solitude as a continuous “personality” variable (Spere \& Evans, 2009; K. Hughes \& Coplan, 2010).

Anxious solitary children at school. Aside from socioemotional outcomes, anxious solitude has been connected to educational outcomes such as low achievement and, more recently, low engagement. Anxious solitude is associated with lower teacher ratings of achievement (K. Hughes \& Coplan, 2010; Lerner, Lerner, \& Zabski, 1985), academic competence (Coplan, Gavinski-Molina, Lagace-Seguin, \& Wichmann, 2001; Fox et al., 2005), poorer linguistic ability (Evans, 1996), and, in some settings, lower vocabulary scores (Crozier \& Hostettler, 2003).

It has been suggested that the classroom is particularly stressful for anxious solitary children and that the school environment may elicit and exacerbate feelings of anxiety and shyness (Coplan \& Arbeau, 2008; Coplan \& Armer, 2007; Evans, 2001; Rimm-Kaufmann \& Kagan, 2005). Anxious solitary children tend to feel anxious and fearful when they are the centre of attention and when they are being formally evaluated. 
Elementary school is the first time most children encounter formal evaluations; not surprisingly, anxious solitary children may experience greater performance anxiety at school (Crozier \& Hostettler, 2003; Crozier \& Perkins, 2002). In addition, classroom discussions, presentations, and even show-and-tell segments in which one child is the focal point of the entire class may be highly uncomfortable for anxious solitary children (Evans, 1987; Kagan, 1997).

As this example suggests, it is not just the academic aspect of the classroom that may impact anxious solitary children. School is an extremely social environment. An elementary classroom that requires peer interaction, group work, and cooperative learning can be daunting to an anxious solitary child (Coplan \& Arbeau, 2008; Kagan, 1997). Moreover, it is not just interaction with peers that can elicit feelings of nervousness, but also the judgment of peers. Because anxious solitary children worry about how their peers perceive them, they may be more preoccupied with fears of having the wrong answer, making a mistake, or being teased by their classmates (Crozier, 2010).

The challenges that anxious solitary children face in the school environment likely place additional importance on the contributions of classroom climate, teacherchild relationships, and peer relations towards anxious solitary children's school adjustment. As previously mentioned, a more supportive and less hostile classroom environment may enhance learning experiences for all children, but particularly for anxious solitary children (Gazelle, 2006). Indeed, research has shown that anxious solitary children are especially sensitive to changes in classroom climate (Gazelle, 2006).

In addition, hesitance towards approaching others may make anxious solitary children less likely to form close positive relationships with teachers (Rudasill, Rimm- 
Kaufmann, Justice, \& Pence, 2006) and peers in the classroom. Indeed, research has consistently shown that anxious solitude is associated with poor peer relationships in school (Chen et al., 2006; Pederson et al., 2007) and with a less close, more dependent teacher-child relationship (Birch \& Ladd, 1997; Rudasill, Rimm-Kaufmann, Justice, \& Pence, 2006). Although teachers may recognize that anxious solitary students need attention and assistance (Arbeau \& Coplan, 2007; Thijs, Koomen, \& Van Der Leij, 2006), they may not know how to respond to this behaviour (Bosacki et al., 2011).

These characteristics of anxious solitary children at school are not benign and may be associated with negative academic outcomes. In particular, anxious solitude has been connected with lower academic achievement (Coplan et al., 2001; Evans, 1996; Fox, 2005). The link between anxious solitude and achievement is perplexing because there is no relationship with IQ or cognitive ability (Crozier \& Perkins, 2002; K. Hughes \& Coplan, 2010). Nevertheless, several theoretical explanations for the link between anxious solitude and achievement have been proposed (see Coplan \& Evans, 2009, for a recent review).

First, anxious solitary children may experience performance anxiety on tests, presentations, and other forms of evaluation (Crozier \& Perkins, 2002). Despite having knowledge in a particular area, anxious solitary children may underperform at school because of a sense of panic that prevents them from performing to their full potential. For example, Crozier and Hostettler (2003) reported that in the cases of written or oral vocabulary tests administered individually, anxious solitary children performed more poorly than nonanxious solitary children. However, when children were asked to complete the same testing in a group context, anxious solitary and nonanxious solitary 
children performed similarly (Crozier \& Hostettler, 2003). The authors suggested that anxious solitary children experience performance anxiety that inhibits their ability to perform to their full potential when they perceived themselves as being watched by the tester.

Performance anxiety may impact academic achievement both directly, on measures of evaluation, and indirectly. One such indirect pathway is language usage. Anxious solitary children are verbally reticent in both small and large groups (Asendorpf, 1994; Evans, 2001; Rimm-Kaufmann \& Kagan, 2005). They are less likely to initiate conversations, and when prompted to speak, use shorter sentences and fewer words (Asendorpf, 1994; Evans, 1987). Although anxious solitary children perform worse than their peers on tests of linguistic ability (Evans 1993; 1996; 2001), this does not appear to be due to a lack of linguistic competence. Instead it may be a problem in performance. For example, Crozier and Perkins (2002) examined storytelling skills in elementary children after controlling for comprehensive vocabulary skills and found that anxious solitary children still had difficulty expressing themselves clearly (Crozier \& Perkins, 2002).

This lack of clarity in expression and an overall different language usage pattern may impact how anxious solitary children are perceived by their teachers. More specifically, reticence in the classroom may be interpreted as lack of knowledge, at least on academic material. Indeed, teachers tend to perceive shy and quiet children as less intelligent and less academically inclined, even when this is not the case (Coplan, Hughes, Bosacki, \& Rose-Krasnor, 2011; Gordon \& Thomas 1967; K. Hughes \& Coplan, 2010; Lerner et al., 1985). These findings suggest that the link between anxious solitude 
and academic achievement may be due to teacher bias. Academic achievement has been typically assessed through teacher ratings and not through actual test scores (Lerner et al., 1985; Zimmerman, 1992). This methodology may be problematic as teacher ratings of academic ability may be influenced by teachers' perceptions of students' behaviour. In this connection it is interesting to note that in one study self-reported anxious solitude was negatively related to teacher ratings of math and reading ability but unrelated to standardized test scores (Hughes \& Coplan, 2010).

Performance anxiety, language usage, and teacher bias may all help explain why anxious solitude is connected to lower academic achievement in elementary school. However, a construct that is more parsimonious theoretically and also empirically substantiated is academic engagement. As the following discussion demonstrates, the relation between anxious solitude and academic engagement has received only limited attention in the literature.

\section{Conceptual \& Empirical Links between Anxious Solitude \& Academic Engagement}

Due to its academic and social demands, anxious solitary children may perceive school as an intimidating environment (Coplan \& Arbeau, 2008). As mentioned previously, anxious solitary children tend to be preoccupied with how they are seen by others and are wary of evaluations - both formal evaluations from teachers and the social judgments of peers (Rubin et al., 2009). In addition, anxious solitary children tend to be reticent: they hesitate to interact verbally with others (Asendorpf, 1994). All of these factors together suggest that anxious solitary children may be less engaged academically.

It can be speculated, that anxious solitary children are less likely to behaviourally engage at school. One possible reason is their tendency to ruminate. If children are 
preoccupied with anxious thoughts, they may have greater difficulty focusing on their academic work. For example, worries about peers' judgments or an upcoming presentation may override their ability to concentrate on school work. In addition, feelings of nervousness may discourage anxious solitary children from contributing to class. They may feel timid at the thought of writing answers on the board, giving an oral presentation, raising their hand to volunteer an answer, or contributing to a group discussion. Anxious solitary children may feel unsure of their answers and conscious of the judgments of others. Therefore they remain a quiet observer in the classroom (Evans, 2001).

Indeed, these theoretical links between anxious solitude and behavioural engagement have been empirically supported (Hoglund, 2007; Li \& Lerner, 2011). Anxious and withdrawn elementary children have been found to be less behaviourally engaged in school (Buhs et al., 2006). Anxiety in adolescence has been connected with low academic engagement over time (Bond et al., 2007; Li, Bebirogiu, Phelps, Lerner, \& Lerner, 2008; Shochet, Dadds, Ham, \& Montague, 2006). Furthermore, child anxiety has been found to mediate the relation between behavioural engagement and peer victimization (Hoglund, 2007).

Results from two recent studies provide additional support for the association between anxious solitude and behavioural engagement. K. Hughes and Coplan (2010) found that self-reported anxious solitude was negatively associated with teacher-rated behavioural engagement in elementary children. In this study, behavioural engagement was assessed through a newly developed scale with items pertaining to conceptually relevant behaviours (e.g., class participation, preparation, attention). Furthermore, this 
negative relation between anxious solitude and behavioural engagement may help explain the relation between anxious solitude and academic achievement. Although Hughes and Coplan (2010) reported that anxious solitude was negatively associated with teacher ratings of academic achievement, behavioural engagement partially mediated this relation. A possible interpretation of this indirect pathway is that feelings of anxious solitude do not directly influence achievement. Instead, feelings of anxious solitude may inhibit children from participating in class, and this lack of participation results in lower achievement (K. Hughes \& Coplan, 2010).

In another recent study, K. Hughes, Coplan, and Rubin (2011) examined the relations between anxious solitude, aggression, and two subcomponents of behavioural engagement: participation and off-task behaviour. Anxious solitude was inversely related to participation but not linked to off-task behaviour, whereas aggression was related to off-task behaviour but not linked to participation. These findings support the notion that anxious solitary children are not disruptive; instead they are reticent to participate in academic activities. This study again found behavioural engagement to be an underlying mechanism in the relation between anxious solitude and achievement: Participation partially mediated the relation between anxious solitude and academic achievement.

However, these two studies are limited by their reliance on teacher ratings of academic engagement and achievement. It is known that teachers may underestimate the academic and cognitive abilities of anxious solitary children (Gordon \& Thomas, 1967; K. Hughes \& Coplan, 2010; Lerner et al., 1985). These known teacher biases indicate that assessing both engagement and achievement via teacher ratings may lead to an 
inflated correlation between the variables. In the current study, behavioural engagement is assessed by researcher observations.

Academic engagement as a mediator. Academic engagement has become a central component of understanding student achievement and holistic well-being (Fredricks et al., 2004). Academic engagement predicts school retention, homework completion, report card grades, disruptive behaviour, mental health, substance abuse, and teenage pregnancy (Janosz et al., 2008; Li \& Lerner, 2011; Manlove, 1998; Pierson \& Connell, 1992). Although researchers have identified many variables that predict academic and socioemotional outcomes in childhood, academic engagement is unique in that it is responsive to many contextual factors as well as the interaction of the individual with contextual factors (Skinner et al., 1990; Finn \& Rock, 1997). In a sense, academic engagement may be considered an overarching construct that takes family, school, and child characteristics into account; it is a stronger predictor of child outcomes than even the sum of these more specific constructs.

In addition, academic engagement appears to be malleable and changeable over time (Fredricks et al., 2004). Changes in academic engagement may be due to changing contextual factors (e.g., classroom experiences). Currently, academic engagement is a key variable in educational intervention research. Due to its malleable nature, it is theorized that manipulation of classroom characteristics may lead to elevated levels of engagement (K. Hughes \& Coplan, 2010). For instance, Dotterer and Lowe found that increased classroom support from grade 3 to grade 5 leads to increased behavioural and emotional engagement. Other studies have found that increasing the quality of teacher-child 
relationships leads to improvements in student engagement (Decker, Dona, \& Christensen, 2007; J. N. Hughes et al., 2008).

Strategies that increase academic engagement may also improve student academic achievement and well-being. Indeed, Dotterer and Lowe (2011) found that increased classroom support led to increased engagement, which in turn predicted increased academic achievement. Cook and colleagues (1999) reported that increasing positive affect and attitudes towards school led to an increase in academic achievement and a decrease in truancy and disciplinary problems.

However, intervention efforts may not succeed with all students. For instance, increased classroom support benefited students without previous academic difficulties, but did not affect academic engagement or achievement for students with previous academic difficulties (Dotterer \& Lowe, 2011). Thus, general intervention strategies may increase student engagement for most but not all students. Improving our understanding of the connections between individual factors and academic engagement may serve to improve intervention strategies. This in turn might help improve academic achievement and well-being.

Differential susceptibility hypothesis. Individual child characteristics may influence the relations between classroom experiences, engagement, and achievement. Although all students are affected by classroom experiences, some children may have more to gain or lose from quality of the learning environment. Vulnerable or at-risk children may benefit more from an extremely positive environment, but they may suffer more in an understimulating or negative learning environment. Resilient children are affected by the environment as well, but to a lesser degree than vulnerable children. 
Therefore, the impact of classroom experiences on academic adjustment may vary as a function of child characteristics.

For instance, an unsupportive or hostile classroom climate may negatively impact academic engagement for all students. However, the impact of this negative learning environment may be more critical for anxious solitary children (Gazelle, 2006).

Similarly, a warm, supportive classroom environment may be protective for all students, but may be particularly beneficial for anxious solitary students (Gazelle, 2006). Similar arguments could be made for other components of classroom experiences, such as teacher-child relationships and peer relationships. As the quality of classroom relationships improves, all students may benefit, but especially vulnerable and anxious children (Arbeau, Coplan, \& Weeks, 2010). Experiencing negative teacher or peer relations may decrease academic engagement for all, but especially for anxious solitary children (Hoglund, 2007).

The idea that some children will profit or suffer more than others from changes in the environment is a central tenet of the differential susceptibility hypothesis (Belsky, 1997). According to this theory, individuals may be more or less susceptible to environmental influences. This is similar to the diathesis-stress model (e.g., Hilsman \& Garber, 1995), which suggests that some individuals are predisposed to be more vulnerable to adverse effects of negative experiences. However, the diathesis-stress model focuses on vulnerability to negative effects, whereas the differential susceptibility hypothesis proposes that individuals are more susceptible to both negative and positive influences in the environment (Belsky, 1997): A positive situation is more beneficial and a negative situation is more harmful. 
The current study examined how child characteristics influence the academic outcomes associated with classroom experiences. As individual factors such as gender and anxious solitude have been found to predict academic engagement, this study investigated the role of such variables as moderators on the relation between contextual factors and academic engagement. That is, the current study investigated the linear associations between individual factors, classroom experiences (classroom climate, classroom relationships), and academic engagement. Specifically, the current study investigated the potential moderating role of anxious solitude and gender on the relation between classroom experiences and academic engagement. It was hypothesized that the relation between classroom experiences and academic engagement would differ among students, depending upon their gender and level of anxious solitude.

\section{The Current Study}

Theoretical model. Drawing upon the extant literature reviewed in this proposal, a theoretical model linking behavioural academic engagement, classroom experiences, anxious solitude, gender, and academic achievement was developed (Figure 1). Theorized predictors of academic engagement include classroom experiences (teacherchild relationships, peer relationships, classroom climate), socio-demographic factors (gender), and child factors (anxious solitude). Classroom experiences are expected to predict academic engagement and achievement, with academic engagement mediating the relation between classroom experiences and academic achievement. Finally, sociodemographic and child factors (gender, anxious solitude) are predicted to moderate the relations between classroom experiences and behavioural engagement. 


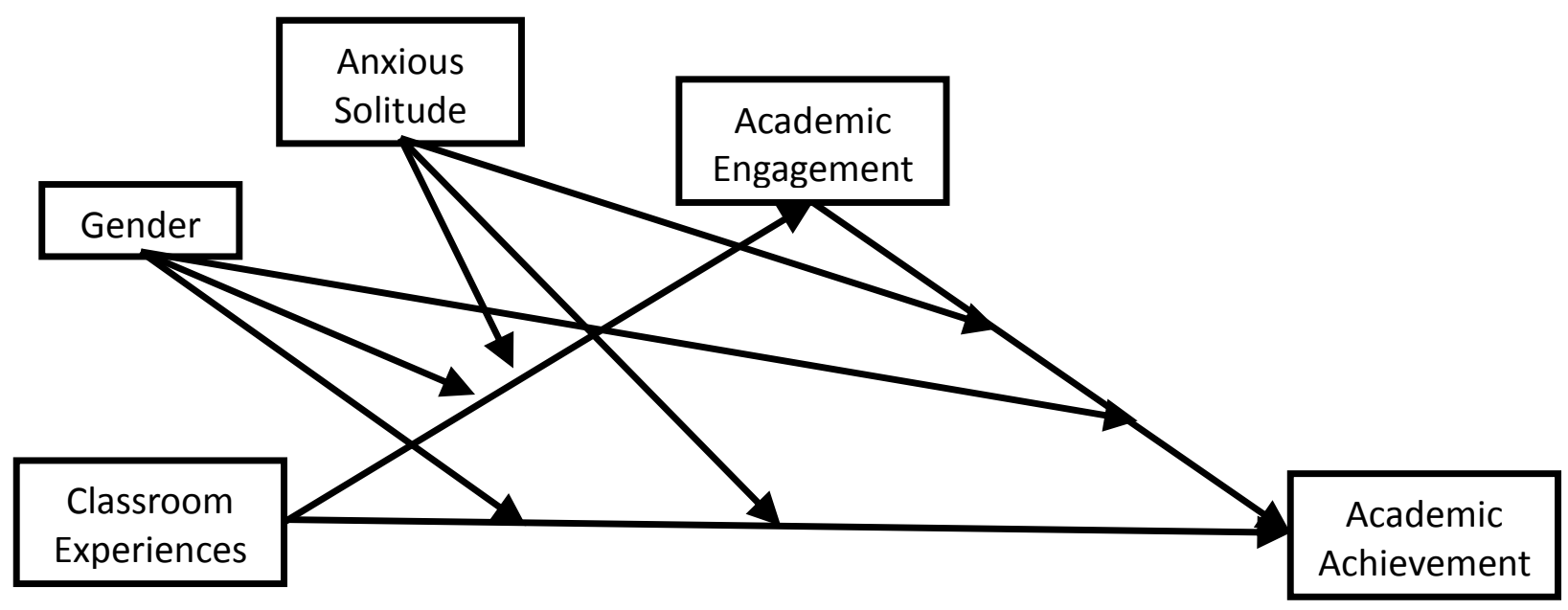

Figure 1. Conceptual model of the moderated-mediation analyses. 
The proposed theoretical model may help to provide insight into the complex associations concerning academic engagement. Most studies to date have examined predictors of engagement in isolation. For example, Furrer and Skinner (2003) examined links between emotional and behavioural engagement, relationships with teachers, peers and parents, and achievement. These researchers reported that each contextual factor uniquely contributed to the prediction of academic engagement. However, child characteristics (e.g., anxious solitude) were not taken into account. To address the unique relation between anxious solitude and academic engagement, as well as to assess the moderating role of child factors on the relation between classroom experiences and academic engagement, the theoretical model as outlined above is proposed. Examining academic engagement as part of a larger, more holistic model would provide a better understanding of the development and implications of this construct.

The primary aim of this research was to examine a theoretical model of the development and implications of academic engagement in childhood (see Figure 1). This included an examination of both short-term and longer-term associates of academic engagement in childhood. Accordingly, the first set of research questions pertained to concurrent predictors and outcomes of academic engagement in grade 1 and grade 3. Predictors explored were socio-demographic and child factors (gender, anxious solitude) and classroom experiences (teacher-child relationships, classroom climate, and peer relations). Academic achievement was included as an outcome variable. In addition, the mediating role of academic engagement in the relations between classroom experiences and achievement was investigated (see Figure 1). As well, the moderating role of socio- 
demographic (gender) and child (anxious solitude) factors on the links between classroom experiences, academic engagement, and academic achievement was explored.

The second set of research questions concern the longer-term implications of academic engagement from early to middle childhood. First, the stability of all variables, including academic engagement, over a two-year period (grade 1 to grade 3) was assessed. Next, the predictive ability of grade 1 child and contextual factors on grade 3 school adjustment variables (engagement, achievement) was assessed. The mediating role of grade 3 academic engagement in the relations between grade 1 classroom experiences and grade 3 achievement was investigated. As well, the moderating role of grade 1 sociodemographic and child factors on the links between grade 1 classroom experiences, grade 3 academic engagement, and grade 3 academic achievement was explored. Finally, the predictive ability of grade 1 child and classroom factors on the longitudinal change in academic engagement from grade 1 to grade 3 was assessed.

\section{Hypotheses}

Concurrent associations. For both the grade 1 and grade 3 concurrent analyses, the following identical set of hypotheses was established:

Linear associations. The predictors of academic engagement explored in this study were socio-demographic factors (gender), child factors (anxious solitude), and classroom experiences (teacher-child relationships, classroom climate, peer relations). Based on previous research reviewed herein, it was hypothesized that academic engagement would be (a) negatively associated with anxious solitude (K. Hughes \& Coplan, 2010); (b) positively associated with SES (Fredricks et al., 2004); and (c) positively associated with close teacher-child relationships, peer acceptance, and positive 
classroom climate (Furrer \& Skinner, 2003; Ladd et al., 1999). It was also predicted that girls would display higher levels of academic engagement than boys (Wang et al., 2011). Finally, it was predicted that academic engagement would be positively associated with academic achievement (Dotterer \& Lowe, 2011).

Mediation effects. It was hypothesized that classroom experiences, academic engagement, and academic achievement would all be positively inter-associated (Furrer \& Skinner, 2003). Based on previous research previously mentioned herein, it was hypothesized that academic engagement would mediate the relations between classroom experiences and academic achievement (Buhs, 2005; Ladd et al., 1999).

Moderation effects. Moderators of the relations between classroom experiences, academic engagement, and achievement explored in the current study were the sociodemographic factor of gender and the child factor of anxious solitude. Based on previous research reviewed herein, it was hypothesized that among children with higher levels of anxious solitude as compared to children with lower levels of anxious solitude, classroom experiences would be more strongly positively associated with academic engagement and that the level of academic engagement among more vulnerable (anxious solitary) children would be more susceptible to environmental influences. In comparison, it was predicted that among children with lower levels of anxious solitude, classroom experiences would be less st000rongly associated with academic engagement. In short, it was predicted that the results would support the differential susceptibility hypothesis (Belsky, 1997).

As boys also may be considered vulnerable students (Wang et al., 2011), it was hypothesized that the differential susceptibility hypothesis would also apply to gender. Boys were predicted to be more susceptible to environmental influences than girls, who 
are relatively resilient. Specifically, it was predicted that classroom experiences would be more strongly associated with academic engagement for boys than for girls. However, anxious solitude and gender were not hypothesized to moderate the relation between classroom experiences and achievement, or the relation between academic engagement and achievement.

Longitudinal associations. Longitudinal associations refer to associations over time from grade 1 to grade 3.

Stability of constructs. It was hypothesized that all study variables would display a high level of stability over time. In particular, it was predicted that early academic engagement would be positively associated with later academic engagement (Fredricks et al., 2004) and that early anxious solitude would be associated with later anxious solitude (Rubin et al., 2009).

Longitudinal predictors of academic adjustment. It was predicted that after controlling for grade 1 academic adjustment (academic engagement, achievement), grade 3 indices of academic adjustment would be predicted by grade 1 child and contextual factors. Based on previous research reviewed herein, it was hypothesized that grade 1 anxious solitude would be negatively associated with grade 3 academic engagement and achievement (K. Hughes \& Coplan, 2010) and that grade 1 classroom experiences (class climate, teacher-child relationships, peer relationships) would be positively associated with grade 3 academic engagement and achievement (Furrer \& Skinner, 2003).

Mediation effects. It was hypothesized that grade 1 classroom experiences, grade 3 academic engagement, and grade 3 academic achievement would all be positively interassociated after controlling for grade 1 engagement and achievement (Furrer \& Skinner, 
2003). Based on previous research, it was hypothesized that grade 3 academic engagement would mediate the relations between grade 1 classroom experiences and grade 3 academic achievement.

Moderation effects. Moderators on the relation between grade 1 classroom experiences, grade 3 academic engagement, and grade 3 achievement that were explored in the current study were the socio-demographic factor of gender and the child factor of grade 1 anxious solitude. Based on previous research reviewed herein, it was hypothesized that anxious solitude and gender would moderate the relation between classroom experiences and academic engagement. Among children with higher levels of grade 1 anxious solitude, it was predicted that grade 1 classroom experiences would be more strongly positively associated with grade 3 academic engagement. That is, the level of grade 3 academic engagement among more vulnerable (anxious solitary) children would be more susceptible to environmental influences in grade 1. In comparison, it was predicted that among children with lower levels of anxious solitude, grade 1 classroom experiences would be less strongly associated with grade 3 academic engagement.

As mentioned, boys may also be considered a vulnerable population (Wang et al., 2011). Therefore boys were expected to be more susceptible than girls to grade 1 environmental influences. Specifically, it was hypothesized that grade 1 classroom experiences would be more strongly associated with grade 3 academic engagement for boys than girls.

Gender and grade 1 anxious solitude were not, however, hypothesized to moderate the relation between grade 1 classroom experiences and grade 3 achievement, or the relation between grade 3 academic engagement and grade 3 achievement. 


\section{Method}

\section{NICHD SECCYD Data Set}

This study drew upon archival data from the National Institute of Child and Human Development (NICHD) Study of Early Child Care and Youth Development (SECCYD). The purpose of this 15-year longitudinal study was to focus on the relations between child care experiences, child characteristics, and developmental outcomes. Data collection began in 1991 in response to concerns raised by researchers and the media about the risks and benefits of out-of-home child care in the United States. The NICHD attempted to address the concerns with an in-depth and multi-site investigation into the effects of child care.

The major goal of the SECCYD was to assess relations between early child care experiences and children's social, emotional, intellectual, linguistic, and physical development (NICHD, 2010). The main interest was exploring family and demographic characteristics associated with child care usage, and comparing the development of children who experienced maternal vs. nonmaternal care.

Research teams in 10 collection sites (Arkansas, California, Kansas, Massachusetts, Pittsburgh, Philadelphia, Virginia, Washington, North Carolina, Wisconsin) developed study instruments, recruited participants, and collected longitudinal data from birth and until ages 14 or 15 . The study examined many domains of child development. During the first years, measures were primarily focused on health assessments, family lifestyle, maternal health, infant cognition, temperament, and child care type and quality. When participants were making the transition to school, socioemotional development, academic outcomes, peer relations, after-school activities, 
and sports participation were included. In mid-elementary years, the measures were expanded, with an even greater emphasis on academic outcomes, peer relations, and after-school activities. The later years of the study included more self-report measures and measures of moral development, risk-taking, and pubertal development.

Data were collected from multiple sources (mothers, father, caregivers, doctors, children, friends, teachers, principals, friends' teachers, friends' parents, census data) and from multiple settings (laboratory, home and school visits, phone interviews). Measures varied in terms of methodology (questionnaires, observations, test batteries, health reports).

NICHD Participants. The SECCYD database contains longitudinal data on 1364 children. To recruit these participants, mothers were first contacted in hospital shortly after giving birth between January and November 1991. Initially, mothers of 8986 children were contacted for the study; 3570 of the mothers immediately met the criteria for exclusion. Reasons for exclusion were as follows: (a) the mother was under 18 years of age; (b) the mother was not conversant in English; (c) the family planned to move within 3 years; (d) the child was hospitalized for more than 7 days after birth; (e) the child had obvious disabilities; (f) the mother had a known substance abuse problem; (g) the family lived far away from data collection site or in an area deemed dangerous for home visits; (h) the child was being placed for adoption.

After participants were screened with these exclusion criteria, 5416 children were still eligible. However, 2401 mothers declined a phone interview 2 weeks later, and an additional 1651 mothers were unable to participate in a 1-month home visit. Therefore, 1364 mothers completed the 1st-month interview. Most of the attrition occurred in the 
first 5 years of the study: at age 6 there were 1088 participants and at age 15 there were 1009.

Participants in current study. This study drew upon data collected when children were in grade 1 and grade 3 . Although 1088 participants were in the study at grade 1, observational data were available only for 966. According to NICHD protocol (2010), participants were excluded who were "out of grade": attending kindergarten, grade 2 , or some other grade when grade 1 data were collected. The rationale was that children who were held back a grade or skipped a grade may have confounded the study. After removing these cases, data were available on 905 participants.

Next, participants in classrooms smaller than 10 or larger than 30 students were excluded. Again this is NICHD protocol (2010); the rationale is that these classrooms may be special education or another type of alternative classroom. After removing students with small and large class sizes, data were available on 837 participants.

Finally, classrooms with more than one study participant were identified. If two or more participants had the same teacher ID, they were considered to be in the same classroom. A random number generator was used to select which participant would remain in the study. All other participants in the same classroom were excluded. This exclusion rule is prescribed by the NICHD to avoid a nested study design. After this criterion was applied, the final sample size was 779 (387 girls, 392 boys).

Although the sample is large, it is important to note a few caveats associated with the recruitment techniques. First, the upshot of the exclusion criteria is that many highrisk families and at-risk children were left out. Excluding young mothers, mothers with substance problems, and children with known disabilities or health problems limits the 
types of research questions that can be adequately addressed with this sample (NICHD, 2010). In addition, the 10 data sites were chosen based on scholarly merit and convenience to university researchers. The data sites cannot be considered a representative sample of the U.S. or any other population. However, the sample can be considered representative of the 10 collection sites (NICHD, 2010).

At each of the collection sites a sampling plan was used during recruitment. Researchers attempted to recruit samples with the following specifications: at least $10 \%$ of mothers were an ethnic minority; at least $10 \%$ were single mothers; at least $10 \%$ had less than a high school diploma; $60 \%$ planned to work full time within a year, $20 \%$ planned to work part time, and $20 \%$ planned to not work. All of these criteria were met for the initial data collection at 1 month: 77\% Caucasian, 12\% Black, $6 \%$ Hispanic, 5\% other; $10 \%$ no high school diploma, $21 \%$ high school or GED, 34\% some college, $21 \%$ college degree, $14 \%$ postgraduate; $14 \%$ single mothers, $86 \%$ partnered.

\section{Measures}

Socio-demographics. Socioeconomic status (SES) was employed as a control variable in the current study. To assess SES, the variable of family finances at 54 months was employed. This is a parent self-report measure consisting of four items rated on a 5point scale. The summary score of family finances can be used to calculate the incometo-needs ratio (Bell, 1982). A higher score indicates more financial resources to meet the family needs; that is, less financial stress.

Anxious solitude. The construct of anxious solitude was taken from the larger Teacher Report Form (TRF; Achenbach, 1991). The TRF is a teacher-rated measure of student behaviour in grade 1 and grade 3 . The measure contains 120 items rated on a 3- 
point scale (not true, somewhat true, very true). Teachers were asked to rate how well each item described the study child. The items on this measure asked teachers about child social problems such as depression, attention problems, and aggression.

Gazelle (2006) identified eight items within the TRF that make up a measure of anxious solitude: (a) would rather be alone than with others, (b) nervous, high strung, or tense, (c) too fearful or anxious, (d) refuses to talk, (e) self-conscious or easily embarrassed, (f) shy or timid, (g) withdrawn/does not get involved with others, and (h) worries. This scale of anxious solitude has been validated to converge with others assessments of solitary behaviour and anxious/withdrawn behaviour in children (Gazelle, 2006, Gazelle \& Spangler, 2007). In the current study, anxious solitude was the weighted sum of the 8 items, and was found to display similar levels of internal consistency at both grade $1(\alpha=.72)$ and grade $3(\alpha=.72)$.

The TRF has been employed as a measure of internalizing problems in a large number of studies (Glaser, Kronsnoble, \& Forkner, 1997). Previous research has found it to be a strong measure of child behaviour and appropriate for elementary-aged children. In addition, extensive research is available on the psychometric properties of this measure. The TRF has been reported to be highly reliable and internally consistent (NICHD, 1998).

Behavioural engagement. Behavioural engagement was assessed with the Classroom Observation Scale (COS; NICHD, 1998). This intensive observation system assesses a variety of class- and child-level variables in the classroom.

In both grade 1 and grade 3, academic engagement was assessed during classroom observations. Children were observed at intervals of 30 seconds over the course of two 
34-min observe/record cycles. Raters were required to give each child a rating of "engaged" or "disengaged" for each interval. Therefore, behavioural engagement scores refer to the proportion of time that children were observed being engaged in academic learning activities. NICHD training manuals define engagement to include active behaviours such as reading aloud, writing, working on a computer, participating in a game, preparing or putting away materials at appropriate times, walking to an activity, raising their hand, or talking to a teacher or peer about an academic activity (NICHD, 1998). In addition, this construct included passive behaviours such as looking at a teacher while instructions are being given, waiting for the teacher's attention, listening to another child read aloud, and standing in line (NICHD, 1998).

This observation protocol was designed by the NICHD for this study. The COS has not been used in other data sets. However, similar protocols with other samples have been studied. A similar observation scale of engagement is the Behavioural Observation of Students in Schools (BOSS; Shapiro, 1996) which assesses active, passive and off-task behaviours in the classroom.

Classroom climate. The COS was also employed as a measure of classroom climate. In addition to the child-level ratings of engagement as described above, the COS contains qualitative ratings of the classroom environment. Of particular interest to the current study are the qualitative ratings of teacher sensitivity, teacher intrusiveness, teacher detachment, classroom over-control, classroom positive emotional climate, classroom negative emotional climate, and classroom management. Each of these seven variables was rated by researchers during classroom visits in grade 1 and grade 3. During each 2-hr classroom visit, researchers rated teacher and classroom quality four times on 
each of these variables on a 7-point scale. Each variable was averaged across observations. The overall measure of classroom climate is sum of the seven variables.

Teacher sensitivity is defined as "child-centered behaviour demonstrated by the teacher" (NICHD, 1998). A high rating on this measure indicates that a teacher is aware of the needs, moods, and interests of students and uses this information to direct the structure of the physical and social environment. A sensitive teacher may give children more choice in activities and may allow students to give their input into decisions made by the class. Sensitivity is also characterized by teachers who scaffold and offer a mix of support and independence to students in their skill development. When students appear to need extra assistance, a sensitive teacher will adjust the level of instruction to meet their needs. Finally, sensitivity is shown in how often the teacher interacts with students and in whether discipline is appropriate (i.e., it matches the violation rather than being a standard punishment).

Teacher intrusiveness characterizes a teacher who is more self-centred and less child-centred. Teachers high in this trait promote their own needs and preferences at the expense of their students'. Intrusive teachers may be more likely to push students beyond their capability or level of skill. Teachers high in intrusiveness may be more likely to use rigid disciplinary rules and less likely to provide support for autonomy in the classroom.

Teacher detachment refers to a lack of involvement with students. A teacher high in detachment may be less likely to check on students completing worksheets and instead may be preoccupied with other activities. A teacher supervising an activity is not considered detached, but a teacher not engaged in students' work, or busy doing other 
tasks is considered detachment. Detached teachers may fail to provide scaffolding and support to students when needed and may also fail to provide discipline when warranted.

At the classroom level, there are four qualitative ratings. Classroom over-control refers to the structure of a classroom, with more rigid, less flexible classrooms having higher scores. Classrooms high in over-control are characterized as presenting students with fewer choices and opportunities for student-directed activities. Classes high in overcontrol may require students to remain quiet in their seats, and may disallow free play.

Positive emotional climate refers to the frequency of events such as pleasant conversation, spontaneous laughter, praise, and warm exchanges between teachers and students. A higher score on this variable indicates a more positive climate.

Negative emotional climate refers to hostile and angry exchanges between teachers and students, along with expressions of disapproval, criticism, and sarcasm. This rating also takes harshness of tone, tenseness of body language, and lack of concern for others into account. A higher rating on this measure indicates a more negative climate.

Classroom management refers to the teacher's ability to maintain order and effectiveness. A classroom high in management has smooth transitions between activities, well-organized materials, and clear instructions for tasks. Students in wellmanaged classrooms have a clear understanding of teacher expectations and they stay on task. In comparison, a classroom low in management is disorganized and chaotic, with students being overly disruptive, not paying attention, or not knowing what is expected of them.

The seven dimensions of classroom quality have been combined into a composite score of classroom emotional quality. The ratings of teacher intrusiveness, teacher 
detachment, and negative emotional climate were reversed. A higher score on this composite indicates a higher degree of child-centredness in the classroom. Internal consistencies for this measure were found to be high in both grade $1(\alpha=.89)$ and in grade $3(\alpha=.83)$.

Teacher-child relationships. The Student Teacher Relationship Scale (STRS; Pianta \& Steinberg, 1992) is a 15-item, 5-point Likert-type measure that was administered to grade 1 and grade 3 teachers as part of a larger questionnaire booklet. Items on this measure referred to closeness (e.g., "Openly shares his/her feelings/experiences") and conflict (e.g., "Is sneaky or manipulative with me"). This measure has been found to be predictive of student behaviours (Pianta \& Steinberg, 1992) and been employed to characterize variability in teacher-child relationships (Pianta, 1994). This measure has been used in a large number of studies and is widely regarded as the best available assessment of teacher-child relationships (Arbeau et al., 2010; Rudasill et al., 2006). In the present study an overall score of teacher-child relationship quality was calculated by subtracting the sum of the scores of the conflicted scale from the sum of the scores of the closeness scale. Internal consistency was high in grade $1(\alpha=.91)$ and grade $3(\alpha=.89)$.

Peer relations. Teacher-rated sociometric status in grade 1 was employed as the measure of popularity in the classroom. This is a 4-item measure in which teachers rate on a 7-point scale how much the child is liked and disliked by peers. The NICHD (1998) cites a conference presentation as their base reference for this measure (Cillessen, Terry, Coie, \& Lochman, 1992). According to Cillessen and colleagues (1992), teacher-rated measures of popularity were accurate for children at this grade level. Further evidence of 
the measure's merit is that ratings made by main and secondary teachers were correlated $(r=.39, p<.001)$ and that teachers' ratings were related to peer nominations (Cillessen et al., 1992). An overall score of peer relationship quality was calculated by subtracting the sum of the scores of the peer rejection from the sum of the scores of peer acceptance.

Academic skills. The Academic Rating Scale was employed as the measure of academic achievement in the current study. This is a teacher-rated measure, assessed at grade 1 and grade 3, that refers to grade-appropriate skills in math and literacy.

The grade 1 assessment asks teachers to rate the study child's skills, knowledge, and behaviours with respect to (a) language and literacy and (b) mathematical thinking. Items are rated on a 5-point scale. The language and literacy scale has 13 items (e.g., "Composes a story with a clear beginning, middle and end"). The mathematical thinking subscale has 10 items (e.g., "Counts change with two different types of coins, for example, two quarters and a nickel, or three dimes and two pennies"). In the present study, the composite (total) score of academic skills was employed $(\alpha=.96)$.

The grade 3 assessment of academic skills is the same as the grade 1 assessment, except that different items are used. In the grade 3 version, the language and literacy scale has 10 items (e.g., "Makes mechanical corrections when reviewing a rough draft") and the mathematical thinking scale has 13 items (e.g., "Demonstrates an understanding of time"). Again the composite score was used $(\alpha=.96)$. This measure is considered to be the best available in a standardized battery of teacher-reported academic skills. It has strong psychometrics (NICHD, 1998), is associated with standardized test scores (Nicholson, Atkins-Burnett, \& Meisels, 2002), and linked to report card grades (NICHD, 2010). 


\section{Results}

\section{Overview of Analytic Plan}

The data analyses are parsed into several components. In the preliminary analyses, missing data at both the item level and the variable level were examined. Next the data were screened for outliers, normality, and differences based on SES and gender.

The first major component of the data analyses was the analysis of Time 1 (grade 1) variables. Concurrent associations between grade 1 variables were assessed. In addition to linear relations, two moderated-mediation models were computed. Significant moderations were further examined using simple slopes analysis.

The second major component was the analysis of Time 2 (grade 3) variables. This was the same as the Time 1 analysis, except using data from grade 3.

The final major component was the longitudinal analysis from grade 1 to grade 3 . At this stage, the stability of variables over time was assessed. Next, the longitudinal prediction of grade 3 outcomes (controlling for grade 1 variables) was conducted. Finally, the prediction of change in engagement over time was assessed.

\section{Preliminary Analyses}

Following protocols outlines in the NICHD (2010) user guide (Technical Note 2), missing scale items were addressed by a simple calculation of the sum of scores divided by total items answered, multiplied by total scale items $\left[(\mathrm{X} / \mathrm{n})^{*} \mathrm{~m}\right]$. Thus, missing data at the item level were addressed using proportional weighting of relevant scale items.

After sample selection criteria were employed (see Methods section for details), the total number of participants in grade 1 was $n=779$. Missing data at the variable level were assessed using missing data analyses in SPSS, which indicated that (a) less than 5\% 
of cases were missing on any variable in grade 1 and (b) missing data appeared to be missing at random. According to Tabachnick and Fidell (2009), in this situation missing is best addressed with pairwise or listwise deletion. Therefore, pairwise deletion was used for each Time 1 (grade 1) analysis.

At grade 3, the total number of participants in the sample decreased from $n=779$ to $n=712$. An attrition analysis revealed that children who left the sample were significantly higher in grade 1 anxious solitude $(M=2.15, S D=2.21)$ than children who remained $(M=1.55, S D=2.01), t(75)=2.12, p<.05$. In addition, children who left the sample $(M=38.57, S D=8.00)$ had significantly lower grade 1 class climate scores higher than children who remained $(M=40.67, S D=6.23 ; t(74)=-2.08, p<.05)$. Among the participants who remained in the sample at Time 2 (grade 3), missing data at the variable level were also found to be less than $5 \%$ and missing at random. Therefore, this was again addressed through pairwise deletion (Tabacnick \& Fidell, 2009).

Next, univariate and multivariate outliers were assessed. Although several cases were found to have scores that were beyond 3 SDs from the mean, further inspection (via studentized deleted residuals, box plots, and frequency distributions) revealed that majority of the outliers were due to the skewness and kurtosis of the distributions. In fact, the majority of the study variable distributions displayed a "trailing off" effect. In the SES distribution, a significant outlier was assigned a score one integer higher than the second highest case.

Descriptive statistics for all study variables are presented in Table 1 (Time 1/Grade 1) and Table 2 (Time 2/Grade 3). Most distributions were significantly different from normal. However, standard transformation techniques (square roots, logarithms, and 
Table 1

Descriptive Statistics for Study Variables at Grade 1 (Time 1)

\begin{tabular}{lrrrrrrr}
\hline & $N$ & $M$ & $S D$ & Min. & Max. & Skewness & Kurtosis \\
& & & & & & & \\
\hline SES & 736 & 3.02 & 2.47 & 0.09 & 16.00 & $2.07^{*}$ & $6.02^{*}$ \\
Anxious Solitude & 768 & 1.60 & 2.04 & 0.00 & 12.00 & $1.62^{*}$ & $2.71^{*}$ \\
Engagement & 779 & 55.96 & 4.67 & 31.00 & 60.00 & $-1.82^{*}$ & $4.01^{*}$ \\
Class Climate & 779 & 40.48 & 6.42 & 13.33 & 49.00 & $-1.14^{*}$ & $.18^{*}$ \\
Teacher Relations & 777 & 23.26 & 7.94 & -14.00 & 33.00 & $-1.08^{*}$ & $1.14^{*}$ \\
Peer Relations & 776 & 3.22 & 2.19 & -6.00 & 6.00 & $-1.00^{*}$ & $.64^{*}$ \\
Achievement & 775 & 3.32 & 0.89 & 1.04 & 5.00 & -.26 & $-.74^{*}$ \\
& & & & & & & \\
\hline
\end{tabular}

*significantly different from normal $(p<.05)$

High scores in teacher relations and peer relations refer to most positive relationship quality. Higher scores in class climate refer to more positive classroom climate. 
Table 2

Descriptive Statistics for Study Variables at Grade 3 (Time 2)

\begin{tabular}{lcrrrrcc}
\hline & $N$ & $M$ & $S D$ & Min. & Max. & Skewness & Kurtosis \\
& & & & & & & \\
\hline Anxious Solitude & 701 & 2.02 & 2.24 & 0.00 & 12.00 & $1.43^{*}$ & $2.07^{*}$ \\
Engagement & 712 & 39.80 & 8.52 & 9.75 & 57.75 & $-.43^{*}$ & -.11 \\
Class Climate & 712 & 27.96 & 3.18 & 13.00 & 34.63 & $-1.27^{*}$ & $2.90^{*}$ \\
Teacher Relations & 704 & 21.54 & 9.16 & -13.00 & 33.00 & $-1.15^{*}$ & 1.08 \\
Peer Relations & 688 & 1.29 & 0.79 & -1.03 & 3.00 & -.26 & -.21 \\
Achievement & 704 & 3.51 & 0.85 & 1.00 & 5.00 & $-.53^{*}$ & -.34 \\
& & & & & & & \\
\hline
\end{tabular}

*significantly different from normal

High scores in teacher relations and peer relations refer to most positive relationship quality. Higher scores in class climate refer to more positive classroom climate. 
inverse reflections) did not improve the skewness or kurtosis. As reported by various statistical guides, transformations (Zimmerman, 2012) can greatly compromise the interpretations, particularly with respect to secondary data. In addition, it is recommended that if standard transformation techniques fail to improve a distribution, the analysis should proceed untransformed. Although previous researchers have transformed NICHD SECCYD data (Runions \& Keating, 2010), the NICHD training manual (2010) recommends that data remain untransformed.

Changes in study variables over time and overall gender differences were assessed with a series of four repeated-measures MANOVAs. The first model examined teacher-child relationships and peer relationships (see Table 3). Significant main effects of grade were found for teacher-child relationships and peer relationships, indicating that the quality of relationships decreased from grade 1 to grade 3 . In addition, significant gender effects indicated that girls formed more positive relationships compared to boys.

Furthermore, there was a significant grade $\times$ gender effect found for teacher-child relationships. This interaction was followed up with pairwise comparisons (see Figure 2). These indicated that the decrease in teacher-child relationship quality was more significant for boys $(F(738)=10.93, p<.01)$ from grade $1(M=21.64, S D=7.86)$ to grade $3(M=19.47, S D=9.75)$ as compared to the decrease in teacher-child relationship quality for $(F(741)=5.64, p<.05)$ girls from grade $1(M=25.04, S D=7.64)$ to grade 3 $(M=23.86, S D=7.87)$.

The second MANOVA examined grade and gender effects of observed class climate and observed academic engagement (see Table 4). Significant main effects of grade were found for classroom climate and academic engagement, indicating that quality 
Table 3

Gender and Grade Effects of Teacher-Child Relationships and Peer Relations

$\begin{array}{lllll}M & (S D) & M & (S D) & F\end{array}$

Teacher Relations

\begin{tabular}{|c|c|c|c|}
\hline \multirow[t]{2}{*}{ Grade Effect } & Grade 1 & \multicolumn{2}{|l|}{ Grade 3} \\
\hline & $23.36 \quad(7.93)$ & $21.69 \quad(9.12)$ & $7042.22 * * *$ \\
\hline Gender Effect & Boys & Girls & \\
\hline & $20.66 \quad(8.78)$ & $24.50 \quad(7.65)$ & $79.91 * * *$ \\
\hline Grade $\times$ Gender Interaction & & & $58.36 * * *$ \\
\hline \multicolumn{4}{|l|}{ Peer Relations } \\
\hline Grade Effect & Grade 1 & Grade 3 & \\
\hline & $3.25 \quad(2.20)$ & $1.29 \quad(0.80)$ & $90.16^{* * *}$ \\
\hline Gender Effect & Boys & Girls & \\
\hline & $(1.97)$ & $(1.93)$ & $6.61 *$ \\
\hline Grade $\times$ Gender Interaction & & & 1.57 \\
\hline
\end{tabular}

$* \mathrm{p}<.05 \quad * * \mathrm{p}<.01 \quad * * * \mathrm{p}<.001$ 
Academic Engagement and Anxious Solitude 72

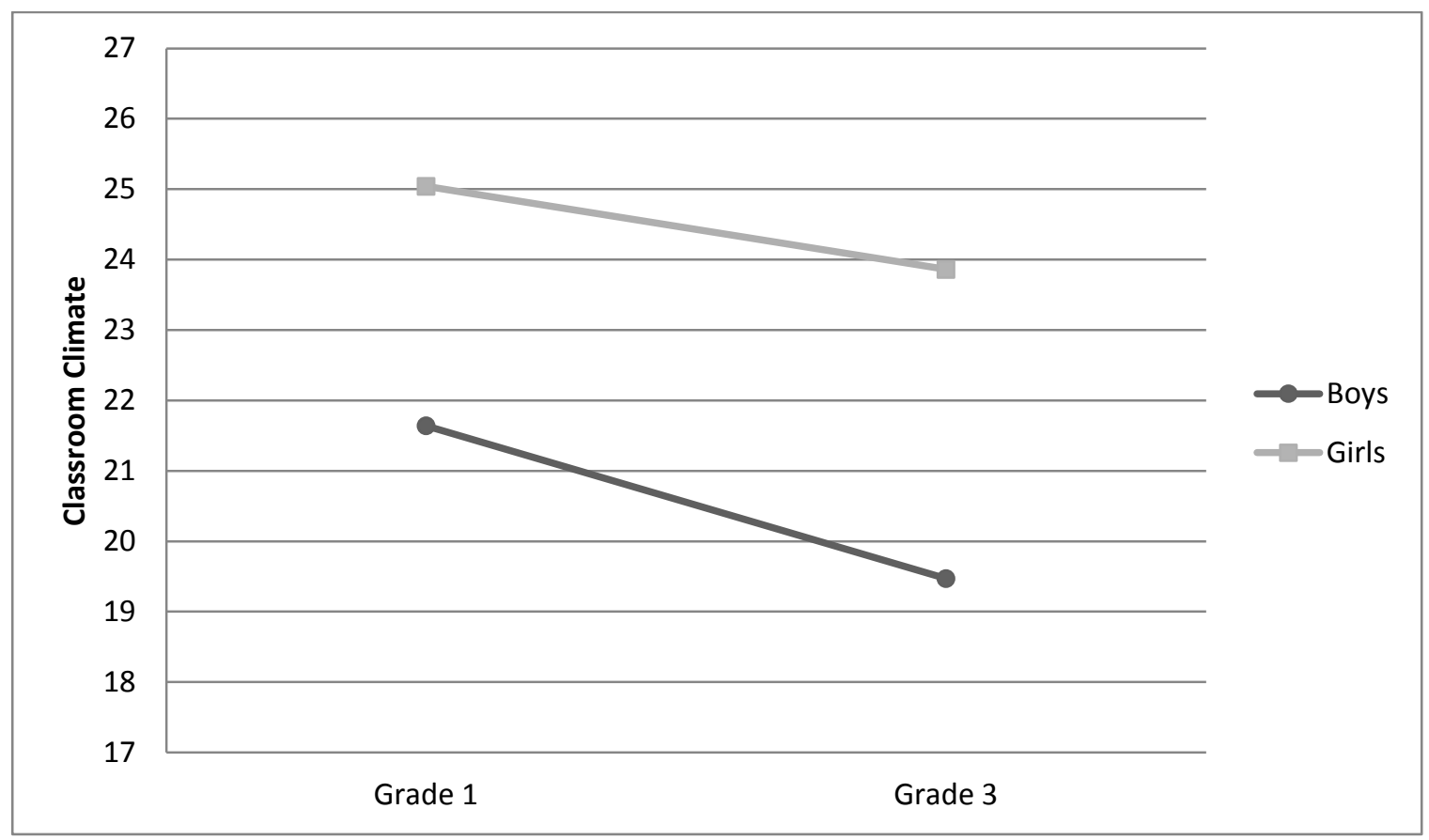

Figure 2. Interaction of gender $\times$ grade effects on teacher-child relationships. 
Table 4

Gender and Grade Effects of Engagement and Classroom Climate

\begin{tabular}{lllll}
\hline & $M \quad(S D)$ & $M \quad(S D)$ & $F$ \\
\hline Engagement & & & \\
& & & \\
\hline & & & \\
Grade Effect & Grade 1 & Grade 3 & \\
& $55.96 \quad(4.70)$ & $39.84 \quad(8.36)$ & $4137.99 * * *$ \\
Gender Effect & Boys & Girls & $13.77^{* * *}$ \\
Grade $\times$ Gender Interaction & $47.92(10.55)$ & $48.98(10.30)$ & 3.81 \\
\hline
\end{tabular}

Classroom Climate

\begin{tabular}{|c|c|c|c|}
\hline Grade Effect & Grade 1 & Grade 3 & \\
\hline & $40.54 \quad(6.40)$ & $28.00 \quad(3.21)$ & $4156.94 * * *$ \\
\hline Gender Effect & Boys & Girls & \\
\hline Grade $\times$ Gender Interaction & $34.48 \quad(7.96)$ & $34.93 \quad(8.27)$ & $\begin{array}{l}4.71^{*} \\
1.64\end{array}$ \\
\hline
\end{tabular}

$* \mathrm{p}<.05 \quad * * \mathrm{p}<.01 \quad * * * \mathrm{p}<.001$ 
of classroom climate and level of student engagement decreased over time. In addition, a significant gender effect of engagement indicated that girls displayed higher levels of engagement than boys. A significant gender effect of classroom climate indicated that girls' classrooms were more positive than boys'. No gender $\times$ grade interactions were found.

The third MANOVA model examined anxious solitude (see Table 5). A significant grade effect indicated that anxious solitude increased from grade 1 to grade 3 . No significant gender or grade $\times$ gender effects were found.

The fourth MANOVA examined achievement (see Table 6). A significant grade effect indicated that achievement increased from grade 1 to grade 3 . No significant gender or interaction effects were found.

Finally, socioeconomic status (SES) was significantly associated with a number of study variables in grade 1 and grade 3 (see Table 7). SES was positively associated with classroom climate, peer relationships, teacher-child relationships, and academic achievement consistently in both grade 1 and grade 3. Notably, SES was not associated with anxious solitude at either grade. Accordingly, it was included as a control variable in all subsequent analyses.

\section{Analyses of Grade 1 (Time 1) Variables}

Correlations. First, the associations among all study variables in grade 1 were assessed. Partial correlations (controlling for SES) are presented in Table 8. Associations among variables were mostly consistent with theoretical expectations. Academic engagement was significantly and positively correlated with classroom climate, teacherchild relationships, peer relationships, and achievement. Anxious solitude was 
Table 5

Gender and Grade Effects of Anxious Solitude

$M \quad(S D) \quad M \quad(S D) \quad F$

Anxious Solitude

Grade Effect

Grade 1

Grade 3

1.60 (2.04)

1.96

(2.20)

$19.25 * * *$

Gender Effect

Boys

1.78 (2.03)

Girls

Grade $\times$ Gender Interaction

$\begin{array}{lll}1.76 & (2.22) \quad .003\end{array}$

.11

$* \mathrm{p}<.05 \quad * * \mathrm{p}<.01 \quad * * * \mathrm{p}<.001$ 
Table 6

Gender and Grade Effects of Achievement

$\begin{array}{lllll}M & (S D) & M & (S D) & F\end{array}$

Achievement

Grade Effect

Grade 1

3.32 (0.88)

Gender Effect

Boys

3.38 (0.89)

Grade 3

3.53

$(0.84)$

$33.73^{* * *}$

Grade $\times$ Gender Interaction

$3.41 \quad(0.87)$

2.432

.06

$* \mathrm{p}<.05 \quad * * \mathrm{p}<.01 \quad * * * \mathrm{p}<.001$ 
Table 7

Correlations (Pearson's r) Between Socioeconomic Status and Study Variables at Grade 1 and Grade 3

\begin{tabular}{lll}
\hline \multirow{2}{*}{ Variable } & \multicolumn{2}{c}{ Socioeconomic Status } \\
& Grade 1 & Grade 3 \\
& & \\
\hline Anxious Solitude & .02 & -.07 \\
Classroom Climate & $.11 * *$ & $.18^{* * *}$ \\
Peer Relations & $.14 * * *$ & $.09 *$ \\
Teacher Relations & $.11 * *$ & $.20^{* * *}$ \\
Engagement & .05 & $.09 *$ \\
Achievement & $.18^{* * *}$ & $.25^{* * *}$ \\
& \\
\hline $\mathrm{p}<.05 \quad * * \mathrm{p}<.01$ & $* * * \mathrm{p}<.001$ &
\end{tabular}


Academic Engagement and Anxious Solitude 78

Table 8

Partial Correlations (Controlling for SES) among Study Variables in Grade 1 (Time 1)

\begin{tabular}{lccccc}
\hline & 2 & 3 & 4 & 5 & 6 \\
\hline 1. Anxious Solitude & .02 & .002 & $-.25^{* * *}$ & $-.14^{* * *}$ & $-.18^{* * *}$ \\
2. Engagement & - & $.21 * * *$ & $.12^{* *}$ & $.16^{* * *}$ & $.15^{* * *}$ \\
3. Class Climate & & - & $.13^{* *}$ & .07 & $.07 *$ \\
4. Teacher Relations & & & - & $.55^{* * *}$ & $.26^{* * *}$ \\
5. Peer Relations & & & & - & $.28^{* * *}$ \\
6. Achievement & & & & & - \\
\hline
\end{tabular}

$* \mathrm{p}<.05 \quad * * \mathrm{p}<.01 \quad * * * \mathrm{p}<.001$ 
significantly and negatively associated with teacher-child relationships, peer relationships, and achievement. However, contrary to expectations, anxious solitude was not significantly associated with academic engagement.

Partial correlations were also computed separately by gender. An online statistics website was used to test the significance of the difference between two correlation coefficients (see Lowry, 2012). Only one significant effect of gender was found. The magnitude of the correlation between anxious solitude and teacher-child relationships was significantly larger for girls $(r=-.34, p<.001)$ than for boys $(r=-.16, p<.001$; $z=2.59, p<.01$.

Moderated-mediation models. Next, the concurrent associations at Time 1 were assessed with a series of moderated-mediation models. For these analyses, teacher and peer relationships were aggregated $(r=.55, p<.001)$ to create a composite variable representing children's classroom relationships. Two models were calculated to examine aspects of the mediating role of academic engagement in the links between classroom experiences and academic achievement. For each model, (a) socioeconomic status was included as a control variable; (b) one component of classroom experiences (i.e., classroom climate, classroom relationships) was included as the predictor variable; (c) academic engagement was entered as a mediator; (d) both anxious solitude and child gender were included as moderator variables (i.e., moderators of the mediated effect); and (e) academic achievement was included as the outcome variable (see Figure 1).

Thus, for each model, the overall mediating effect of academic engagement in the relation between classroom experiences and achievement was assessed, along with the moderating role of both anxious solitude and gender on the relations between (a) class 
experiences and academic engagement; (b) class experiences and achievement; and (c) academic engagement and achievement.

Each model was conducted using SPSS and the PROCESS macro as designed by Hayes (2012). The macro is available online (Hayes, 2013), and is highly customizable. Hayes developed this SPSS macro as an extension of his previous work examining simple mediation effects and indirect effects. Using the PROCESS macro, researchers can examine complex pathways of associations (similar to path analysis), while also testing specific hypotheses (similar to regression).

On the strengths of this approach, is that the PROCESS macro directly assesses the moderation-mediation models that were hypothesized in the current study. That is, this macro can examine all of the components of the moderated-mediation, and in the most parsimonious and direct way, and it does not need to be done as a series of steps. This methodology also reduces the errors associated with examining multiple pathways in one model. Finally, the PROCESS macro reflects the most recent knowledge concerning moderation and mediation statistics (i.e., bootstrapping confidence intervals are used to assess mediations), and the creator of this macro continually updates his work to include the latest advances in statistics (Hayes, 2013).

Although control variables are entered into the PROCESS model, one of the benefits of this macro is that the overall model is assessed in one step. Therefore, the output from this macro differs from conventional SPSS output. For both the mediator (e.g., engagement), and outcome (e.g., achievement), one set of model fit statistics is given. For all direct and indirect pathways, only the unstandardized coefficients in the final model are presented. Standardized coefficients are not made available in this macro, 
as they are considered misleading in causal modeling, particularly when including dichotomous variables (Hayes, 2013). Therefore, the findings from this approach are presented as a series of unstandardized coefficients, and bootstrapping confidence intervals.

Classroom climate. The first moderated-mediation model for grade 1 examined classroom climate as a predictor. Data on $n=722$ children were available for this model. A full list of results is presented in Table 9 and illustrated in Figure 3. Academic engagement was found to significantly mediate the relation between classroom climate and achievement $\left(\mathrm{CI}_{95} .0114-.0454\right)$. In addition, gender was found to moderate the relation between classroom climate and academic engagement. This significant interaction term was further examined in a simple slopes analysis (Figure 4). The positive relation between classroom climate and academic engagement was found be significantly stronger for boys $(\beta=1.26(0.23), p<.001)$ than for girls $(\beta=0.55(0.25), p<.51)$.

No other significant interaction terms were found within this model. Classroom climate and gender both significantly predicted academic engagement, and academic engagement significantly predicted achievement. Anxious solitude did not predict either engagement or achievement in this model.

Classroom relationships. The second moderated-mediation model for grade 1 examined an aggregate measure of teacher and peer relationship quality as a predictor. Data on $n=718$ children were available. Full results are presented in Table 10 and illustrated in Figure 5. Academic engagement was found to mediate the relation between classroom relationships and achievement $\left(\mathrm{CI}_{95}=.0049-.0283\right)$. No significant 
Table 9

Unstandardized Coefficients of the Moderated-Mediation Regression of Class Climate and Academic Adjustment in Grade 1

\begin{tabular}{lcc}
\hline Predictor & \multicolumn{2}{c}{ Outcome } \\
\cline { 2 - 3 } & \multicolumn{2}{c}{$\begin{array}{c}\text { Engagement } \\
\end{array}$} \\
& $R^{2}=0.07$ & Achievement \\
& & $F(7,714)=10.44, p<.001$ \\
& $R^{2}=0.09$ \\
\hline Class Climate & $.90^{* * *}$ & .04 \\
SES & .04 & $.06^{* * *}$ \\
Gender & $1.16^{* * *}$ & -.38 \\
Anxious Solitude & .11 & -.61 \\
Class Climate $\times$ Gender & $-.71^{*}$ & -.05 \\
Class Climate $\times$ Anxious Solitude & -.04 & .04 \\
Class Climate (indirect) & - & .02 \\
Engagement & - & $.03 * * *$ \\
Engagement $\times$ Gender & - & .01 \\
Engagement $\times$ Anxious Solitude & - & .01 \\
\end{tabular}

${ }^{*} p<.05 \quad * * * p<.001$ 


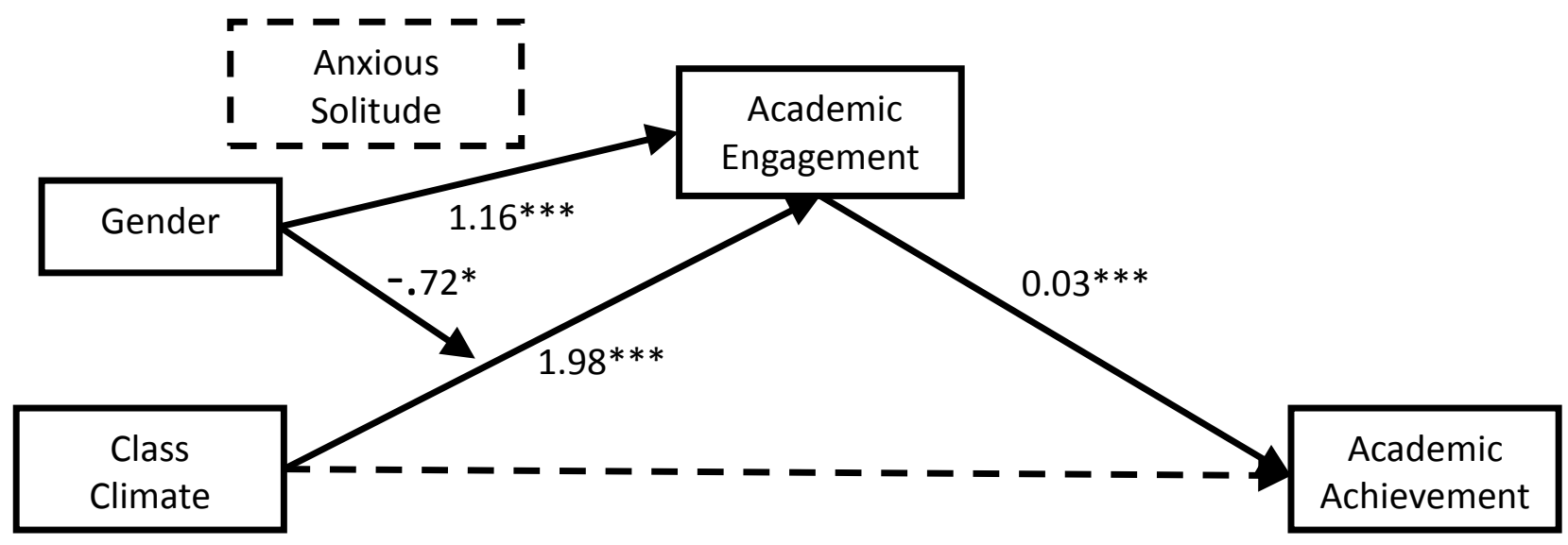

Figure 3. Illustration of the significant pathways in Table 9. (Class Climate and Academic Adjustment in Grade 1)

$* \mathrm{p}<.05 \quad * * * \mathrm{p}<.001$ 
Academic Engagement and Anxious Solitude 84

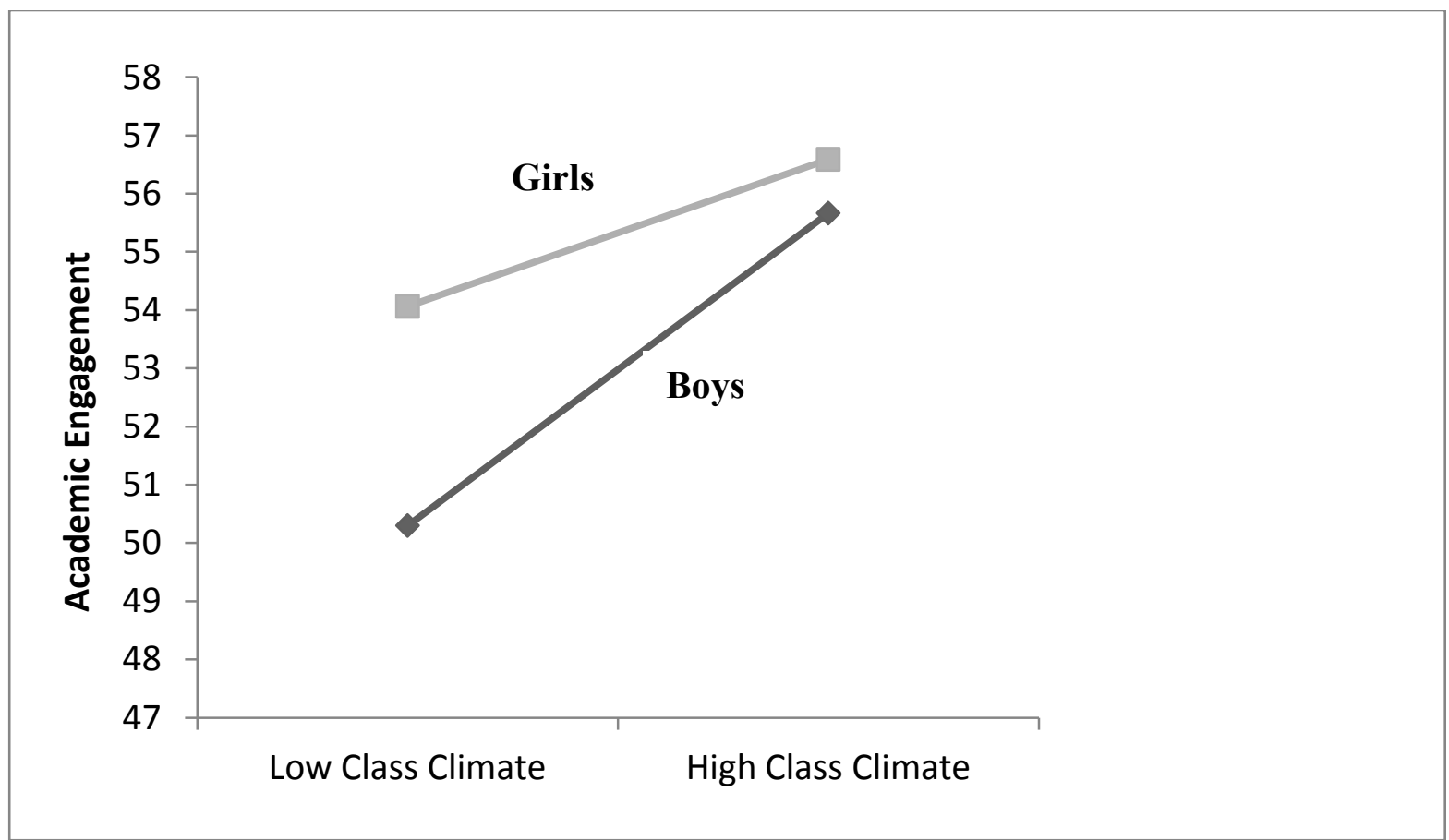

Figure 4. Simple slopes of gender as a moderator on the relation between grade 1 class climate and grade 1 academic engagement. 
Table 10

Unstandardized Coefficient of the Moderated-Mediation Regression of Classroom Relations and Academic Adjustment in Grade 1

\begin{tabular}{|c|c|c|}
\hline \multirow[t]{2}{*}{ Predictor } & \multicolumn{2}{|c|}{ Outcome } \\
\hline & $\begin{array}{l}\text { Engagement } \\
1)=5.67, p<.001 \\
R^{2}=0.05\end{array}$ & $\begin{array}{c}\text { Achievement } \\
F(7,710)=18.33, p<.001 \\
R^{2}=0.15\end{array}$ \\
\hline Classroom Relationships & $.66 * * *$ & $.26 * * *$ \\
\hline SES & .06 & $.05 * * *$ \\
\hline Gender & $1.12 * *$ & -.23 \\
\hline Anxious Solitude & .24 & .52 \\
\hline Class Relations $\times$ Gender & -.15 & -.08 \\
\hline Class Relations $\times$ Anxious Solitude & -.06 & -.03 \\
\hline Class Relations (indirect) & - & .01 \\
\hline Engagement & - & $.02 * *$ \\
\hline Engagement $\times$ Gender & - & .003 \\
\hline Engagement $\times$ Anxious Solitude & - & .01 \\
\hline
\end{tabular}

$* \mathrm{p}<.05 \quad * * \mathrm{p}<.01 \quad * * * \mathrm{p}<.001$ 


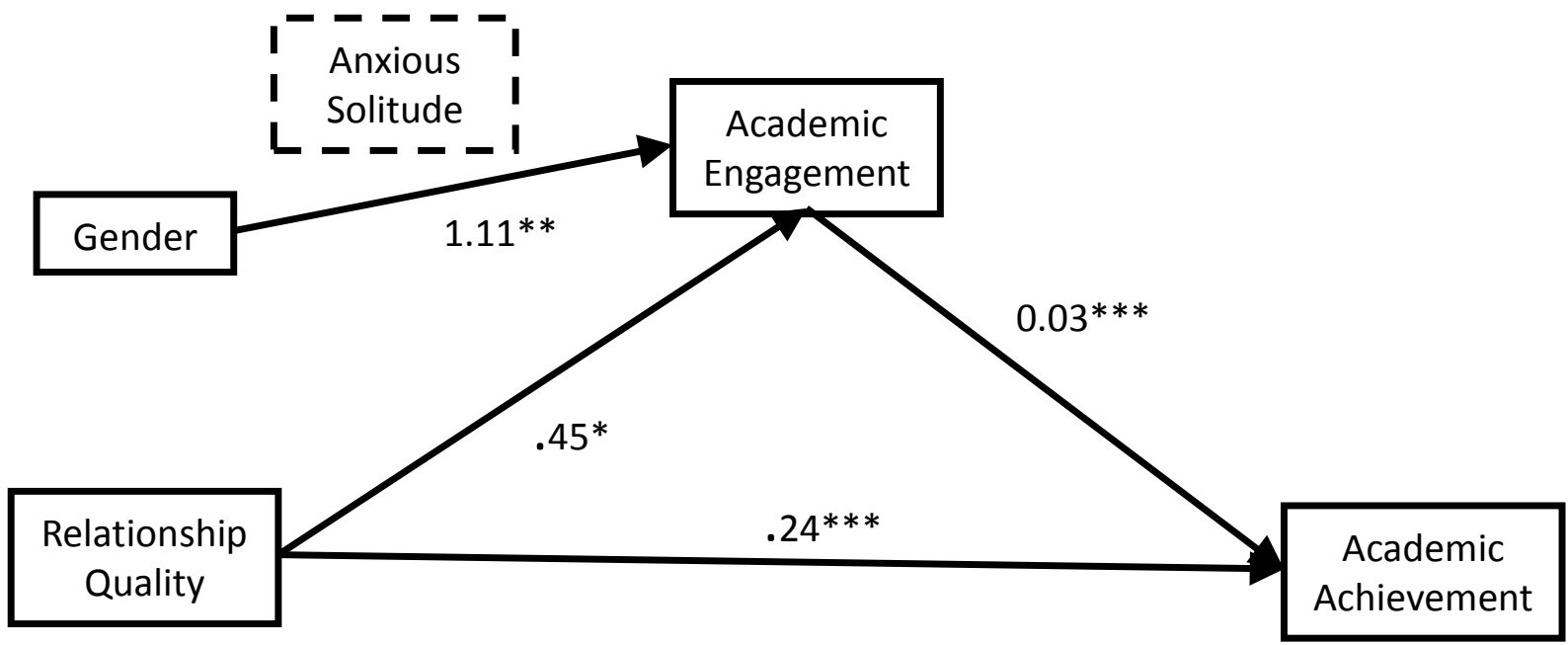

Figure 5. Illustration of significant pathways in Table 10. (Classroom relationships \& academic adjustment in Grade 1

$* \mathrm{p}<.05 \quad * * \mathrm{p}<.01 \quad * * * \mathrm{p}<.001$ 
interaction terms were found. Classroom relationships and gender were found to be significant predictors of engagement. Classroom relationships and academic engagement were found to be significant predictors of achievement. Anxious solitude was not found to be a significant predictor of either engagement or achievement in this model. Overall, there was a lack of significant findings for this model.

Summary of Analyses of Grade 1 (Time 1) variables. In grade 1, the interassociations among classroom experiences (i.e., classroom climate and relationships) and academic adjustment (academic engagement and achievement) were significant and in the expected direction. Gender moderated the relation between classroom climate and academic engagement. However, at this grade level there was a general lack of significant findings with respect to anxious solitude.

\section{Analyses of Grade 3 (Time 2) Variables}

Correlations. First, the associations among all study variables in grade 3 were assessed. Partial correlations (controlling for SES) are presented in Table 11. As in grade 1, associations among variables in grade 3 were generally consistent with theoretical expectations. For example, academic engagement was significantly and positively associated with classroom climate, achievement, teacher-child relationships, and peer relationships. Anxious solitude was significantly and negatively associated with teacherchild relationships, peer relationships, and achievement. However, the negative relation between anxious solitude and academic engagement only approached conventional levels of statistical significance. As with the grade 1 data, teacher and peer relationships were aggregated to create a composite variable of classroom relationships $(r=.52, p<.001)$; this measure was employed for the subsequent moderated-mediation models. 
Table 11

Partial Correlations (Controlling for SES) among All Study Variables in Grade 3

$\begin{array}{lllll}2 & 3 & 4 & 5 & 6\end{array}$

\begin{tabular}{lcccrr}
\hline 1. Anxious Solitude & $-.07^{+}$ & -.06 & $-.29 * * *$ & $-.13^{* *}$ & $-.15^{* * *}$ \\
2. Engagement & - & $.31 * * *$ & $.26 * * *$ & $.25 * * *$ & $.23^{* * *}$ \\
3. Class Climate & & - & $.14 * * *$ & $.15^{* * *}$ & $.15^{* * *}$ \\
4. Teacher Relations & & & - & $.52 * * *$ & $.27 * * *$ \\
5. Peer Relations & & & & - & $.24 * * *$ \\
6. Achievement & & & & & -
\end{tabular}

$$
{ }^{+} \mathrm{p}=.06 * * \mathrm{p}<.05 \quad * * \mathrm{p}<.01 \quad * * * \mathrm{p}<.001
$$


As before, partial correlations were computed separately for each gender and tested using an online statistics website. Results indicated a significant gender difference only in the magnitude of the positive correlation between engagement and peer relationship, with a stronger effect evident for girls $(r=.32, p<.001)$ than for boys $(r=.16, p<.01 ; z=-2.15, p<.05)$.

Moderated-mediation models. Next, the concurrent associations at Time 2 were assessed with a series of moderated-mediation models. This set of analyses is similar to the grade 1 concurrent analyses. As before, two models were calculated to examine aspects of the mediating role of academic engagement in the links between classroom experiences and academic achievement. For each model, (a) SES was included as a control variable; (b) one component of classroom experiences (classroom climate or classroom relationships) was included as a predictor variable; (c) academic engagement was entered as a mediator; (d) both anxious solitude and child gender were included as moderator variables (i.e., moderators of the mediated effect); and (e) academic achievement was included as the outcome variable.

Thus for each model, the overall mediating effect of academic engagement in the relation between classroom experiences and achievement was assessed, along with the moderating role of anxious solitude and gender on the relations between (a) class experiences and academic engagement; (b) class experiences and achievement, and (c) academic engagement and achievement. Each model was conducted using SPSS and the PROCESS macro as designed by Hayes (2012). Please see page 80 for an overview of this statistical macro and the output provided by this analysis. 
Classroom climate. The first moderated-mediation model for Grade 3 examined classroom climate as a predictor. Data on $N=644$ children were available for this model. A full list of results is presented in Table 12 and illustrated in Figure 6. Academic engagement was found to significantly mediate the relation between classroom climate and achievement $\left(\mathrm{CI}_{95} .0264-.0754\right)$. In addition, gender was found to moderate the relation between classroom climate and academic engagement. This significant interaction term was further examined in a simple slopes analysis (Figure 7). Similar to the findings in grade 1 , the positive relation between classroom climate and academic engagement was found to be significantly stronger for boys $(\beta=3.36(0.47), p<.001)$ than for girls $(\beta=2.01(0.46), p<.001)$.

Results from this model also indicated that anxious solitude was found to moderate the relation between classroom climate and academic engagement. This significant interaction term was further examined with a simple slopes analysis (Figure 8). The positive relation between classroom climate and academic engagement was found to be significantly stronger at higher levels of anxious solitude $(\beta=6.50(1.56), p<.001)$ than at low levels of anxious solitude $(\beta=2.92(1.45), p<.05)$.

In addition to interaction effects, classroom climate and gender were both found to significantly predict academic engagement. Classroom climate and academic engagement significantly predicted achievement. Anxious solitude was not a significant predictor of either engagement or achievement in this model.

Classroom relationships. The second moderated-mediation model for grade 3 examined an aggregate measure of teacher and peer relationship quality as a predictor. Data on $N=630$ were available for this model. Full results are presented in Table 13 and 


\section{Table 12}

Unstandardized Coefficient of the Moderated-Mediation Regression of Class Climate and Academic Adjustment in Grade 3

\begin{tabular}{|c|c|c|}
\hline \multirow[t]{2}{*}{ Predictor } & \multicolumn{2}{|r|}{ Outcome } \\
\hline & $\begin{array}{l}\text { Engagement } \\
37)=15.07, p<.001 \\
R^{2}=0.12\end{array}$ & $\begin{array}{c}\text { Achievement } \\
F(7,636)=14.76, p<.001 \\
R^{2}=0.14\end{array}$ \\
\hline Class Climate & $2.69 * * *$ & $.08^{*}$ \\
\hline SES & .07 & $.07 * * *$ \\
\hline Gender & $1.51 *$ & .01 \\
\hline Anxious Solitude & -.56 & -.15 \\
\hline Class Climate $\times$ Gender & $-1.36^{*}$ & -.09 \\
\hline Class Climate $\times$ Anxious Solitude & $.55^{*}$ & .001 \\
\hline Class Climate (indirect) & - & .05 \\
\hline Engagement & - & $.02 * * *$ \\
\hline Engagement $\times$ Gender & - & .002 \\
\hline Engagement $\times$ Anxious Solitude & - & .001 \\
\hline
\end{tabular}

$* \mathrm{p}<.05 \quad * * \mathrm{p}<.01 \quad * * * \mathrm{p}<.001$ 


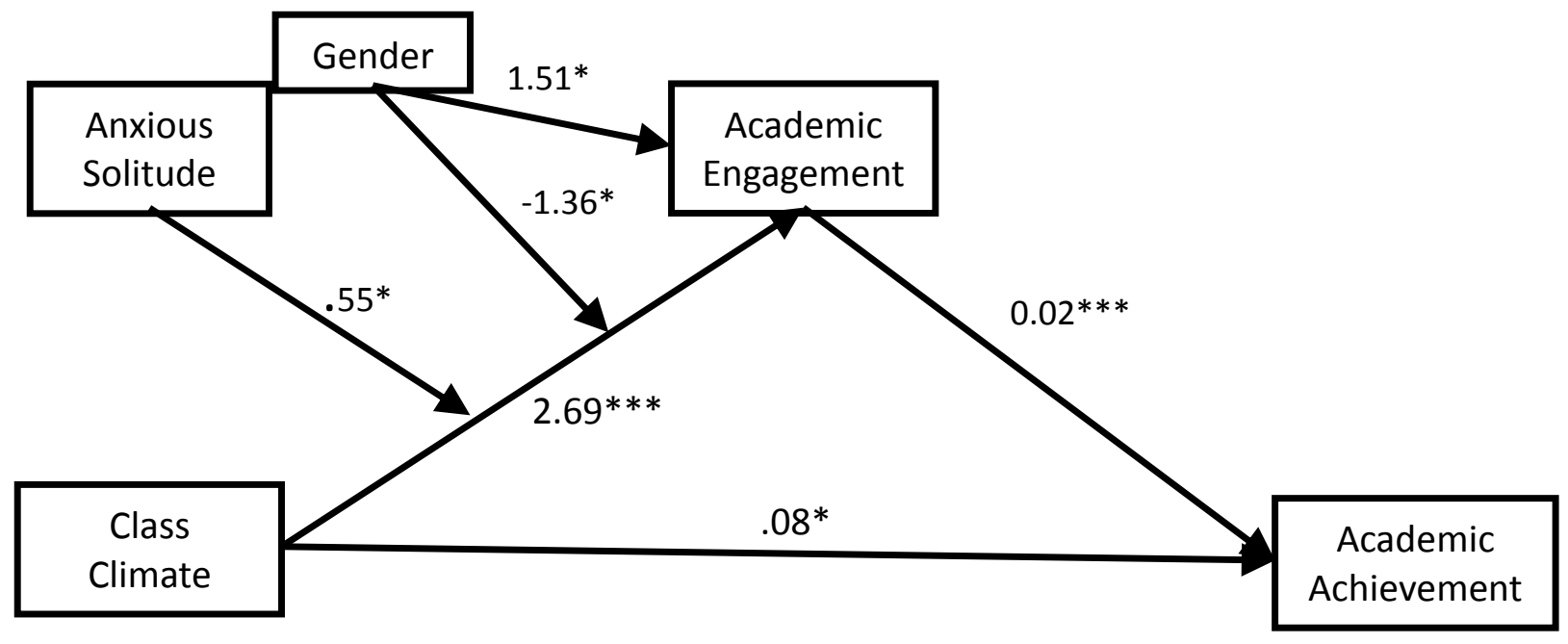

Figure 6. Illustration of the significant pathways displayed in Table 11. (Class Climate \& Academic Adjustment in Grade 3)

$* \mathrm{p}<.05 * * \mathrm{p}<.01 * * * \mathrm{p}<.001$ 


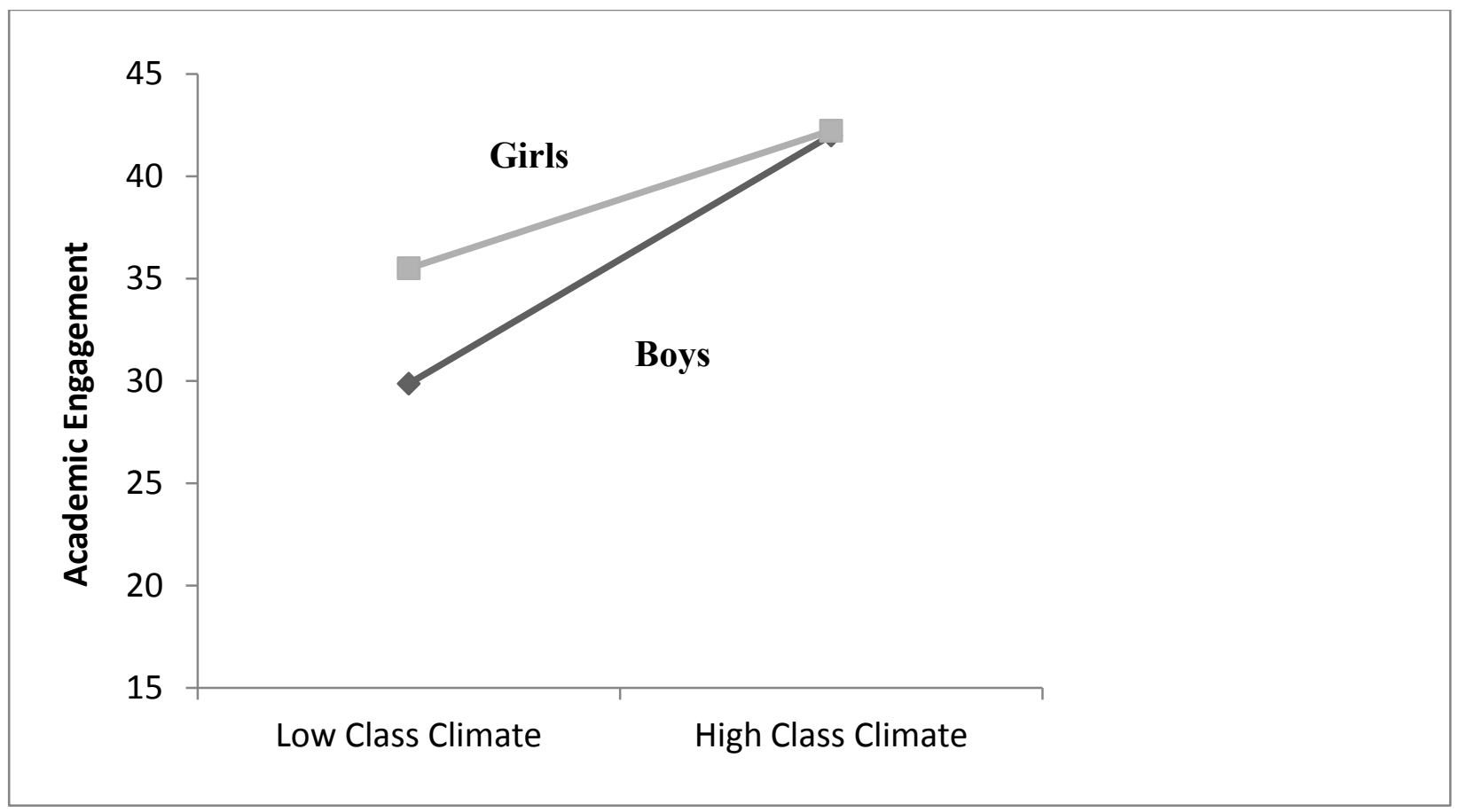

Figure 7. Simple slopes of gender as a moderator on the relation between grade 3 class climate and grade 3 academic engagement. 


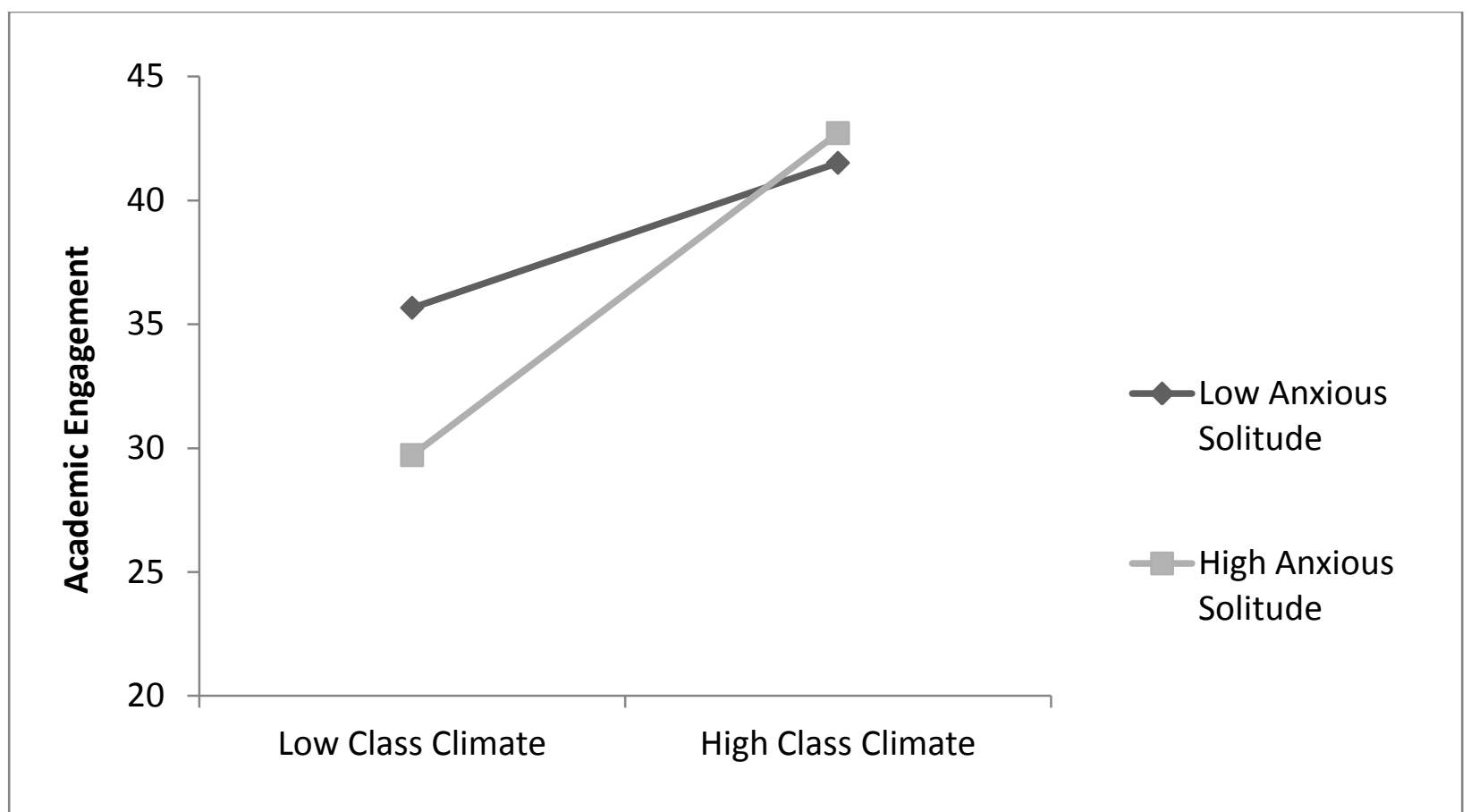

Figure 8. Simple slopes of grade 3 anxious solitude as a moderator of the relation between grade 3 class climate and grade 3 academic engagement. 


\section{Table 13}

Unstandardized Coefficients of the Moderated-Mediation Regression of Classroom Relations and Academic Adjustment in Grade 3

\begin{tabular}{|c|c|c|}
\hline \multirow[t]{2}{*}{ Predictor } & \multicolumn{2}{|c|}{ Outcome } \\
\hline & $\begin{array}{l}\text { Engagement } \\
8)=11.26, p<.001 \\
R^{2}=0.10\end{array}$ & $\begin{array}{c}\text { Achievement } \\
F(7,617)=17.92, p<.001 \\
R^{2}=0.17\end{array}$ \\
\hline Classroom Relationships & $2.47 * * *$ & $.21 * * *$ \\
\hline SES & .14 & $.07 * * *$ \\
\hline Gender & .16 & -.16 \\
\hline Anxious Solitude & .10 & -.13 \\
\hline Class Relations $\times$ Gender & .83 & -.01 \\
\hline Class Relations $\times$ Anxious Solitude & .52 & -.01 \\
\hline Class Relations (indirect) & - & .03 \\
\hline Engagement & - & $.01 * * *$ \\
\hline Engagement $\times$ Gender & - & .003 \\
\hline Engagement $\times$ Anxious Solitude & - & .002 \\
\hline
\end{tabular}

$* \mathrm{p}<.05 \quad * * \mathrm{p}<.01 \quad * * * \mathrm{p}<.001$ 


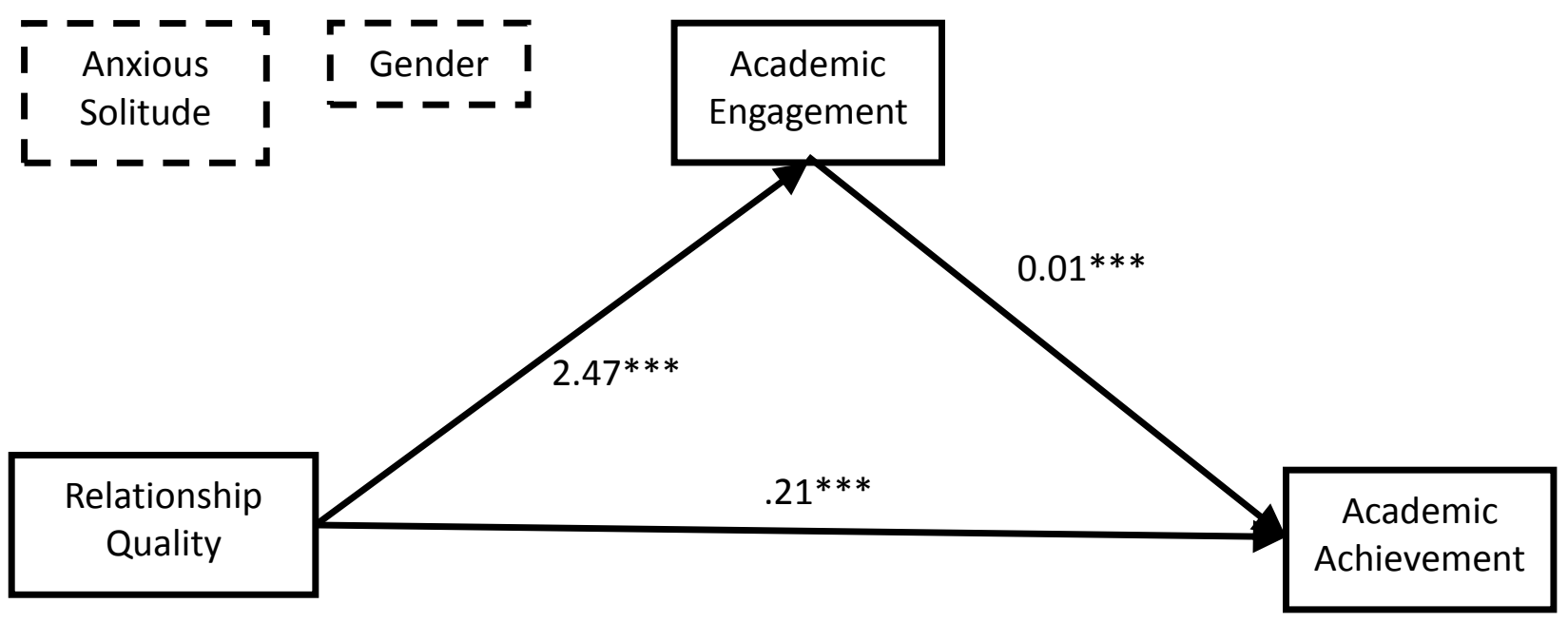

Figure 9. Illustration of the significant pathways display in Table 12. Moderatedmediation Regression of Classroom Relationships \& Academic Adjustment in Grade 3. $* \mathrm{p}<.05 * * \mathrm{p}<.01 * * * \mathrm{p}<.001$ 
illustrated in Figure 9. Academic engagement was found to mediate the relation between classroom relationships and achievement $\left(\mathrm{CI}_{95}=.0152-.0565\right)$. No significant interaction terms were found. Classroom relationships were found to be a significant predictor of engagement. Classroom relationships and academic engagement were significant predictors of achievement. Anxious solitude was not a significant predictor of either engagement or achievement in this model. Overall, there was a lack of significant findings for this model.

Summary of analyses of grade 3 (time 2) variables. In grade 3 , the interassociations among classroom experiences (climate and relationships) and academic adjustment (engagement and achievement) were significant and in the expected direction. In addition, anxious solitude significantly moderated the relations between classroom experiences and academic engagement. In particular, the positive relation between classroom climate and academic engagement was strengthened at high levels of anxious solitude. Gender also moderated the relation between class climate and academic engagement. Conversely, neither gender nor anxious solitude moderated the relation between classroom relationships and academic engagement.

\section{Longitudinal Analyses of Grade 1 and Grade 3 (Time 1 and Time 2) Variables}

After examining concurrent effects in grades 1 and 3, a series of longitudinal analyses were conducted. The primary goal was to examine the longitudinal prediction of grade 3 academic achievement from grade 1 classroom experiences and anxious solitude.

Correlations. Partial correlations between Time 1 and Time 2 variables (after controlling for SES) are presented in Table 14. Overall, constructs displayed moderate 
Table 14

Partial Correlations (controlling for Socioeconomic Status) of Study Variables Employed in Longitudinal Analyses (Time 1 and Time 2)

\begin{tabular}{|c|c|c|c|c|c|c|}
\hline & \multicolumn{6}{|c|}{ Grade 3} \\
\hline & 1 & 2 & 3 & 4 & 5 & 6 \\
\hline \multicolumn{7}{|l|}{ Grade 1} \\
\hline 1. Anxious Solitude & $.20 * * *$ & -.05 & -.02 & $-.12 * *$ & -.03 & $-.09 *$ \\
\hline 2. Engagement & -.04 & $.22 * * *$ & .02 & $.18 * * *$ & $.15 * * *$ & $.18 * * *$ \\
\hline 3 Class Climate & .02 & .06 & $.13 * *$ & .06 & .07 & .05 \\
\hline 4. Teacher Relations & $-.10^{*}$ & $.12 * *$ & .06 & $.40 * * *$ & $.25 * * *$ & $.17 * * *$ \\
\hline 5. Peer Relations & $-.10^{*}$ & $.15 * * *$ & .07 & $.28 * * *$ & $.22 * * *$ & $.19 * * *$ \\
\hline 6. Achievement & $-.09 *$ & $.18 * * *$ & .07 & $.13 * *$ & $.17 * * *$ & $.55^{* * *}$ \\
\hline
\end{tabular}

$* \mathrm{p}<.05 \quad * * \mathrm{p}<.01 \quad * * * \mathrm{p}<.001$

Bolded values $=$ stability coefficients 
stability over time. In addition, associations among variables were consistent with theoretical expectations. For example, academic engagement, achievement, teacher-child relationships, and peer relations were all significantly inter-associated with each other over time. Although grade 1 anxious solitude was significantly and negatively associated with grade 3 teacher-child relationship and grade 3 achievement, it did not significantly correlate with grade 3 academic engagement or grade 3 peer relations.

Only one significant gender difference in these associations was found. The stability of anxious solitude from grade 1 to grade 3 was significantly stronger for girls $(r=.27, p<.001)$ than for boys $(r=.11, p=.06 ; z=-2.14, p<.05)$.

Moderated-mediation models. Next, the longitudinal associations of time 1 and time 2 (grade 1 and grade 3 ) were assessed with a series of moderated-mediation models. Two models were calculated to examine aspects of the mediating role of academic engagement in the links between classroom experiences and academic achievement. For each model, (a) SES, grade 1 academic engagement, and grade 1 achievement were included as control variables; (b) one component of classroom experiences (grade 1 classroom climate or grade 1 classroom relationships) was included as the predictor variable; (c) grade 3 academic engagement was entered as a mediator; (d) both grade 1 anxious solitude and child gender were included as moderator variables (i.e., moderators of the mediated effect); and (e) grade 3 academic achievement was included as the outcome variable.

Thus, for each model, the overall mediating effect of grade 3 academic engagement in the relation between grade 1 classroom experiences and grade 3 achievement was assessed, along with the moderating role of grade 1 anxious solitude 
and gender on the relations between (a) grade 1 class experiences and grade 3 academic engagement, (b) grade 1 class experiences and grade 3 achievement, and (c) grade 3 academic engagement and grade 3 achievement. Each model was tested using SPSS and the PROCESS macro designed by Hayes (2012). Please see page 80 for an overview of this statistical macro and the output provided by this analysis.

Classroom climate. The first longitudinal moderated-mediation model examined grade 1 classroom climate as a predictor. Data on $N=637$ children were available for this model. A full list of results is presented in Table 15. Overall, this model displayed a lack of significant results. Grade 3 academic engagement did not mediate the relation between grade 1 classroom climate and grade 3 achievement $\left(\mathrm{CI}_{95}=-.0070-.0082\right)$. In addition, there were no significant interaction terms, and, aside from the control variables of grade 1 academic engagement and achievement, no significant predictors of grade 3 academic engagement or grade 3 achievement.

Classroom relationships. The second longitudinal moderated-mediation model examined grade 1 classroom relationships as a predictor. Data on $N=633$ children were available for this model. Full results are presented in Table 16. Like the previous one, this model displayed a lack of significant results. Grade 3 academic engagement did not mediate the relation between grade 1 classroom relationships and grade 3 achievement $\left(\mathrm{CI}_{95}=-.0002-.0179\right)$. In addition, there were no significant interaction terms, and no significant predictors of grade 3 academic engagement or achievement, aside from the control variables of grade 1 academic engagement and achievement.

Moderated regression of change in engagement. The goal of these final analyses was to assess predictors of change in academic engagement from grade 1 (Time 


\section{Table 15}

Unstandardized Coefficients of the Longitudinal Moderated-Mediation Regression of Class Climate and Academic Adjustment

\begin{tabular}{lcc}
\hline Predictor & \multicolumn{2}{c}{ Outcome } \\
\cline { 2 - 3 } & \multicolumn{1}{c}{ Grade 3 Engagement } & Grade 3 Achievement \\
& $F(8,628)=6.67, p<.001$ & $F(9,627)=41.29, p<.001$ \\
& $R^{2}=0.08$ & $R^{2}=0.37$ \\
\hline Gr 1 Engagement & $.32^{* * *}$ & $.01^{*}$ \\
Gr 1 Achievement & $1.55^{* * *}$ & $.49^{* * *}$ \\
Gr 1 Class Climate & .03 & -.01 \\
SES & .17 & $.06^{* * *}$ \\
Gender & .59 & -.03 \\
Gr 1 Anxious Solitude & -.37 & -.11 \\
Gr 1 Class Climate $\times$ Gender & .53 & .06 \\
Gr 1 Class Climate $\times$ Gr 1 Anxious Solitude & .04 & .03 \\
Gr 1 Class Climate (indirect) & - & .03 \\
Gr 3 Engagement & $-01^{* *}$ \\
Gr 3 Engagement $\times$ Gender & - & .001 \\
Gr 3 Engagement $\times$ Gr 1 Anxious Solitude & - & .003 \\
\end{tabular}

$* \mathrm{p}<.05 \quad * * \mathrm{p}<.01 \quad * * * \mathrm{p}<.001$ 
Table 16

Unstandardized Coefficients of the Longitudinal Moderated-Mediation Regression of Classroom Relationships and Academic Adjustment

\begin{tabular}{|c|c|c|}
\hline \multirow[t]{2}{*}{ Predictor } & \multicolumn{2}{|c|}{ Outcome } \\
\hline & $\begin{array}{c}\text { Grade } 3 \text { Engagement } \\
F(8,624)=7.04, p<.001 \\
R^{2}=0.08\end{array}$ & $\begin{array}{c}\text { Grade } 3 \text { Achievement } \\
F(9,623)=41.31, p<.001 \\
R^{2}=0.37\end{array}$ \\
\hline Gr 1 Engagement & $.31 * * *$ & $.01 *$ \\
\hline Gr 1 Achievement & $1.29 * *$ & $.48 * * *$ \\
\hline Gr 1 Class Relationships & .61 & .02 \\
\hline SES & .15 & $.06 * * *$ \\
\hline Gender & .51 & -.03 \\
\hline Gr 1 Anxious Solitude & -.21 & -.11 \\
\hline Gr 1 Class Relations $\times$ Gender & .90 & -.10 \\
\hline Gr 1 Class Relations $\times$ Gr 1 Ar & nxious Solitude .04 & .04 \\
\hline Gr 1 Class Relations (indirect) & - & .004 \\
\hline Gr 3 Engagement & - & $.01 * *$ \\
\hline Gr 3 Engagement $\times$ Gender & - & .001 \\
\hline Gr 3 Engagement $\times$ Gr 1 Anxic & ious Solitude & .002 \\
\hline
\end{tabular}

$* \mathrm{p}<.05 \quad * * \mathrm{p}<.01 * * * \quad \mathrm{p}<.001$ 
1) to grade 3 (Time 2). First, adjusted residual scores were calculated. This was done by constructing a linear regression model with grade 1 academic engagement as the predictor and grade 3 academic engagement as the outcome and saving the predicted scores. This method was employed instead of using the absolute difference scores over time between grade 1 and grade 3 to reduce error (Glymour, Weuve, Berkman, Kawachi, \& Robins, 2005). The change in engagement was then calculated by subtracting grade 3 academic engagement from the adjusted residual scores. Scores were available for $N=712$ participants. Change scores ranged from -26.37 to $20.26(M=.001, S D=8.41)$. The distribution was found to be normal with a skewness $=-.41$ a kurtosis of -..15. Hierarchical regression analyses were then conducted to examine predictors of change in engagement. At step 1, SES was entered as a control variable. At step 2, main effects variables (gender, grade 1 anxious solitude, grade 1 classroom climate, grade 1 teacher-child relationship, and grade 1 peer relations) were entered. At step 3, conceptually relevant two-way interaction terms (i.e., those including either gender or anxious solitude) were entered. At step 4, conceptually relevant three-way interaction terms (Gender $\times$ Anxious Solitude $\times$ Classroom Climate; Gender $\times$ Anxious Solitude $\times$ Teacher-Child Relationships; Gender $\times$ Anxious Solitude $\times$ Peer Relations) were entered.

Results from the model are summarized in Table 17. A sample of $N=660$ was included in this analysis. Grade 1 anxious solitude was found to significantly predict change in academic engagement from grade 1 to grade 3 . This negative association was the only significant main effect. However, this main effect was superseded by a significant two-way interaction between anxious solitude and gender. As displayed in Figure 10, results from the simple slopes analysis indicated that the negative relation 
Table 17

Predictors of Change in Engagement from Grade 1 to Grade 3

Predictor Standardized Coefficient

Gr 1 Anxious Solitude

$-3.95 * *$

Gr 1 Class Climate .14

Gr 1 Teacher Relations

1.11

Gr 1 Peers Relations

$-1.81$

Gender

Gr 1 Anxious Solitude $\times$ Gender

Gr 1 Anxious Solitude $\times$ Gr 1 Class Climate

$-.62$

Gr 1 Anxious Solitude $\times$ Gr 1 Teacher Relations

$-.70$

Gr 1 Anxious Solitude $\times$ Gr 1 Peer Relations

$-.95$

Gender $\times$ Gr 1 Class Climate

$-.04$

Gender $\times$ Gr 1 Teacher Relations

$-.39$

Gender $\times$ Gr 1 Peer Relations

$1.60 *$

Gr 1 Anxious Solitude $\times$ Gender $\times$ Gr 1 Class Climate .39

Gr 1 Anxious Solitude $\times$ Gender $\times$ Gr 1 Teacher Relations

.59

Gr 1 Anxious Solitude $\times$ Gender $\times$ Gr 1 Peer Relations

.46 


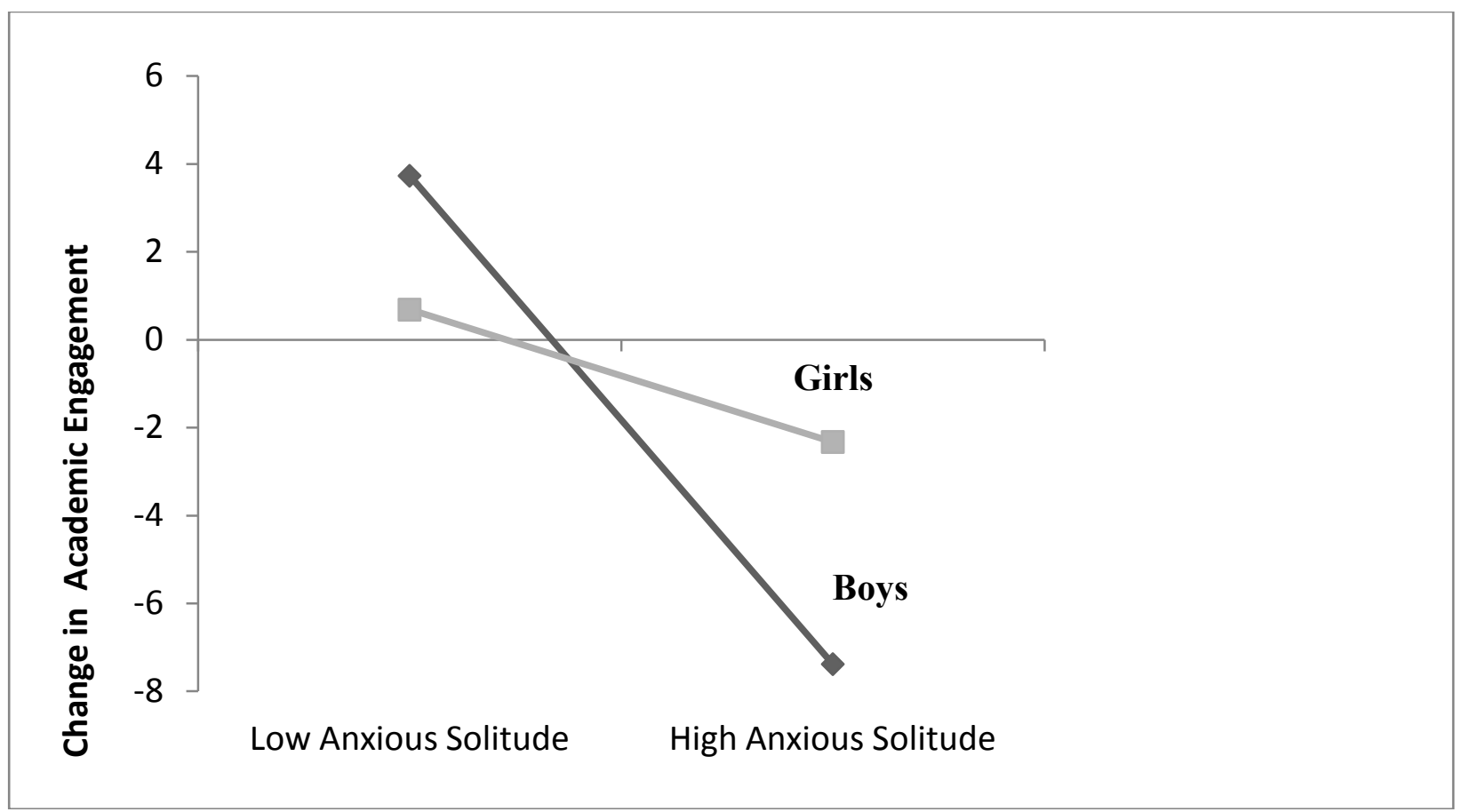

Figure 10. Simple slopes of gender as a moderator on the relation between grade 1 anxious solitude and change in academic engagement over time. 
between anxious solitude and change in engagement over time was significantly stronger among boys $(\beta=-6.03(1.75), p<.001)$ than girls $(\beta=-1.72(0.05), p<.001)$. This indicates that anxious solitary boys will display a greater decrease in engagement than anxious solitary girls.

The two-way interaction term of gender and peer relations was also found to be significant. Results from the simple slopes analysis (see Figure 11) indicated that for girls, the association between grade 1 peer relations and the change in engagement over time was nonsignificant $(\beta=0.17(0.45), p=.72)$. For boys, the association between grade 1 peer relations and the change in engagement over time was also nonsignificant. However, the association was negative for boys and of greater magnitude than it was for girls $(\beta=-2.74(1.66), p=.10)$. This indicates that the relation between peer relations and change in engagement over time is stronger and more negative for boys as compared to girls. No significant three-way interactions were found.

Summary of longitudinal analyses. Despite a lack of significant findings with respect to the longitudinal moderated-mediation models, examining the change in engagement over time led to several significant findings. In particular, gender moderated the relation between peer relations and change in engagement, as well as the relation between anxious solitude and change in engagement. Anxious solitude was a significant predictor of change in engagement from grade 1 to grade 3. 
Academic Engagement and Anxious Solitude 107

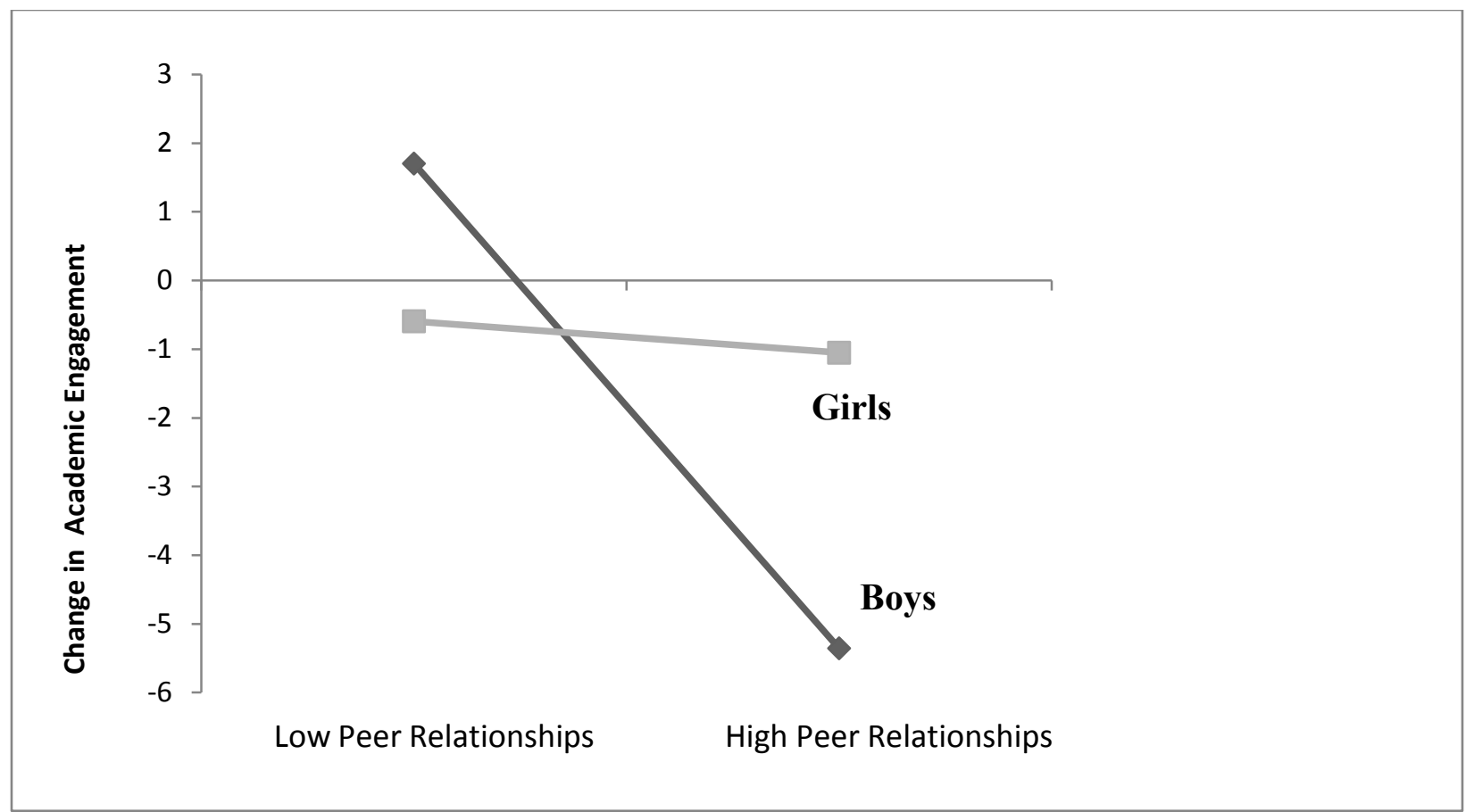

Figure 11. Simple slopes of gender as a moderator on the relation between grade 1 peer relationships and change in academic engagement over time. 


\section{Discussion}

The central aim of this dissertation research was to examine a theoretical model of the development and implications of academic engagement in childhood. This included an examination of both short- and longer-term associates of academic engagement in childhood. Subcomponents of this work included (a) examining child and contextual predictors of academic engagement; (b) assessing the mediating effect of academic engagement in the relation between classroom experiences and academic achievement; (c) exploring the moderating roles of gender and anxious solitude on the links between classroom experiences, academic engagement, and achievement; and (d) examining the longitudinal effects of child and contextual factors on the development of academic engagement from grades 1 to 3 .

Overall, the results were mixed. Support was found for some of the hypotheses. For instance, results indicated that positive classroom experiences (i.e., positive classroom climate, teacher-child relationships, and peer relations) were positively linked to concurrent measures of academic adjustment (i.e., engagement and achievement). In addition, a significant moderating effect of anxious solitude on the links between class climate and academic was found in grade 3 . This indicated that the relation between classroom climate and academic engagement was strongest at high levels of anxious solitude. Therefore, academic outcomes of anxious solitary children may be more susceptible to the learning environment as compared to nonanxious children.

However, limited support was found for other hypotheses. For example, notable nonsignificant findings included the lack of predicted linear associations between anxious solitude and academic engagement, the lack of a moderating effect of child factors on the 
relation between classroom relationships and academic engagement, and the lack of significant longitudinal moderated-mediation models. Finally, some significant findings within the current research were unexpected. These include the significant gender difference on the long-term stability of academic engagement.

A detailed discussion of these findings is presented in the following sections. First, the conceptualization of academic engagement, its stability and association with other educational factors (including classroom experiences) is presented. Second, the findings with regard to anxious solitude, its linear associations, stability, and moderations are discussed. Third, an overview of the gender effects as they relate to engagement and to anxious solitude is presented. After this discussion, an overview of the limitations of the current research, ideas for future research, and final conclusions are presented.

\section{Importance of Academic Engagement in Children's School Adjustment}

Academic engagement was found to be stable from grade 1 to grade 3 . This evidence of the stability of academic engagement supports previous findings (Wang et al., 2011). The current study also reported a slight decline in academic engagement from grade 1 to grade 3 . Again, this is consistent with previous findings that academic engagement tends to decrease with age (Li \& Lerner, 2011). Overall, this indicates that although there is a slight decrease in engagement, it is still a fairly stable construct.

The current study found support for academic engagement as a central component and marker of educational well-being (Fredricks et al., 2004). This was evidenced by the linear associations between academic engagement and other educational components such as academic achievement, teacher-child relationships, and peer relations. Consistent with previous studies (Hoglund, 2007; Ladd et al., 1999; Roorda et al., 2011), the present 
results indicate that both teacher-child and peer relationships are concurrently associated with academic engagement in grades 1 and 3. Moreover, teacher-child and peer relationships in grade 1 significantly predicted engagement two years later. Thus, children who formed more positive relationships with teachers (Dotterer \& Lowe, 2011) and peers (Buhs et al., 2006) were more likely to participate in the classroom two years later. In addition, earlier school relationships were found to predict later school outcomes, despite the changing composition of the classroom from year to year. This may indicate that children who form positive relationships in early elementary will continue to be engaged and to achieve over time.

Although academic engagement was longitudinally associated with classroom relationships, there were a lack of significant associations between grade 1 classroom relationships and grade 3 academic engagement after grade 1 academic engagement was taken into account. After accounting for earlier engagement and achievement, early classroom relationships were not associated with later engagement and achievement. Also, after early academic outcomes were taken into account, no significant mediation or moderation effects were found. This indicates that although classroom relationships are connected to concurrent and later engagement, once earlier engagement is accounted for, classroom relationships are no longer significant predictors of engagement. This may indicate that classroom relationships influence early engagement and they may be associated with later engagement, but early classroom relationships do not influence later engagement over and above the concurrent influence on early engagement.

For instance, having a positive relationship with a teacher in grade 1 may influence a particular child to engage in the classroom in grade 1. This relationship in 
grade 1 does not predict engagement in grade 3 over and above the predictive ability of engagement in grade 1 . Therefore, engagement in grade 1 may act as an underlying mechanism that explains the linear association between grade 1 classroom relationships and grade 3 academic engagement.

In addition, classroom climate was found to be positively associated with concurrent academic engagement. This supports previous findings indicating that a warm, supportive, and organized classroom engages children and encourages them to stay on task and participate in class activities (Dotterer \& Lowe, 2011; Ecceles et al, 1998; Patrick et al., 2007; Ryan \& Patrick, 2001). Schools that offer a welcoming environment may help students to feel more comfortable in the classroom so that they can participate in classroom activities (Wang \& Holcolme, 2010). In addition, a well-organized and well-structured classroom allows children to understand what is expected from them so that they may be more confident in taking risks and volunteering in school (Wang \& Holcolme, 2010).

Therefore, educators and researchers should be aware of how a child's learning and engagement can be influenced by the larger educational climate. Possible implications of this finding could include regular assessments of elementary classroom climates, teacher professional development workshops to improve class climate, and regular "check ins" with educators to discuss tactics in improving the quality of the learning environment of their school.

These connections between classroom relationships and classroom climate with academic engagement suggest that children who have more positive experiences at school are more likely to behaviourally engage with academic activities and learning 
opportunities. If academic engagement is indeed influenced by contextual factors in the school environment, school administrators and educators who want to improve engagement scores among their students should also consider interventions that directly target the classroom context. For example, teacher-training initiatives could inform teachers on how to improve their organizational and student-management skills. Studentfocused interventions such as positive participation programs and anti-bullying programs could be used to increase peer support and encouragement in the classroom. Finally, administrative changes such as providing educational assistants and allowing for team teaching (or co-teaching) could improve the quality of instruction and enhance the implementation of lesson plans in the classroom.

Academic engagement was also found to be significantly associated with children's academic achievement, both concurrently (in grades 1 and 3) and longitudinally (from grade 1 to 3 ). As previous studies have indicated, children who engage and participate more in classroom activities are more likely to achieve, particularly on teacher-rated measures of academic achievement (K. Hughes \& Coplan, 2010; Li \& Lerner, 2012). Children who participate more in classroom activities may be given more opportunities to practice and develop academic skills (Wang \& Eccles, 2012). In addition, children who are more likely to participate in school may have a better understanding of the lesson plans and the intellectual concepts being presented in class. This deeper understanding of class content can help children perform better on tests and other methods of evaluation.

Children who are academically engaged in early elementary may be more likely to achieve in later years. This supports previous findings that have linked early 
engagement to later achievement and school completion (Archambault et al., 2009). This may indicate that children who participate in classroom activities and stay focused on learning tasks are more likely to continue to succeed in school through the elementary years. In addition, this may suggest that early engagement is an important step on the path to long-term academic success. Therefore, understanding how to increase student engagement in the early years of elementary may be important for understanding how to improve academic success for children of all ages.

Academic engagement mediated the concurrent relation between classroom experiences and academic achievement. This is consistent with previous studies that have examined indirect pathways that may link classroom experiences to engagement and achievement (Buhs, 2005; Ladd et al., 1999; Wang et al., 2011). In addition to classroom relationships, the current research is the first to explicitly examine the mediating role of academic engagement in the relation between classroom climate and academic achievement. Although the current study was correlational in design, mediated models can suggest a possible causal pathway. One possible interpretation of this significant mediation is that children who have more positive experiences at school may be more likely to participate and engage in school. This increased level of participation may in turn give children extra opportunities to practice skills or gain knowledge of course content, which can in turn increase levels of academic achievement.

The implication of these findings is that academic engagement may be a crucial link between school environment and achievement. Therefore, improving classroom experiences may be a catalyst for improving academic engagement and achievement. There are many aspects of the classroom environment that could be enhanced: among 
others, creating more classroom support and encouragement, organizing classrooms better, coaching teachers on how to improve relationships with students, and facilitating students' social skills to improve peer relationships. Through modifying such contextual factors, educators may be successful in increasing levels of attention, participation, and on-task behaviour for their students (Decker et al., 2007; Dotterer \& Lowe, 2011). Increased engagement may in turn lead to improved understanding of class concepts, academic skills sets, and test scores. Therefore, engagement should be considered as an underlying mechanism that contributes to achievement. Indeed, recent intervention studies have begun to incorporate academic engagement as a key element of improve student academic achievement and well-being (Decker et al., 2007; Dotterer \& Lowe, 2011).

Despite concurrent associations between classroom climate and academic engagement, grade 1 classroom climate was not associated with grade 3 academic engagement. This may suggest that the influence of classroom climate on academic engagement is limited to the current school year. Given that classroom climate is a classroom-level variable as opposed to a child-level variable, it is not solely determined by the behaviours of a particular study child. Instead, all members of a classroom contribute to climate.

Overall, results concerning academic engagement were as anticipated. Academic engagement was found to be an outcome of classroom experiences and a predictor of academic success. As such, academic engagement could be considered a critical element of academic well-being. Indeed, educational interventions have previously established that a modification in classroom experiences can lead to a change in engagement (Decker 
et al., 2007; Dotterer \& Lowe, 2011). The current research adds to the extant literature by suggesting that a modification in classroom experiences could increase academic engagement, which in turn increases academic achievement.

However, SES was associated with many components of classroom experiences and academic adjustment. Indeed, children from lower socioeconomic backgrounds were found to have classrooms characterized by poorer classroom climate. This negative learning environment may in turn impact the quality of classroom relationships, levels of student engagement, and achievement. Therefore, children from lower socioeconomic backgrounds may be at risk for poor academic outcomes partly due to the quality of their learning environment. This is consistent with previous studies that have found a link between SES and educational resources and outcomes (Elias \& Haynes, 2008). However, it should be noted that in some instances, SES has had a reverse effect on educational outcomes, with children from lower SES backgrounds displaying better coping skills as compared to children from middle or upper SES backgrounds (Englund, 2009).

Finally, it is important to note that intervention studies may not work equally well for all students, and that the role of individual child factors needs to be considered. For instance, individual factors such as anxious solitude and gender may impact how children respond to given classroom environments. As such, an overview of the results with regards to gender and anxious solitude will now be presented.

\section{Gender and School Adjustment}

Results from the current study indicate a number of gender effects. Compared to boys, girls were more engaged and had more positive relationships with teachers and peers. These results are consistent with previous findings that girls are more engaged in 
school and develop more positive relationships with teachers (Fredricks et al., 2004;

Hamre \& Pianta, 2001; Roorda et al., 2011). Many theoretical explanations of this gender effect are possible. Girls may have lower levels of surgency or hyperactivity than boys (Else-Quest, Hyde, Goldsmith, \& Van Hulle, 2006) and therefore may be more capable of staying on task and forming positive relationships in the classroom. Another interpretation is that girls are more likely than boys to be socialized to value relationships, cooperation, sitting quietly to complete work, and to conform to expectations in the classroom (Schmitt et al., 2008). By comparison, boys are more likely to be socialized to value activity and rough-and-tumble play, and therefore may have more difficultly staying focused in school and forming positive relationships (Block, 1983; Lowe, 1989).

In addition to main gender effects, the concurrent association between peer relationships and academic engagement in grade 3 differed as a function of gender: The positive relation between peer relations and engagement was stronger for girls. This may suggest that girls' engagement is more influenced by the quality of their peer relationships in the classroom. This again would support the idea that girls are socialized to value relationships (Schmitt et al., 2008). Positive peer relationships in the classroom may be particularly beneficial for girls' engagement as compared to boys. Negative peer relationships, however, may be especially detrimental to girls' engagement.

Girls in grade 1 had classrooms characterized by more positive classroom climate compared to boys. Interpretation of this finding is problematic due to limitations of secondary data analyses. Although NICHD documentation includes copies of all manuals and implementation guides, there is some information that is not made available to 
secondary researchers. Class sizes are available in the NICHD data set, but it is unknown what proportion of students attended single-gender or mixed-gender classrooms.

Therefore, it is possible that boys' classroom climate was more negative because boys in the study sample attended all-male classrooms that differed from all-female or mixedgender classrooms. Furthermore, it is important to note that this study did not use a nested design, as only one study child was included from each classroom.

Gender moderated relations between classroom climate and academic engagement. At both grade 1 and 3, the association between classroom climate and academic engagement was stronger for boys than girls. Although it was predicted that positive classroom climate would be associated with higher levels of engagement for all children, it was boys who especially benefited. Therefore, negative classrooms, characterized by hostility, disorganization, or a lack of warmth, may lead to disengagement and poor participation for all students, but especially for boys. In comparison, girls were more resilient across variations in classroom climate. This finding supports the differential susceptibility hypothesis (Belsky, 1997), which predicted that boys would be more influenced by the quality of the learning environment than girls.

Gender was also found to moderate the relation between grade 1 peer relationships and change in academic engagement over time. The negative association between grade 1 peer relationships and change in engagement was significantly stronger for boys than for girls. Thus, being accepted by peers in grade 1 is more strongly predictive of a decline in academic engagement for boys than girls. One possible explanation of this finding is that boys are socialized to devalue school (Wang \& Eccles, 
2012): Boys who are deemed "cool" or popular with their peers may be actively discouraged from engaging in school.

Taken together, the findings from this research suggest that boys face numerous educational challenges as compared to girls. Boys are at a greater risk in school for starting behind and for falling behind over time. Although girls' engagement may be more influenced by relationship quality in the classroom, boys' academic engagement may be more influenced by the classroom climate itself. In particular, boys may suffer more when placed in classrooms that are disorganized or dysfunctional.

\section{Implications of Anxious Solitude for School Adjustment}

The current study predicted that anxious solitude would be a risk factor for academic outcomes. In particular, it was hypothesized that anxious solitude would be negatively associated with academic engagement. Furthermore, it was predicted that anxious solitude would moderate the concurrent associations between classroom experiences (i.e., classroom climate, teacher-child relationships, peer relations) and academic engagement in both grade 1 and grade 3 . Finally, it was hypothesized that anxious solitude in early elementary would predict a decrease in academic engagement from grade 1 to grade 3 .

The distribution of anxious solitude was highly positively skewed. This indicates that the majority of participants were relatively low in anxious solitude. Fewer participants scored moderately on the scale, and a minority scored high. This skewed distribution is consistent with previous research on anxious solitary, shy, and socially withdrawn children (Rubin et al., 2009). Indeed, previous findings suggest that only a 
minority of students are characterized by strong feelings of shy-anxious and withdrawn behaviours (Coplan et al., 2004).

Similar to aggression research, research on internalizing difficulties indicates that only a small number of children are strongly affected. Neither externalizing nor internalizing difficulties are normally distributed (Valeski \& Stipek, 2001). Teachers and other educators should be aware that a small number of students in any given classroom may be experiencing feelings of anxious solitude to a much larger degree than their peers. Anxious solitude was found to be modestly stable from grade 1 to grade 3 , but it did increase over time. Thus, on average, teachers rated children as more anxious in grade 3 than in grade 1 . This supports previous findings that feelings of anxiety and worry increase with age during childhood (Rubin et al., 2009) as do diagnoses of clinical anxiety (Rapee et al., 2005). In addition, studies have shown that children begin to make social comparisons at approximately age 5 and that these social comparisons may lead to a decline in self-esteem and an increase in anxiety (Baumeister, 1997). Therefore, in grade 1 , the social demands of the classroom may not be as anxiety provoking to the extent they are in grade 3 . Therefore, displays of anxious solitary behaviour may increase from grade 1 to 3 .

Anxious solitude was associated with a number of indices of negative school adjustment. For example, anxious solitude was concurrently related to more negative teacher-child relationships and peer relationships in both grade 1 and grade 3 . This supports previous findings that anxious withdrawal can be detrimental to forming positive, supportive, and beneficial relationships (Rudasill \& Rimm-Kaufmann, 2009). That is, anxious solitary children may lack the social skills necessary to form positive 
relationships in school. As anxious solitude is characterized by feelings of nervousness and hesitance towards social situations (Rubin et al., 2009), these children may feel uncomfortable approaching other members of their class and may struggle to form strong connections with teacher or peers. This does not bode well for anxious children in school, as many researchers have argued that classroom relationships are critical indicators of socioemotional development and adjustment in childhood (Coplan \& Arbeau, 2008; Curby et al, 2011).

Anxious solitude was negatively associated with academic achievement at both grade 1 and grade 3 . This indicates that children who are high in anxious solitude are at a greater risk for academic problems. This is consistent with research that reports a link between anxious solitude (and other internalizing difficulties) with academic difficulties (Gazelle, 2006; Li \& Lerner, 2011). For instance, shy and anxious children receive more negative teacher ratings of academic ability (Rudasill et al., 2006).

A possible interpretation of this finding is that the demands of the school environment elicit feelings of nervousness in anxious solitary children, which prevent them from concentrating on academic tasks. Therefore feelings of anxiety are detrimental to school performance (Coplan \& Arbeau, 2008; Coplan \& Evans, 2009).

Alternatively, anxious solitary children may possess academic skills but do not readily display them in school. Shy and anxious children may have the required knowledge and skills, but are unable to perform to their full potential formal evaluations. As anxious solitary children tend to feel especially anxious during formal evaluations, it is possible that test anxiety prevents them from doing their best (Crozier \& Hostettler, 2003). Further studies are needed to distinguish between the competence and 
performance explanations of why anxious solitary children achievement less academically.

Taken together these significant linear associations suggest that anxious solitary children do not thrive socially (in terms of relationship quality) or academically (in terms of achievement) in school.

Interestingly, no significant linear associations were found between anxious solitude and academic engagement either concurrently or longitudinally. These results are inconsistent with past findings suggesting that anxious solitary children are less likely to be engaged academically (K. Hughes \& Coplan, 2010; K. Hughes et al., 2011). However, the previous studies included samples of older students (grades 4-6). In the current study, the strength of the relation between anxious solitude and academic engagement increased from grade 1 to grade 3. Although the partial correlation (after controlling for SES) only approached significance, the bivariate association in grade 3 was found to be significant and negative. This may indicate that the link between anxious solitude and academic engagement is weak or nonexistent in early elementary, but becomes stronger over time.

One possible explanation for this lack of linear association between anxious solitude and engagement is the grade-related demands of the classroom environment. In early elementary (such as kindergarten and grade 1) class activities may largely consist of explorative play, listening to stories, and designing crafts (California Board of Education, 2007). In comparison, activities in grade 3 tend to focus more on the completion of worksheets, participating in classroom discussions, delivering short presentations, and writing tests (California Board of Education, 2007). Thus the demands of the classroom change over time, becoming more focused on individual, cognitive tasks. To be engaged 
in these different environments could mean different things. In early elementary, engagement may require listening or following along with a group story. In mid-to-late elementary, engagement may require reading out loud to the class or writing answers on the board.

For anxious solitary children, the demands of the classroom in the early elementary school grades may not pose significant obstacles, as it may be easier to participate while remaining silent and following along. However, by the later elementary years, the demands of the classroom environment may include new stressors, such as formal evaluations, class presentations, and being placed at the centre of attention. Such environments may inhibit academic engagement for anxious solitary children (Coplan \& Arbeau, 2008).

In the longitudinal analysis, grade 1 anxious solitude did not predict grade 3 engagement when grade 1 engagement was taken into account. However, grade 1 anxious solitude was a significant predictor of the change in academic engagement from grade 1 to 3: Higher scores in grade 1 anxious solitude were predictive of a greater decrease in academic engagement over time. This indicates that anxious solitude may be a risk factor for disengagement over time. In particular, children who are high in anxious solitude in grade 1 may be most at risk for a decrease in engagement.

Again, this may be due to the grade-specific demands of the classroom. Anxious solitude may not interfere with children's ability to listen or follow along with group activities in grade 1, but as the demands of the classroom increase, children who are anxious solitary may be more likely to withdraw and disengage from the classroom. This 
would explain why early levels of anxious solitude predict long-term but not short-term disengagement.

Contrary to predictions, anxious solitude did not moderate the concurrent relations between class experiences and academic engagement in grade 1 . That is, the positive association between classroom experiences and academic engagement did not vary as a function of anxious solitude; instead, all students benefited from positive classroom experiences to a similar extent. Again, a possible explanation for this finding is that in grade 1 , the low level of academic demands is not particularly daunting for anxious solitary children.

In grade 3, anxious solitude did not moderate the relation between classroom relationships and academic engagement. That is, the positive association between classroom relationships and academic engagement did not vary as a function of anxious solitude. This means positive classroom relationships predicted academic engagement similarly regardless of children's level of anxious solitude. In short, all students benefited from positive classroom relationships.

This may indicate that anxious solitary children are not more susceptible to variation in classroom relationships: Positive classroom relationships do not especially benefit them relative to nonanxious solitary children. Similarly, negative classroom relationships may be detrimental to all students but not especially harmful for anxious solitary children.

In comparison, anxious solitude in grade 3 did moderate the relation between classroom climate and academic engagement: The positive association between classroom climate and academic engagement was stronger at higher levels of anxious 
solitude. Although this is a novel finding in the anxious solitude and engagement literature, it supports the differential susceptibility hypothesis (Belsky, 1997). That is, positive classroom climates benefited all students, but especially anxious solitary ones. A possible explanation is that a warm, supportive, and well-structured classroom environment creates a more comfortable learning experience for anxious solitary children, helping them overcome feelings of anxiety enough that they can participate in class.

However, the differential susceptibility hypothesis asserts that vulnerable individuals are more susceptible to negative influences as well. As such, a negative classroom environment may be detrimental for all students, but particularly detrimental for anxious solitary ones. In a disorganized, hostile, or chaotic classroom, all children may be predicted to disengage, but anxious solitary children may be at the greatest risk for disengagement. In comparison, children who are low in anxious solitude may be more resilient to variation in classroom climate.

Consistent with the differential susceptibility hypothesis, the present findings suggest that different children will have different reactions to the same classroom environment. A resilient child may engage and display similar behaviours regardless of what classroom environment they are placed in. However, a vulnerable child may be more responsive to the contextual features of a classroom, and may alter their behaviours and level of engagement based on the climate of the learning environment.

In terms of educational policy, some children could be expected to thrive even in challenging environments. Such children could be placed in a variety of classrooms with very little variation in their behaviour. In comparison, other children could be expected to 
have very distinct educational outcomes depending upon the type of learning environment they are placed in. As anxious solitary children appear to be especially vulnerable to classroom environment, the type of classroom they are enrolled in may play a key role in their academic success.

Therefore, the present results may be used to inform educational policy and teacher-training practices. For instance, it would be useful to identify children who are more susceptible to changes in the learning environment. Such knowledge could be used to adjust classroom rosters or to improve classroom management strategies.

In summary, these results indicate that anxious solitude is a risk factor for a number of negative academic outcomes, including poorer classroom relationships and poorer achievement. In addition, a significant moderation in grade 3 indicated that anxious solitary children may be more susceptible to variations in classroom environment. Finally, early anxious solitude was found to be a strong predictor of change in academic engagement over time.

Although the main findings concerning engagement, gender, and anxious solitude have been discussed, the current dissertation reported many gender effects of anxious solitude. An overview of the findings with concern to gender and anxious solitude will now be discussed.

Gender and anxious solitude. No gender effects in either grade 1 or grade 3 were found in terms of the average levels of anxious solitude. That is, boys and girls were not found to differ in terms of the level of anxious solitude at either grade 1 or grade 3 . This supports previous findings which indicate that levels of shyness and social 
withdrawal are consistent across genders (Coplan et al., 2007; Rubin \& Coplan, 2010; Rubin et al., 2009).

However, gender effects were found with respect to the stability of anxious solitude from grade 1 to grade 3 . Anxious solitude was more stable for girls than boys. To the best of our knowledge, no previous studies have reported a gender difference in the stability of anxious solitude, shyness, or related concepts (Coplan et al., 2011; Rubin et al., 2009). This novel finding that boys become more anxious solitary through the elementary years may be due to teachers' perceptions of gendered behaviour. That is, for reasons discussed earlier, boys' may feel less comfortable in the classroom as compared to girls (Schmitt et al., 2008). As the demands of the classroom shift throughout the elementary years, boys may be more likely to withdraw both academically and emotionally in the classroom (Roorda et al., 2011). This withdrawal may be perceived by teachers as a display of anxious solitary behaviours.

A gender effect was also found with respect to the linear association between grade 1 anxious solitude and grade 1 teacher-child relationships. The negative relation between anxious solitude and teacher-child relationships was stronger for girls than for boys. Girls who are identified as being high in anxious solitude may be more noticeable in others ways, such as struggling in the classroom or having a negative relationship with the teacher. Alternatively, teachers may perceive quiet, reticent, and anxious girls as having weaker social skills and this perception contributes to a less positive teacher-child relationship.

Finally, gender moderated the negative association between grade 1 anxious solitude and change in academic engagement from grade 1 to grade 3 . The association 
was stronger for boys; that is, grade 1 boys' anxious solitude was a better predictor of their disengagement over time than it was for girls. This suggests that the consequences of anxious solitude are especially serious for boys, and supports previous findings that shy and anxious boys may be exposed to more negative outcomes compared to shy and anxious girls (Coplan et al., 2007; Coplan, Hughes, \& Rowsell, 2009). Therefore, anxious solitary boys may be a particularly high-risk subpopulation for academic disengagement.

Possible implications for educators and school administrators include a teaching training and initiative focused on feelings of anxiety and withdrawal among boys. In particular, early prevention programs directed at improving classroom climate and maintaining academic engagement for anxious solitary boys should be considered.

\section{Limitations and Future Directions}

The aim of this research was to examine the development and implications of academic engagement in childhood. In particular, this study examined the interassociations among classroom experiences and academic adjustment, and the moderating role of socio-demographic and child factors. However, some caveats are in order.

The largest caveat concerns the limitations of working with a secondary or archival data set. Indeed, working with secondary data sets poses many methodological, measurement, and analytical obstacles. In terms of the sample, the NICHD SECCYD contained many exclusion criteria that, for example, eliminated many high-risk participants. As such, the data set reflects a largely typically developing sample that does not experience extraordinary circumstances such as extreme poverty. The sample is not considered to be representative of the U.S. population, but it is considered to be representative of the ten testing locations within the U.S. Therefore, the generalizability 
of this sample is questionable, despite the large number of studies and programs that have used it.

Another important concern of the current study is attrition. The majority of sample attrition occurred between birth and age four, so no academic or school-related variables are available on participants who left the study before grade 1. It is possible that students who remained in the study at grade 1 were more interested and engaged in school than those who left. In addition, there were significant differences between the participants who remained in the study at grade 3 and those who left between grade 1 and grade 3 . Notably, children who left the study between grades 1 and 3 had higher anxious solitude scores and more negative classroom climates than those who stayed. Previous reports have shown that participants who are particularly shy or anxious are more likely to withhold survey responses or to withdraw from research surveys (Rubin \& Coplan, 2010). In addition, schools characterized by poor classroom climate may be located in disadvantaged neighbourhoods. Therefore, lower SES may contribute to selective attrition. This is problematic, as such attrition could potentially explain the different findings between grade 1 and grade 3 .

Aside from concerns with the sample, secondary data analysis also poses problems in terms of measurement selection. For instance, some measures were abbreviated or condensed. This included the teacher-child relationship scale, which assessed only the subscales of closeness and conflict, and omitted the third subscale of dependence. Although conflict and closeness are very strongly negatively correlated, dependence has been shown to be connected to anxious solitude and internalizing problems (Ladd \& Burgess, 1999); it would have been beneficial to the current study. 
Other constructs were assessed in only a limited way or using a limited methodology. For instance, peer relationships were a teacher-rated measure. No child- or peer-rated measures were available in early elementary. In addition, the protocol for some measures changed over time, with researchers adapting and modifying some measures as the longitudinal study progressed. For instance, the instruction manual and report form for the classroom observation system was modified between grade 1 and grade 3 .

The final limitation with respect to measurement selection was the exclusion of certain constructs. For instance, the data set did not contain any information on emotional or cognitive engagement in early or mid-elementary school. In addition, the observational protocol was administered only in grades 1 and 3 . Therefore, no data on class climate or academic engagement were available at grade 2.

Using a secondary data set also poses limitations in terms of what is known about the data collection techniques and the study sample. This is particularly relevant to the grade 1 gender differences in classroom climate. Although class sizes are available in the NICHD data set, it is unknown what proportion of students attended single-gender or mixed-gender classrooms.

Some final caveats of this research relate to characteristics of the NICHD SECCYD data set that have been reported in previous research studies (e.g., Curby et al., 2011). First, a large number of variable distributions are significantly different from normal. In the current study, the majority of the distributions were different from normal, and transformations were not successful in normalizing them. This violation of normality could potentially compromise the interpretations of the data and therefore this violation should be noted. 
In addition, some variables in the SECCYD database are statistically significant, but their correlations and effect sizes are small (Curby et al., 2011; Rudasill \& RimmKaufmann, 2009). For the current study, the implication is that "significant" predictors may still account for only a small amount of variance in a given outcome variable. Recommended interventions or other modifications to classroom experiences may therefore be only partially successful in modifying academic engagement.

Finally, this work relies on correlational data. Although moderated-mediated models may indicate a possible causal pathway between variables, these models cannot determine causality. For example, the mediating role of engagement on the relation between classroom climate and academic achievement could be interpreted differently. It could be argued that children who are more successful in school will be more likely to engage, and that such children contribute positively to classroom climate; therefore increased student engagement leads to increased classroom climate quality over time.

The moderating role of child factors on the relation between classroom experiences and academic engagement could also be viewed from another perspective. Here the argument was framed by the differential susceptibility hypothesis: Different children respond differently to similar class environments. It is possible, however, to consider classroom experiences as moderators of the relation between child factors and academic outcomes. That is, a significant moderation may indicate that different classrooms differentially influence the academic outcomes of a particular group of children.

Many of the findings presented here could inspire future research in academic engagement and anxious solitude. Although no linear associations between anxious 
solitude and academic engagement were found, it is important to note that only behavioural engagement was examined in this study. It would be useful to consider the linkages between anxious solitude and cognitive engagement: Children who are overwhelmed by feelings of anxiety in school may be less capable of focusing and attending to cognitive tasks (Chonglian, Hangham, \& Ling, 2003). Exploring the connections between anxious solitude and emotional engagement may also be useful. In the present study, anxious solitude was negatively associated with teacher and peer relationship quality; perhaps lower-quality relationships are connected to lower levels of self-belonging and school liking (Buhs et al., 2006).

Along with examining additional components of academic engagement, future work should aim to examine academic engagement at additional grade levels. Although the current study found no significant linear associations between anxious solitude and academic engagement in early elementary, previous studies have reported a strong linear association in the later grades of elementary school (K. Hughes \& Coplan, 2010; K. Hughes et al., 2010).

The initiatives to examine additional components of engagement and additional grade levels could both be accomplished with the NICHD SECCYD database. Observations of behavioural engagement are again available in grade 5 (with the same measurement instrument), and student self-reports of cognitive and emotional engagement are available in grade 6 . Therefore, further research employing these later measures would be an appropriate follow-up to this research.

Although the current study did not find significant results in terms of the longitudinal moderated-mediated models, significance was found in change in 
engagement over time. This could be further investigated to examine long-term predictors of change in engagement in later elementary and also in adolescence or early adulthood. Particularly, as grade 1 anxious solitude was a significant predictor of change in academic engagement in elementary, it would be important to investigate how strong the predictive effect is in later elementary and secondary school. The fluctuations in anxious solitude over time could also be examined (Karevold, Ystrøm, Coplan, Sanson, \& Mathiesen, 2012).

In terms of short-term, cross-sectional analyses, inspirations for future work includes the development and extension of various measures or constructs. For instance, the current sample lacked a self-report measure of peer relationship quality and a studentrated measure of teacher-child relationship quality. The inclusion of student-based measures may help to address the lack of statistical significance with respect to the moderating role of anxious solitude on the relation between classroom relationships and academic engagement.

As for gender, the findings from this study highlight the need for further exploration of the relationship between boys' peer relationships and disengagement from school. Although the strength of the relationship was nonsignificant, it did differ significantly from girls', suggesting perhaps that positive peer relationships for boys are more harmful than helpful in terms of academic adjustment. Finally, more research is needed into why girls' engagement is more influenced by relationship quality than is boys'.

In addition, future work on the links between gender and academic adjustment may do well to focus on large-scale, societal and cultural influences of gender. Although 
elementary aged boys in contemporary North America may be at-risk for disengagement as compared to girls, it is important to note that this may not be generalizable to all boys, everywhere. Around the world, different cultural, societal, geographical, and political processes may influence the links between gender and academic engagement. In particular, in some societies, it may be less acceptable for girls to go to school, or for girls to be active members of their classrooms (Tembon \& Fort, 2008).

Even within North American society, there is evidence to suggest that girls may be at risk for disengagement as compared to boys in certain circumstances. Recent evidence has suggested that while girls may be more engaged in elementary and secondary school, they may become disengaged in university (Cundiff, Vescio, Loken, \& Lo, 2013). In what is described as the Leaky Pipeline phenomenon, girls may become especially disengaged in certain subject areas such as science, technology, engineering, and math (STEM) as compared to boys (Cundiff et al., 2013).

Finally, it should be noted that over time, the links between gender and engagement have shifted. Previously, boys were thought to be more assertive in school and to engage and achieve more as compared to girls (Entwisle \& Baker, 1983). In comparison, girls were considered to be passive and withdrawn in school (Prawat \& Jarvis, 1980). As current educational policies attempt to increase engagement amongst boys, it is important to consider this previous gender shift. Rather than continually portraying one gender as the underdog, policies must seek a strategy that benefits all children, regardless of gender, rather than focusing on one gender to the detriment of the other. 
Finally, future research could consider additional child-level factors that may influence academic engagement or school outcomes, such as aggression and hyperactivity (Bierman, Coie, Dodge, Greenberg, \& Lochman, 2010). Although the predictive ability of these factors has been examined, their role as moderators has been considerably less examined. Future work could therefore examine the responsiveness of child factors to a given environment. This would add to our knowledge of the differential susceptibility hypothesis with respect to several subpopulations of children.

\section{Conclusions}

The current research makes several significant and novel contributions to the literature. As there has been limited research on the connections between anxious solitude and academic engagement, the current study brought together the historical literature from educational psychology on academic engagement with the social developmental literature on anxious solitude and internalizing problems in childhood. Although some of the theoretical predictions concerning anxious solitude and academic engagement were not supported, significant and meaningful results were found. In particular, anxious solitude was found to moderate the association between classroom climate and academic engagement in grade 3, and grade 1 anxious solitude was found to predict the change in academic engagement over time. These findings indicate that anxious solitude is a risk factor for disengagement and that anxious solitude may make children more vulnerable to variations in the classroom environment.

This study was also novel in considering child factors as moderators. This was done to explore how individual child factors affect children's responses to changes in the environment. Findings from this research support the differential susceptibility 
hypothesis. In addition, this study considered academic engagement as a mediating variable on the relation between classroom experience and academic achievement. Findings from this study support for the notion that academic engagement is central to student academic success and a possible underlying mechanism.

A particular strength of the current study was using observational measures of both academic engagement and classroom climate. Observational measures help reduce "shared method variance", which occurs when many different measures are rated by the same source, such as when teachers rate both engagement and achievement. Using observations helps reduce the impact of teacher biases on results.

Finally, the current study reports novel and noteworthy gender effects with respect to engagement, sensitivity to classroom climate, and anxious solitude. Although previous studies have reported that boys are more likely to disengage from school, results from this study indicate that anxious solitary boys may be the most at risk for disengagement and, furthermore, that disengagement could be connected to heightened sensitivity to classroom climate.

In summary, this research examined a theoretical model of the development and implications of academic engagement in childhood. Academic engagement is an essential component of educational success, but gender and anxious solitude are risk factors. These findings could be applied in early elementary school to help improve educational outcomes for vulnerable students. 


\section{References}

Achenbach, T. M. (1991). Manual for the Child Behavior Checklist/4-18 and 1991 Profile. Burlington: University of Vermont Dept. Psychiatry.

Akey, T. M. (2006). School Context, Student Attitudes, and Behavior, and Academic Achievement: An Exploratory Analysis. Washington, DC: MDCR.

Alexander, K. L., Entwisle, D. R., \& Dauber, S. L. (1993). First-grade classroom behavior: Its short- and long-term consequences for school performance. Child Development, 64(3), 801-814.

Appleton, J. J., Christenson, S. L., Kim, D., \& Reschly, A. L. (2006). Measuring cognitive and psychological engagement: Validation of the Student Engagement Instrument. Journal of School Psychology, 44(5), 427-445.

Archambault, I., Janosz, M., Morizot, J., \& Pagani, L. (2009). Adolescent behavioral, affectives, and cognitive engagement in school: Relationship to dropout. Journal of School Health, 79, 408-415.

Arbeau, K. A., \& Coplan, R. J. (2007). Kindergarten teachers' beliefs and responses to hypothetical prosocial, asocial, and antisocial children. Merrill-Palmer Quarterly, 53, 291-318.

Arbeau, K. A., Coplan, R. J., \& Weeks, M. (2010). Shyness, teacher-child relationships, and socio-emotional adjustment in grade 1. International Journal of Behavioral Development, 34, 259-269.

Asendorpf, J. B. (1991). Development of inhibited children's coping with unfamiliarity. Child Development, 62, 1460-1474. 
Asendorpf, J. B. (1993). Personality effects on children's speech in everyday life: Sociability-mediated exposure and shyness-mediated reactivity to social situations. Journal of Personality and Social Psychology, 64(6), 1072-1083.

Asendorpf, J. B. (1994). The malleability of behavior inhibition: A study of individual developmental functions. Developmental Psychology, 30(6), 912-919.

Asendorpf, J. (1990). Beyond social withdrawal: Shyness, unsociability and peer avoidance. . Human Devellopment, 33, 250-259.

Asendorpf, J. B. \& Meier, G. H. (1993). Personality effects on children's speech in everday life: Sociability-mediated exposure and shyness-mediated reactivity to social situations. Journal of Personality and Social Psychology, 64(6), 10721083.

Baker, J. A. (2006). Contributions of teacher-child relationships to positive adjustment during elementary school. Journal of School Psychology, 44, 211-229.

Battistich, V., Solomon, D., Watson, M., \& Schaps, E. (1997). Caring school communities. Educational Psychologist, 32(3), 137-151.

Baumeister, R. F. (1997). Identity, self-concept, and self-esteem: The self lost and found. In R. Hogan, J. Johnson, \& S. Briggs (Eds.), Handbook of personality psychology (pp. 681-711). New York: Academic Press.

Belsky, J. (1997). Theory testing, effect-size evaluation, and differential susceptibility to rearing influence: The case of mothering and attachment. Child Development, $68(4), 598-600$.

Berndt, T. J., \& Keefe, K. (1995). Friends' influence on adolescents' adjustment to school. Child Development, 66(5), 1312-1329. 
Bierman, K. L., Coie, J. D., Dodge, K. A., Greenberg, M. T., \& Lochman, J. E. (2010). The effects of a multiyear universal social-emotional learning program: The role of student and school characteristics. Journal of Consulting and Clinical Psychology, 78(2), 156-168.

Birch, S. H., \& Ladd, G. W. (1997). The teacher-child relationship and children's early school adjustment. Journal of School Psychology, 35(1), 61-79.

Block, J. H. (1983). Differential premises arising from differential socialization of the sexes: Some conjectures. Child Development, 54, 1335-1354.

Blumenfeld, P. C., \& Meece, J. L. (1988). Task factors, teacher behavior, and students' involvement and use of learning strategies in science. The Elementary School Journal. Special Issue: Schoolwork and academic tasks, 88(3), 235-250.

Bond, L., Butler, H., Thomas, L., Carlin, J., Glover, J., Bowes, G., et al. (2007). Social and school connectedness in early secondary school as predictors of late teenage substance use, mental health, and academic outcomes. Journal of Adolescent Health, 40(4), 9-18.

Bosacki, S. L., Coplan, R. J., Rose-Krasnor, L., \& Hughes, K. (2011). Elementary school teachers' reflections on shy children in the classroom. Alberta Journal of Educational Research, 57(3), 273-287.

Boxer, P., Goldstein, S. E., DeLorenzo, T., Savoy, S., \& Mercado, I. (2010). Educational spiration-expectation discrepancies: Relation to socioeconomic and academic risk-related factors. Journal of Adolescence, 34(4), 609-617.

Brophy, J. (1986). Teacher influences on student achievement. American Psychologist. Special Issue: Psychological science and education, 41(10), 1069-1077. 
Buhs, E. S. (2005). Peer Rejection, Negative Peer Treatment, and School Adjustment: Self-concept and Classroom Engagement as Mediating Processes. Journal of School Psychology, 43, 407-424.

Buhs, E. S., \& Ladd, G. W. (2001). Peer rejection as antecedent of young children's school adjustment: An examination of mediating processes. Developmental Psychology, 37(4), 550-560.

Buhs, E. S., Ladd, G. W., \& Herald, S. L. (2006). Peer exclusion and victimization: Processes that mediate the relation between peer group rejection and children's classroom engagement and achievement? Journal of Educational Psychology, 98, $1-13$.

California Board of Education (2007). Reading/language arts framework for California public schools: Kindergarten through grade twelve (pp. 386). Sacramento: California Department of Education.

Caspi, A., Elder, G. H., \& Bem, D. J. (1988). Moving away from the world: Life-course patterns of shy children. Developmental Psychology, 24, 824-831.

Cheek, J. M., \& Buss, A. H. (1981). Shyness and sociability. Journal of Personality and Social Psychology, 41(2), 330-339.

Chen, X., Chang, L., He, Y., \& Liu, H. (2005). The peer group as a context: Moderating effects on relations between maternal parenting and social and school adjustment in Chinese children. Child Development, 76(2), 417-434.

Chen, X., DeSouza, A., Chen, H., \& Wang, L. (2006). Reticent behavior and experiences in peer interactions in Canadian and Chinese children. Developmental Psychology, 42, 656-665. 
Chonglian, Z., Hangham, L., Ling, W. (2003). A further investigation of the factors related to middle school students' achievement. Psychological Science, 26(3), $430-432$.

Church, M. A., Elliot, A. J., \& Gable, S. L. (2001). Perceptions of classroom environment, achievement goals, and achieveemtn outcomes. Journal of Educational Psychology, 93(1), 43-54.

Connell, J. P. (1990). Context, self, and action: A motivational analysis of self-system processes across the life span. In D. Cicchetti \& M. Beeghly (Eds.) The self in transition: Infancy to childhood (pp. 61-97). Chicago: University of Chicago Press.

Connell, J. P., Halpern-Felsher, B. L., Clifford, E., \& Crichlow, W. (1995). Hanging in there: Behavioral, psychological, and contextual factors affecting whether African-American adolescents stay in high school. Journal of Adolescent Research. Special Issue: Creating supportive communities for adolescent development: Challenges to scholars, 10(1), 41-63.

Connell, J. P., Spencer, M. B., \& Aber, J. L. (1994). Educational risk and resilience in African-American youth: Context, self, action, and outcomes in school. Child Development. Special Issue: Children and poverty, 65(2), 493-506.

Connell, J. P., \& Wellborn, J. G.. (1991). Competence, autonomy, and relatedness: A motivational analysis of self-system processes. In M. Gunnar \& L. A. Sroufe (Eds.) Minnesota Symposium on Child Psychology (Vol. 23). Chicago: University of Chicago Press. 
Cook, T. D., Habib, F. N., Philips, M., Settersten, R. A., Shagle, S. C., \& Degirmencioglu, S. R. (1999). Comer's School Development Program in Prince George's County, Maryland: A theory-based evaluation. American Educational Research Journal, 36, 543-597.

Coplan, R. J., \& Arbeau, K. A. (2008). The stresses of a "brave new world": Shyness and school adjustment in kindergarten. Journal of Research in Childhood Education, $22,377-389$.

Coplan, R. J., Arbeau, K. A., \& Armer, M. (2008). Don’t fret, be supportive! Maternal characteristics linking child shyness to psychosocial and school adjustment in kindergarten. Journal of Abnormal Child Psychology, 36, 359-371.

Coplan, R. J., \& Armer, M. (2005). Talking yourself out of being shy: Shyness, expressive vocabulary, and adjustment in preschool. Merrill-Palmer Quarterly, $51,20-41$.

Coplan, R. J., Closson, L., \& Arbeau, K. (2007). Gender differences in the behavioral associates of loneliness and social dissatisfaction in kindergarten. Journal of Child Psychology and Psychiatry [Special Issue on Preschool Mental Health], 48, 988-995.

Coplan, R. J., \& Evans, M. A. (2009). At a loss for words? Introduction to the special issue on shyness and language in childhood. Infant and Child Development, 18(3), 211-215.

Coplan, R. J., Gavinski-Molina, M. H., Lagace-Seguin, D., \& Wichmann, C. (2001). When girls versus boys play alone: Gender differences in the associates of nonsocial play in kindergarten. Developmental Psychology, 37, 464-474. 
Coplan, R. J., Girardi, A., Findlay, L. C., \& Frohlick, S. L. (2007). Understanding solitude: Young children's attitudes andresponses towards hypothetical sociallywithdrawn peers. Social Development, 16, 390-409.

Coplan, R. J., Hughes, K., Bosacki, S. L., \& Rose-Krasnor, L. (2011). Is silence golden? Elementary school teachers' strategies and beliefs towards hypothetical shy/quiet and talkative/exuberant children. Journal of Educational Psychology, 103(4), 939-951.

Coplan, R. J., Hughes, K., \& Rowsell, H. C. (2010). 'Once upon a time there was a blushful hippo and a meek mouse': A content analysis of shy characters in young children's storybooks. In: The Development of Shyness and Social Withdrawal. Rubin, K. H., \& Coplan, R. J. (Eds.). Guilford Press: New York.

Coplan, R. J., Prakash, K., O’Neil, K., \& Armer, M. (2004). Do you “want” to play? Distinguishing between conflicted shyness and social disinterest in early childhood. Developmental Psychology, 40 (2), 244-258.

Coplan, R. J., Reichel, M., \& Rowan, K. (2009). Exploring the associations between maternal personality, child temperament, and parenting: A focus on emotions. Personality and Individual Differences, 46(2), 241-246.

Crozier, W. R. (1995). Shyness and self-esteem in middle childhood. British Journal of Educational Psychology, 65, 85-95.

Crozier, W. R. (2010). Shyness and the development of embarrassment and the selfconscious emotions. In K. H. Rubin, \& R. J. Coplan, The development of shyness and social withdrawal (pp. 42-63). New York: Guilford Press. 
Crozier, W. R., \& Hostettler, K. (2003). The influence of shyness on children's test performance. British Journal of Educational Psychology, 73(3), 317-328.

Crozier, W. R., \& Perkins, P. (2002). Shyness as a factor when assessing children. Educational Psychology in Practice, 18(3), 239-244.

Cundiff, J. L., Vescio, T. K., Loken, E., \& Lo, L. (2013). Do gender-science stereotypes predict science idenficiation and science career aspirations among undergraduate science majors? School Psychology of Education, [Advanced Online Publication].

Curby, T. W., Rudasill, K. M., Edwards, T., \& Perez-Edgar, K. (2011). The role of classroom quality in ameliorating the academic and social risks associated with difficult temperament. School Psychology Quarterly, 26, 175-188.

Decker, D. M., Dona, D. P., \& Christenson, S. L. (2007). Behaviorally at-risk African American students: The importance of student-teacher relationships for student outcomes. Journal of School Psychology, 45, 83-109.

Degnan, K. A., \& Fox, N. A. (2007). Behavioral inhibition and anxiety disorders: Multiple levels of a resilience process. Developmental Psychopathology, 19, 729746.

DeRosier, M., Kupersmidt, J. B., \& Patterson, C. J. (1994). Children's academic and behavioral adjustment as a function of the chronicity and proximity of peer rejection. Child Development, 65(6), 1799-1813.

DiPerna, J. C., Volpe, R. J., \& Elliot, S. N. (2002). A model of academic enablers and elementary reading/language arts achievement. School Psychology Review, 31(3), $298-312$. 
Dolan, L. J. (1983). Validity analyses for the School Attitude Measures at three grade levels. Educational and Psychological Measurement, 43(1),, 295-303.

Dotterer, A. M. \& Lowe, K. (2011). Classroom context, school engagement, and academic achievement in early adolescence. Journal of Youth and Adolescence, 40(12), 1649-1660.

Dubow, E. F., Boxer, P., \& Huesmann, L. R. (2009). Long-term effects of parents’ education on children's educational and occupational success: Mediation by family interactions, child aggression, and teenage aspirations. Merrill-Palmer Quaterly: Journal of Developmental Psychology. Special Issue: Educational attainment in developmental perspective, 55(3), 224-249.

Duchesne, S., \& Ratelle, C. (2010). Parental behaviors and adolescents' achievement goals at the beginning of middle school: Emotional problems as potential mediators. Journal of Educational Psychology, 102(2), 497-507.

Elias, M. J., \& Haynes, N. M. (2008). Social competence, social support, and academic achievement in minority, low-income, urban elementary school children. School Psychology Quarterly, 23(4), 474-495.

Else-Quest, N. M., Hyde, J. S., Goldsmith, H. H., and Van Hulle, C. A. (2006). Gender differences in temperament: A meta-analysis. Psychological Bulletin, 132, 33-72.

Englund, J. M. (2009). Underachievement among white middle- and high-SES gifted males. Doctoral Dissertation, University of Virginia, Currie School of Education.

Entwisle, D. R., \& Baker, D. P. (1983). Gender and young children's expectations for performance in arithmatic. Developmental Psychology, 19(2), 200-209. 
Epstein, J. L., \& McPartland, J. M. (1976). The concept and measurement of the quality of school life. American Educational Research Journal, 13(1), 15-30.

Evans, M. A. (1993). Communicative competence as a dimension of shyness. In K. H. Rubin, \& J. B. Asendorpf, Social withdrawal, inhibition, and shyness in childhood (pp. 189-212). Hillsdale, NJ: Lawrence Erlbaum.

Evans, M. A. (1987). Discourse characteristics of reticent children. Applied Psycholinguistics, 8, 171-184.

Evans, M. A. (1996). Reticent primary grade children and their more talkative peers: verbal, nonverbal, and self-concept characteristics. Journal of Educational Psychology, 88, 739-749.

Evans, M. A. (2001). Shyness in the classroom and home. In W. R. Crozier, \& L. E. Alden, International handbook of society anxiety: Concepts, research, and interventions relating to the self and shyness (pp. 159-183). Westport, CT: Wiley.

Ewing, A. R., \& Taylor, A. R., (2009). The role of child gender and ethnicity in teacherchild relationship quality and children's behavioral adjustment in preschool. Early Childhood Research Quarterly, 24, 92-105.

Finn, J. D. (1989). Withdrawing from school. Review of Educational Research, 59 (2), $117-142$.

Finn, J. D., \& Rock, D. A. (1997). Academic success among students at risk for school failure. Journal of Applied Psychology, 82(2), 221-234.

Finn, J. D., Pannozzo, G. M., \& Voelkl, K. E. (1995). Disruptive and inattentivewithdrawn behavior and achievement among fourth graders. The Elementary School Journal, 95(5), 421-434. 
Fox, N. A., Henderson, H. A., Marshall, P. J., Nichols, K. E., \& Ghera, M. M. (2005). Behavioral inhibition: Linking biology and behvior within a developmental framework. Annual Review of Psychology, 56, 235-262.

Fox, N. A., Henderson, H. A., Rubin, K. H., Calkins, S. D., \& Schmidt, L. A. (2001). Continuity and discontinuity of behavioral inhibition and exuberance: Psychophysiological and behavioral influences across the first four years of life. Child Development, 72, 1-21.

Fredricks, J. A., Blumenfeld, P. C., \& Paris, A. H. (2004). School engagement: Potential of the concept, state of the evidence. Review of Educational Research, 74, 59109.

Furrer, C., \& Skinner, E. (2003). Sense of relatedness as a factor in children's academic engagement and performance. Journal of Educational Psychology, 95, 148-162.

Garcia-Coll, C. Kagan, J. \& Reznick, J. S. (1984). Behavioral inhibition in young children. Child Development, 55(3), 1005-1019.

Gazelle, H. (2006). Class climate moderates peer relations and emotional adjustment in children with an early history of anxious solitude: A child $\times$ environment model. Developmental Psychology, 42, 1179-1192.

Gazelle, H., \& Ladd, G. W. (2003). Anxious solitude and peer exclusion: A diathesisstress model of internalizing trajectories in childhood. Child Development, 74, $257-278$.

Glaser, B. A., Kronsnoble, K. M., \& Forkner, C. B. (1997). Parents and teachers as raters of children's problem behaviors. Child \& Family Behavior Therapy, 19(4), 1-13. 
Glymour, M. M., Weuve, J., Berkman, L. F., Kawachi, I., \& Robins, J. M. (2005). When is baseline adjustment useful in analyses of change? An example with educational and cognitive change. American Journal of Epidemiology, 162(3), 267-278.

Gordon, E. M., \& Thomas, A. (1967). Children's behavioral style and the teacher's appraisal of their intelligence. Journal of School Psychology, 5, 292-300.

Greene, B. A., Miller, R. B., Crowson, H. M., Duke, B. L., \& Akey, K. L. (2004). Predicting high school students' cognitive engagement and acheivement: Contributions of classroom perceptions and motivation. Contemporary Educational Psychology, 29, 462-482.

Hamre, B. K., \& Pianta, R. C. (2001). Early teacher-child relationships and the trajectory of children's school outcomes through eighth grade. Child Development, 72, 625638.

Hayes, A. F. (2012). PROCESS: A versatile computational tool for observed variable moderation, mediation, and conditional process modeling.

Hayes, A. F. (2013). Introduction to Mediation, Moderation, and Conditional Process Analysis: A Regression-Based Approach. New York: Guilford Press.

Hilsman, R., \& Garber, J. (1995). A test of the cognitive diathesis-stress model of depression in children: Academic stressors, attributional style, perceived competence, and control Journal of Personality \& Social Psychology, 69(2), 370380.

Hoglund, W. L. (2007). School functioning in early adolescence: Gender-linked responses to peer victimization. Journal of Educational Psychology, 99(4), 683699. 
Hughes, K., \& Coplan, R. J. (2010). Exploring the processes linking shyness and academic achievement in childhood. School Psychology Quarterly, 25, 213-222.

Hughes, K., Coplan, R. J., \& Rubin, K. H. (2011, April). The role of academic engagement in the links between social withdrawal, aggression, and academic achievement. Society for Research in Child Development (SRC) Biennial Conference, Montreal, Quebec.

Hughes, J. N., Luo, W., Kwok, O.-M., \& Loyd, L. K. (2008). Teacher-student support, effortful engagement, and achievement: A 3-year longitudinal study. Journal of Educational Psychology, 100(1), 1-14.

Janosz, M., Archambault, I., Morizot, J., \& Pagani, L. S. (2008). School engagement trajectories and their differential predictive relations to dropout. Journal of Social Issues, 64, 21-40.

Janosz, M., LeBlanc, M., Boulerice, B., \& Tremblay, R. E. (2000). Predicting types of school dropouts : A typological approach with two longitudinal samples. Journal of Educational Psychology, 92, 171-190.

Jimerson, S. R., Campos, E., \& Greif, J. L. (2003). Toward an unerstanding of definitions and measures of school engagement and related terms. The California School Psychologist, 8, 7-27.

Johnson, M. K., Crosnoe, R., \& Elder, G. H. (2001). Students' attachment and academic engagement: The role of ethnicity. Sociology of Education, 74, 318-340.

Jordan, W. J. (2000). Black high school students' participation in school-sponsored sports activities: Effects on school engagement and achievement. Journal of Negro Education, 68, 54-71. 
Kagan, J., Snidman, N., Kahn, V., \& Towsley, S. (2007). The preservation of two infant temperaments into adolescence. Monographs of the Society for Research in Child Development,

Kagan, J., Reznick, J. S., \& Snidman, N. (1988). Biological bases of childhood shyness. Science, 240, 167-171.

Kagan, J., Snidman, N., Zentner, M., \& Peterson, E. (1999). Infant temperament and anxious symptoms in school age children. Development and Psychopathology, 11, 209-224.

Kaili, A., \& Ziol-Guest, K. M. (2005). Single mothers' employment dynamics and adolescent well-being . Child Development, 76, 196-211.

Kalutskaya, I. \& Buhs, E. S. (2013). Socio-Emotional Characteristics and School Adjustment of Socially Withdrawn Early Adolescents in Russia. International Journal of Adolescence and Youth. Advance online publication.

DOI:10.1080/02673843.2013.806270

Karevold, E., Ystrøm, E., Coplan, R. J., Sanson, A., \& Mathiesen, K. S. (2012). A prospective longitudinal study of shyness from infancy to adolescence: Stability, age-related changes, and prediction of socio-emotional functioning. Journal of Abnormal Child Psychology, 40, 1167-1177.

Kindermann, T. A. (1993). Natural peer groups as contexts for individual development: The case of children's motivation in school. Developmental Psychology, 29(6), 970-977. 
Ladd, G. W. (1990). Having friends, keeping friends, making friends, and being liked by peers in the classroom: Predictors of children's early school adjustment? Child Development, 61(4), 1081-1100.

Ladd, G. W., Birch, S. H., \& Buhs, E. S. (1999). Children's social and scholastic lives in kindergarten: Related spheres of influence? Child Development, 70, 1373-1400.

Ladd, G. W., \& Burgess, K. B. (1999). Charting the relationship trajectories of aggressive, withdrawn, and aggressive/withdrawn children during early grade school. Child Development, 70(4), 910-929.

Ladd, G. W., \& Burgess, K. B. (2001). Do relational risks and protective factors moderate the linkages between childhood aggression and early psychological and school adjustment? Child Development, 72, 1579-1601.

Ladd, G. W., \& Dinella, L. M. (2009). Continuity and change in early school engagement: Predictive of children's achievement trajectories from first to eight grade? Journal of Educational Psychology, 101(1), 190-206.

Ladd, G. W., Kochenderfer, B. J., \& Coleman, C. C. (1997). Classroom peer acceptance, friendship, and victimization: Distinct relational systems that contribute uniquely to children's school adjustment. Child Development, 68(6), 1181-1197.

Leach, D. J., \& Dolan, N. K. (1985). Helping teachers increase student academic engagement rate: The evaluation of a minimal feedback procedure. Behavior Modification, 9(1), 55-71.

Lerner, J. V., Lerner, R. M., \& Zabski, S. (1985). Temperament and elementary school children's actual and rated academic performance: A test of "goodness of fit" model. Journal of Child Psychology, 26, 125-136. 
Levy-Garboua, L., Loheac, Y., \& Fayolle, B. (2006). Preference formation, school dissatisfaction, and risky behavior of adolescents. Journal of Economic Psychology, 27, 165-183.

Li, Y., Bebirogiu, N., Phelps, E., Lerner, J. V., \& Lerner, R. M. (2008). Out-of-school time activity participation, school engagement and positive youth development: Findings from the 4-H Study of Positive Youth Development. Journal of Youth Development, 3(3), 45-59.

Li, Y., \& Lerner, R. M. (2011). Trajectories of school engagement during adolescence: Implications for grades, depression, delinquency, and substance use. Developmental Psychology, 47(1), 233-247.

Long, G., Stinson, M. S., \& Braeges, J. (1991). Students’ perceptions of communication ease and engagement: How they relate to academic success. American Annals of the Deaf, 136(5), 414-421.

Low, B. (1989). Cross-cultural patterns in the training of children: An evolutionary perspective. Journal of Comparative Psychology, 103, 311-319.

Lowry, R. (2012). Significance of the difference between two correlation coefficients. VassarStats: Website for Statistical Computation. Retrieved from http://vassarstats.net/rdiff.html

Maccoby, E. E. (1998). The two sexes: Growing apart, coming together. Cambridge, MA: Belknap.

Manlove, J. (1998). The influence of high school dropout and school disengagement on the risk of school-age pregnancy. Journal of Research on Adolescence, 8(2), 187220. 
Marks, H. M. (2000). Student engagement in instructional activity: Patterns in the elementary, middle, and high school years. American Educational Research Journal, 37(1), 153-184.

McLoyd, V. C. (1998). Socioeconomic disadvantage and child development. American Psychologist, 53, 185-204.

McMahon, S. D., \& Wernsman, J. (2009). The relation of classroom environment and school belonging to academic self-efficacy among urban fourth and fifth grade students. The Elementary School Journal, 109(3), 267-281.

Meloth, M. S., \& Deering, P. D. (1994). Task talk and task awareness under different cooperative learning conditions. American Educational Research Journal, 31(1), 138-165.

Miller, S. E., Leinhardt, G., \& Zigmond, N. (1988). Influencing engagement through accommodation: An ethonographic study of at-risk students. American Educational Research Journal, 25(4), 465-487.

NICHD. (1998). Study of early child care \& youth development: All instrument rationale. Ann Arbor: University of Michigan.

NICHD. (2010). Study of early child care \& youth development: User trainer guide. Ann Arbor: University of Michigan.

Patrick, B. C., Skinner, E. A., \& Connell, J. P. (1993). What motivates children's behavior and emotion? Joint effects of perceived control and autonomy in the academic domain. Journal of Personality and Social Psychology, 65(4), 781-791. 
Peterson, P. L., Swing, S. R., Stark, K. D., \& Wass, G. A. (1984). Students' cognitions and time on task during mathematics instruction. American Educational Research Journal, 21(3), 487-515.

Pianta, R. C., Steinberg, M. S., \& Rollins, K. B. (1995). The first two years of school: Teacher- child relationships and deflections in children's classroom adjustment. Development and Psychopathology, 7, 295-312.

Pierson, L. H., \& Connell, J. P. (1992). Effect of grade retention on self-system processes, school engagement, and academic performance. Journal of Educational Psychology, 84(3), 300-307.

Prawat, R. S., \& Jarivs, R. (1980). Gender differences as a factor in teachers' perceptions of students. Journal of Educational Psychology, 72(6), 743-749.

Prior, M., Smart, D., Sanson, A., \& Oberklaid, F. (2000). Does shy-inhibited temperament in childhood lead to anxiety problems in adolescence? Journal of the American Academy of Child and Adolescent Psychiatry, 39, 461-468.

Randolph, J. J., Kangas, M., \& Ruokamo, H. (2010). Predictors of Dutch and Finnish children's satisfaction with schooling. Journal of Happiness Studies, 11, 193-204.

Rapee, R. M., \& Spence, S. H. (2004). The etiology of social phobia: Empirical evidence and an initial model. Clinical Psychology Review: Special Issue: Social Phobia and Social Anxiety, 24, 737-767.

Rapee, R., Kennedy, S., Ingram, M., Edwards, S., \& Sweeney, L. (2005). Prevention and early intervention of anxiety disorders in inhibted preschool children. Journal of Consulting and Clincial Psychology, 73, 488-497. 
Rimm-Kaufmann, S. E., \& Kagan, J. (2005). Infant predictors of kindergarten behavior: The contribution of inhibited and uninhibited temperament types. Behavioral Disorder, 30, 329-346.

Rubin, K. H., Burgess, K. B., \& Hastings, P. D. (2002). Stability and social-behavioral consequences of toddlers' inhibited temperament and parenting behaviors. Child Development, 73(2), 483-495.

Rubin, K. H., \& Coplan, R. J. (2004). Paying attention to and not neglecting social withdrawal and social isolation. Merrill-Palmer Quarterly, 50, 506-534.

Rubin, K. H., \& Coplan, R. J. (2010). The development of shyness and social withdrawal. New York: Guilford Press.

Rubin, K. H., Coplan, R. J., \& Bowker, J. C. (2009). Social withdrawal in childhood. Annual Review of Psychology, 60, 141-171.

Rubin, K. H., \& Mills, R. S. (1992). Maternal beliefs about adaptive and maladaptive social behaviors in normal, aggressive, and withdrawn preschoolers. Journal of Abnormal Child Psychology, 18(4), 419-435.

Rubin, K. H., Wojslawowicz, J. C., Rose-Krasnor, L., Booth-LaForce, C. L., \& Burgess, K. B. (2006). The best friendships of shy/withdrawn children: Prevalence, stability, and relationship quality. Journal of Abnormal Child Psychology, 34 , 139-153.

Rudasill, K. M., \& Rimm-Kaufmann, S. E. (2009). Teacher-child relationship quality: The role of child temperament and teacher-child interactions. Early Childhood Research Quarterly, 24, 107-120. 
Rudasill, K. M., Rimm-Kaufmann, S. E., Justice, L. M., \& Pence, K. (2006).

Temperament and language skills as predictors of teacher-child relationship quality in preschool. Early Education and Development, 17, 271-291.

Roorda, D. L., Koomen, H. M., Spilt, J. L., \& Oort, F. J. (2011). The influence of affective teacher-student relationships on students' school engagement and achievement: A meta-analytic approach. Review of Educational Research, 81(4), 493-529.

Rumberger, R. W., \& Larson, K. A. (1998) Student mobility and the increased risk of high school dropout. American Journal of Education, 107, 1-35.

Runions, K. C., \& Keating, D. P. (2011). Anger and inhibitory control as moderators of children's hostile attributions and aggression. Journal of Applied Developmental Psychology, 31 (5), 370-378.

Ryan, A. M., (2012, November). Changes in peer relations during early adolescence: Are there differences between K-8 and middle schools? Peers, Classroom, and School Dynamics. Paper presented at International Video Conference on Peer Relations, Concordia University.

Ryan, A. M., \& Patrick, H. (2001). The classroom social environment and changes in adolescents' motivation and engagement during middle school. American Educational Research Journal, 38(2), 437-460.

Ryan, R. M., Stiller, J. D., \& Lynch, J. H. (1994). Representations of relationships to teachers, parents, and friends as predictors of academic motivation and selfesteem. The Journal of Early Adolescence. Special Issue: Middle grades schooling and early adolescent development: Early adolescents' psychological 
characteristics, relationships with others, and school performance, 14(2), 226249.

Sage, N. A., \& Kindermann, T. A. (1999). Peer networks, behavior contingencies, and children's engagement in the classroom. Merrill-Palmer Quaterly: Journal of Developmental Psychology. Special Issue: Peer influences in childhood and adolescence, 45(1), 143-171.

Schmidt, L. A., \& Buss, A. H. (2010). Understanding shyness: Four questions and four decades of research. In K. H. Rubin \& R. J. Coplan (Eds.), The development of shyness and social withdrawal (pp. 22-41). New York: Guilford Press.

Schmitt, D. P., Realo, A., Voracek, M., \& Allik, J. (2008). Why can't a man be more like a woman? Sex differences in Big Five personality traits across 55 cultures. Journal of Personality and Social Psychology, 94(1), 168-182

Schneider, B. H., Younger, A. J., Smith, T., \& Freeman, P. (1998). A longitudinal exploration of the cross-contextual stability of social withdrawal in early adolescence. The Journal of Early Adolescence, 18(4), 374-396.

Shernoff, D. J., \& Schmidt, J. A. (2008). Further evidence of an engagement-achievement paradox among US high school students. Journal of Youth and Adolescence, 37, 564-580.

Shochet, I. M., Dadds, M. R., Ham, D., \& Montague, R. (2006). School connectedness is an underemphasized parameter in adolescent mental health: Results of a community prediction study. Journal of Clinical Child and Adolescent Psychology, 35, 170-179. 
Skinner, E. A., \& Belmont, M. J. (1993). Motivation in the classroom: Reciprocal effects of teacher behavior and student engagement across the school year. Journal of Educational Psychology, 85(4), 571-581.

Skinner, E. A., Wellborn, J. G., \& Connell, J. P. (1990). What it takes to do well in school and whether I've got it: A process model of perceived control and children's engagement and achievement in school. Journal of Educational Psychology, 82(1), 22-32.

Spere, K., \& Evans, M. A. (2009). Shyness as a continuous dimension and emergent literacy in young children. Is there a relation? Infant and Child Development, 18(3), 216-237.

Stipek, D., \& Miles, S. (2008). Effects of aggression on achievement: Does conflict with the teacher make it worse? Child Development, 79, 1721-1735.

Tembon, M. M., \& Fort, L., (2008). Girls' Education in the $21^{\text {st }}$ Century: Gender Equality, Empowerment, and Growth. London: Corona Publishing Co.

Thijs, J. T., Koomen, H. M., \& Van der Leij, A. (2006). Teachers' self-reported pedagogical practices toward socially inhibited hyperactive and average children. Psychology in the Schools, 43, 635-651.

Turner, J. C., Meyer, D. K., Cox, K. E., Logan, C., DiCintio, M., \& Thomas, C. T. (1998). Creating contexts for involvement in mathematics. Journal of Educational Psychology, 90(4), 730-745.

Valeski, T. N., \& Stipek, D. J. (2001). Young children's feelings about school. Child Development, 72(4), 1198-1213. 
Vile Junod, R. E., DuPaul, G. J., Jitendra, A. K., Volpe, R. J., \& Cleary, K. S. (2006). Classroom observations of students with and without ADHD: Differences across types of engagement. Journal of School Psychology, 44, 87-104.

Voelkl, K. E. (1997). Identification with school. American Journal of Education, 105(3), 294-318.

Wang, M., \& Eccles, J. S. (2012). Adolescent behavioral, emotional, and cognitive engagement trajectories in school and their differential relations to educational success. Journal of Research on Adolescence, 22(1), 31-39.

Wang, M., \& Holcombe, R. (2010). Adolescents' perceptions of school environment, engagement, and academic achievement in middle school. American Educational Research Journal, 47, 633-662.

Wang, M., Willet, J. B., \& Eccles, J. S. (2011). The assessment of school engagement: Examining dimensionality and measurement invariance by gender and race/ethnicity. Journal of School Psychology 49(4), 465-480.

Weiss, C. C., Carolan, B. V., \& Baker-Smith, E. C. (2010). Big school, small school: (Re)testing assumptions about high school size, school engagement and mathematics achievement. Journal of Youth and Adolescence, 39, 163-176.

Wentzel, K. R. (1994). Relations of social goal pursuit to social acceptance, classroom behavior, and perceived social support. Journal of Educational Psychology, 86(2), $173-182$.

Wentzel, K. R. (1997). Student motivation in middle school: The role of perceived pedagogical caring. Journal of Educational Psychology, 89, 411-419. 
Wentzel, K. R. (1999). Social-motivational processes and interpersonal relationships: Implications for understanding motivation at school. Journal of Educational Psychology, 91(1), 76-97.

Wentzel, K. R., Barry, C. M., \& Caldwell, K. A. (2004). Friendships in middle school: Influences on motivation and school adjustment. Journal of Educational Psychology, 96(2), 195-203.

Wentzel, K. R.., Battle, A., Russell, S. L., \& Looney, L. B. (2010). Social supports from teachers and peers as predictors of academic and social motivation. Contemporary Educational Psychology, 35, 193-202.

Whitlock, J. L. (2006). Youth perceptions of life at school: Contextual correlations of school connectedness in adolescence. Applied Developmental Science 10, 13-29.

Yamamoto, K., Thomas, E. C., \& Karns, E. A. (1969). School-related attitudes in middle school age students. American Educational Research Journal, 6(2), 191-206.

Zimbardo, P. G. (1977). Shyness: What is it and what to do about it. New York: Symphony Press.

Zimmerman, B. J. (1990). Self-regulating academic learning and achievement: The emergence of a social cognitive perspective. Educational Psychology Review, 2(2), 173-201. 